\title{
Impact of Irminger Rings on Deep Convection in the Labrador Sea: \\ Mooring Instrument, Cruise CTD, and APEX Data Report September 2007 - September 2009
}

by

H. H. Furey, T. K. McKee, M. F. de Jong, P. E. Robbins, and A. S. Bower May 2013

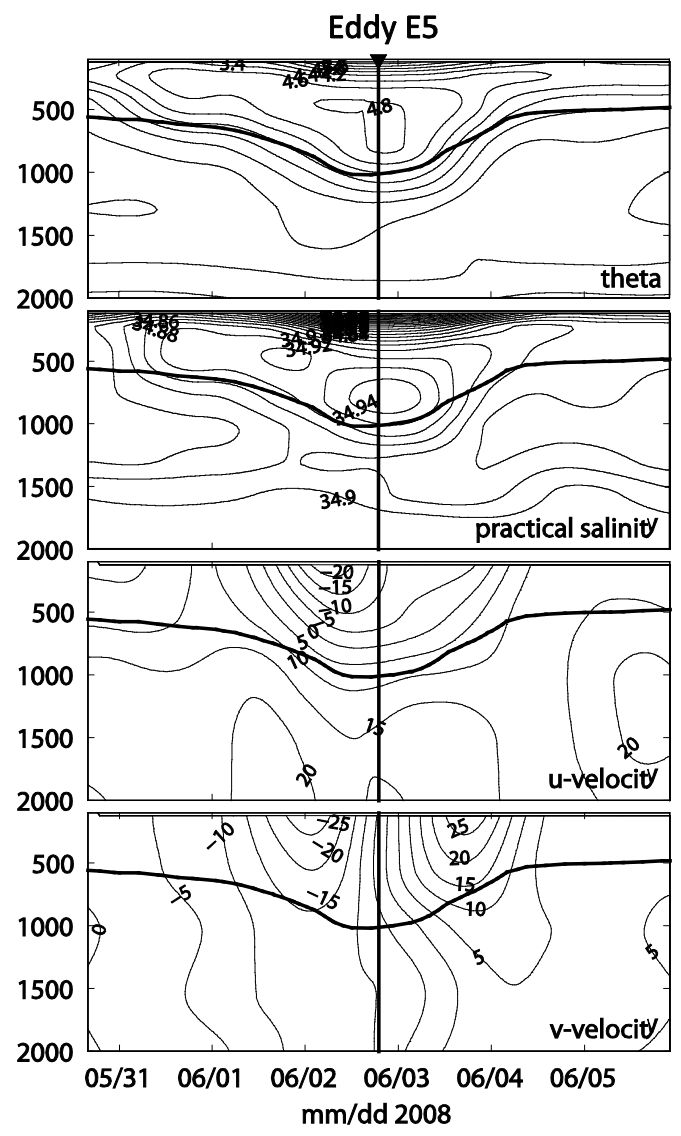

\section{Technical Report}

Funding was provided by the National Science Foundation Grant OCE-0623192.

Approved for public release; distribution unlimited. 



\section{WHOI-2013-05}

\section{Impact of Irminger Rings on Deep Convection in the Labrador Sea: Mooring Instrument, CTD, and APEX Data Report September 2007 - September 2009}

by

H. H. Furey, T. K. McKee, F. M. de Jong, P. E. Robbins, and A. S. Bower

Woods Hole Oceanographic Institution

Woods Hole, Massachusetts 02543

May 2013

\section{Technical Report}

Funding was provided by the National Science Foundation through Grant No. OCE-0623192.

Reproduction in whole or in part is permitted for any purpose of the United States Government. This report should be cited as Woods Hole Oceanographic Institution Technical Report, WHOI-2013-05.

Approved for public release; distribution unlimited.

Approved for Distribution:

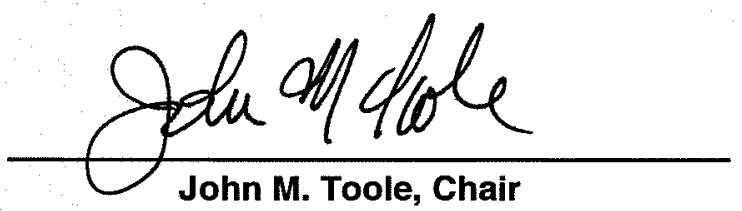

Department of Physical Oceanography 



\begin{abstract}
This is the final data report of all hydrographic station, mooring, and subsurface float data collected by the Woods Hole Oceanographic Institution in 2007-2009 during the Impact of Irminger Rings on Deep Convection in the Labrador Sea experiment (IRINGS). The objectives of IRINGS were to (1) to determine the full water column hydrographic and velocity structure of newly-formed Irminger Rings that have entered the interior Labrador Sea; (2) to observe how Irminger Ring core properties are modified by atmospheric forcing over their lifetime; and (3) to improve the interpretation of sea surface height (SSH) anomalies in terms of newly formed coherent heat containing Irminger Rings. The mooring deployment and recovery cruises were both on the $R / V$ Knorr: KN192-01 in September 2007 and KN196-01 in September 2009, respectively.

The single mooring held eight Aanderaa current meters (RCM-11), two Submerged Autonomous Launch Platforms (SALPs), and nine Seabird microcats (SBE37), deployed from 26 September 2007 through 27 September 2009, yeilding full water column (1003000 meters) records of temperature, salinity, pressure, and velocity data for the two year period. The two SALP cages contained eleven APEX floats, and released some of these floats according to local oceanographic conditions, so as to seed the floats in passing Irminger Rings, and the remainder of floats as timed releases. Thirteen conductivitytemperature-depth (CTD) stations were taken on the mooring recovery cruise, creating a boundary current cross-section from the mooring site to Nuuk, Greenland.
\end{abstract}




\section{Front Cover Figure Caption:}

One example of an Irminger Ring found in the mooring record (June 2008). From top to bottom: theta, practical salinity, u-velocity, and v-velocity. The center of the eddy (bold vertical black line) is calculated as the point of maximum (downward) displacement of the $27.7 \sigma_{0}$ isopycnal (bold black line). The thin vertical lines 24 hours before and after eddy center mark the approximate eddy core in time. Adapted from Furey et al. (2013). 


\section{Table of Contents}

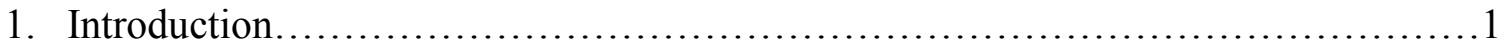

2. Mooring setup and instrument performance...................................

3. Mooring instrument quality control and calibration...............................

3.1. Submerged Autonomous Launch Platforms (SALPs) T/P modules...............4

3.2. Aanderaa Current Meters (RCM1 1s) ................................... 5

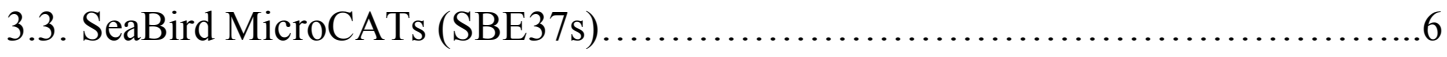

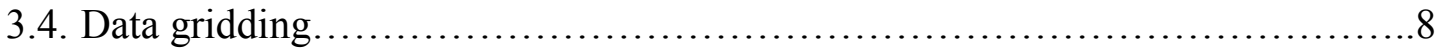

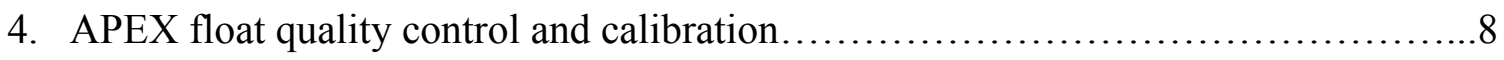

5. Conductivity-Temperature-Depth quality control and calibration................... 9

6. Acknowledgements................................................. 10

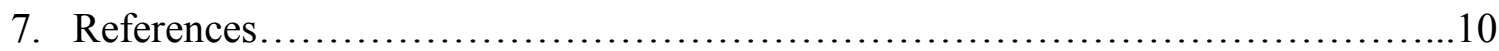

Appendix A. Mooring diagram and metadata tables.............................. 13

Appendix B. SALP pressure and temperature records...........................25

Appendix C. Current meter property plots...................................... 27

Appendix D. Microcat property plots.......................................... 35

Appendix E. CTD individual station property plots............................ 45

Appendix F. APEX trajectories and property plots...............................51

\section{List of Figures}

Figure 1. Mooring location, surrounding geography, and ocean currents................1

Figure 2. Geographic locations of collected data and measurement timeline.............2

Figure 3. Mooring schematic...............................................

Figure 4. Example of current meter data compared to APEX float positions...............5

Figure 5. Modeled mooring blowdown ......................................6

Figure 6. CTD versus microcat and APEX conductivity ...........................

Figure A1. Mooring diagram.............................................. 14

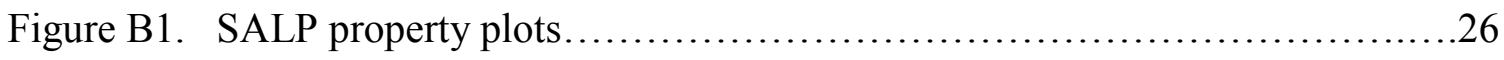

Figure C1-C7. Current meter property plots................................. 28-34

Figure D1-D9. Microcat property plots.................................... $36-44$

Figure E1-E3. CTD property plots.....................................47-49

Figure F1. APEX trajectory 'spaghetti' plot....................................53

Figure F2-F12. Individual APEX calibration plots.............................54-95

\section{List of Tables}

Table 1. Mooring instrument layout..........................................

Table A1. Instrument property simple statistics.............................15-16 
Table A2. Instrument accuracy and resolution................................. 17

Table A3. Microcat conductivity corrections....................................... 17

Table A4. Instrument clock offsets.............................................18

Table A5. APEX releases..................................................... 19

Table A6. APEX identification numbers, URLs, and processing notes................20

Tables A7-A9. Instrument data structure configuration..........................21-23 


\section{Introduction}

Large, coherent, long-lived anticyclonic eddies are shed from a localized formation site off west Greenland into the Labrador Sea interior (e.g., Hátún et al., 2007; Lilly et al., 2003). These Irminger Rings (IRs) are thought to transport an isolated core of anomalous water predominantly along a narrow corridor toward the south (Lilly et al., 2003). Data and modeling studies indicate that these rings are important contributors to the heat and freshwater budgets of the Labrador Sea (Lazier, 1980; Lazier et al., 2002; Pickart et al., 2002; Lilly et al., 2003; Straneo, 2005; Spall, 2004; Katsman et al., 2004; Hátún et al., 2007; Rykova et al., 2009; Gelderloos et al. 2011; De Jong et al., submitted), but

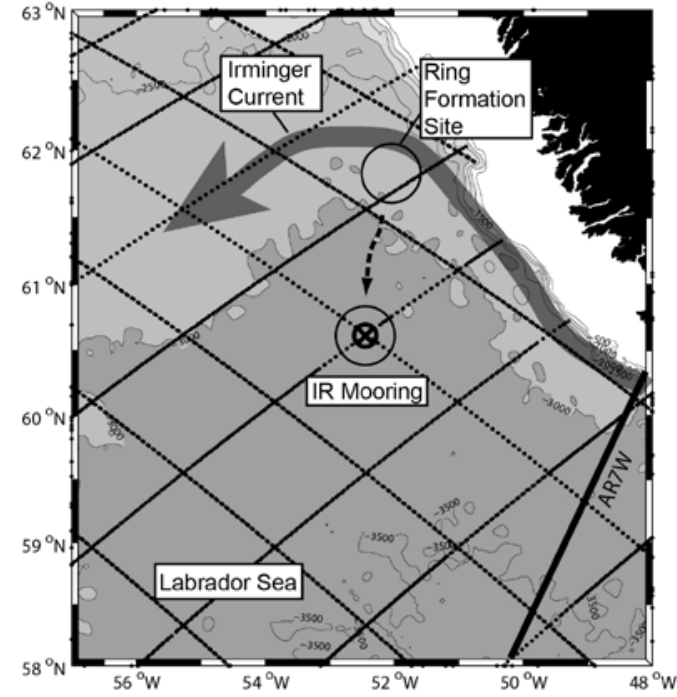

Figure 1. Chart showing the location of the IRINGS mooring, super-imposed on bathymetry (500 m contour interval) and Jason altimeter ground tracks. Outer circle represents ring with $20-\mathrm{km}$ core radius. considerable uncertainty remains because previous observations have been mainly limited to older, weaker eddies and those that had not yet left the boundary.

The goal of the Impact of Irminger Rings on Deep Convection in the Labrador Sea experiment (IRINGS) was to advance our understanding of the impact of IRs on deep convection and restratification by collecting new information on their initial structure and life history. The specific objectives were: (1) to determine the full water column hydrographic and velocity structure of newly-formed IRs that have entered the interior Labrador Sea, (2) to observe how IR core properties are modified by atmospheric forcing over their lifetime, and (3) to improve the interpretation of sea surface

height anomalies in terms of newly formed coherent heat containing IRs.

To achieve these objectives, we deployed one densely instrumented, two-year mooring in the northeastern Labrador Sea in the path of newly formed IRs (Figure 1). As well as current meter, temperature and salinity instrumentation, the mooring held two Submerged Autonomous Launch Platforms (SALPs; Fratantoni, 2010). The SALPs contained eleven APEX profiling floats, some of which were released singly or in pairs each time an eddy core passed by the mooring, and the remainder at pre-programmed timed intervals. The APEX floats parked and drifted at 300 meters depth, and profiled from the surface to 1000 meters at five-day intervals. Thirteen conductivity-temperature-depth (CTD) stations were taken on the mooring recovery cruise, creating a boundary current cross- 
section from the mooring site to Nuuk, Greenland, the final port. The geographical locations and timeline of these measurements are depicted in Figure 2.
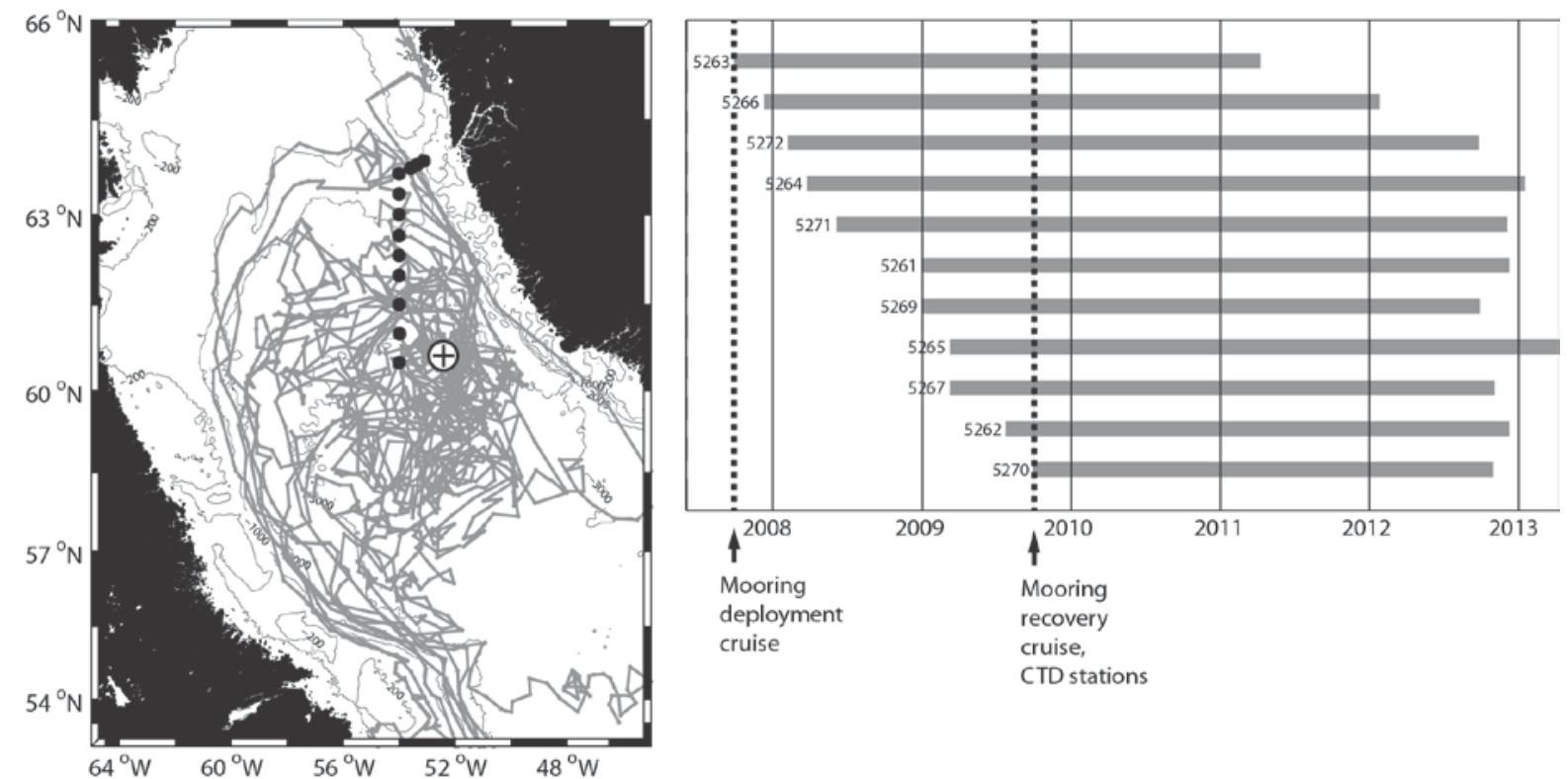

Figure 2. (left) Chart showing mooring location (circle-x), CTD locations (at black dots and at circle-x), and APEX trajectories (gray lines) from start of experiment in September 2007 through the present, in the Labrador Sea. (APEX travelled outside of this basin, see Appendix F.) Bathymetry is labeled in meters. (right) Duration chart showing timing of deployment and recovery cruises, CTD stations, and APEX first through final transmissions.

\section{Mooring setup and instrument performance}

The mooring included an array of eight Aanderaa RCM-11 current meter instruments and nine Seabird SBE-37 microcats from 100 - 3000 meters depth, and two SALP cages at $\sim 500 \mathrm{~m}$ with their own pressure and temperature recording devices. The mooring was deployed from 25 September 2007 through 28 September 2009. All instruments returned $100 \%$ of expected data, except for one current meter at $250 \mathrm{~m}$ which failed early, so that no data were recovered for this instrument. The SALP cages contained six bays each, and were loaded with profiling APEX floats. The SALP controller released APEX floats from the cage bays using criteria based on real-time pressure and temperature measurements recorded by the instrument. The approximate depth of the SALPs were chosen to target the vertical position where the eddy would exhibit the highest temperatures associated with the IRs (front cover figure). The mooring was designed to be less stiff than a traditional mooring by using less flotation. This was done to enhance dips in pressure caused by the passage of eddies, so that this information could be utilized 
by the SALP controller to identify when the SALP cage was in an eddy. Table 1 lists the mooring instrument types, serial numbers and properties measured, Figure 3 shows a mooring schematic and Figure A1 shows the mooring diagram. Current meter, MicroCAT, and SALP instrument mean, maximum, minimum, and standard deviation are listed in Table A1. A summary of instrument accuracy and resolution may be found in Table A2. A review of the SALP mechanics and the SALP controller algorithm may be found in Furey et al. (2013).

Table 1. Mooring layout with nominal instrument depths and properties. The observed parameters are eastward velocity $(\mathrm{u})$, northward velocity $(\mathrm{v})$, temperature $(\mathrm{T})$, conductivity $(\mathrm{C})$, and pressure $(\mathrm{P})$.

\begin{tabular}{|c|c|c|}
\hline Depth $(\mathrm{m})$ & Instrument Type \#s/n & Properties / Notes \\
\hline 100 & RCM11 \#147 & $u, v, T$ \\
\hline 101 & SBE37 \#5291 & $P, C, T$ \\
\hline 200 & SBE37 \#2043 & $\mathrm{C}, \mathrm{T}$ \\
\hline 250 & RCM11 \#345 & Instrument failed. \\
\hline 400 & SBE37 \#2029 & $\mathrm{C}, \mathrm{T}$ \\
\hline 500 & RCM11 \#160 & $u, v, T$ \\
\hline 511 & SALP master & $P, T$ \\
\hline 518 & SALP slave & $\mathrm{P}, \mathrm{T}$ \\
\hline 750 & SBE37 \#5290 & $P, C, T$ \\
\hline 1000 & RCM11 \#128 & $u, v, T$ \\
\hline 1001 & SBE37 \#1649 & $\mathrm{C}, \mathrm{T}$ \\
\hline 1250 & SBE37 \#1644 & $C, T$ \\
\hline 1500 & RCM11 \#162 & $u, v, T$ \\
\hline 1501 & SBE37 \#2037 & C, T \\
\hline 1750 & SBE37 \#1637 & C, T \\
\hline 2000 & RCM11 \#374 & $u, v, T$ \\
\hline 2001 & SBE37 \#2030 & $\mathrm{C}, \mathrm{T}$ \\
\hline 2500 & RCM11 \#159 & $u, v, T$ \\
\hline 3000 & RCM11 \#156 & $u, v, T$ \\
\hline
\end{tabular}

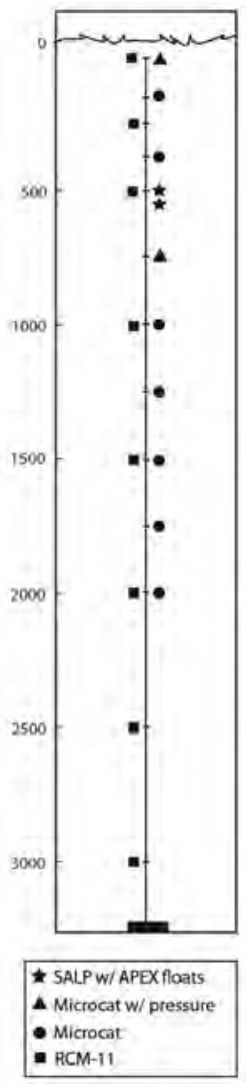

Figure 3. Mooring schematic.

\section{Mooring instrument quality control and calibration}

All instrument data were truncated to in-water time periods, from 26 September 2007 00:00 to 28 September 2009 00:00. The initial and final instrument clock offsets were applied as linear offsets to each mooring instrument. Initial clock offsets were all assumed to be 0 , as we had no information to the contrary. Current meter final clock offsets were provided in a spreadsheet by Scott Worrilow (WHOI); microcat final clock offsets were recorded in the ship's log sheets by John Lund (WHOI). The SALP 
instruments had no retrieval log sheets, and therefore initial and final clock offsets were assumed to be zero. Final clock offsets were recorded on deck at recovery, and may be found in Table A4.

All mooring pressure data (SALP, current meter, and pressure-recording microcat) were de-trended as follows: Because the mooring was designed to have large pressure excursions during high-speed current events (blow downs), and because there were more blow-down events in the latter half of the mooring record, a simple de-trend algorithm was biased by the latter blow downs. Therefore, the large pressure excursions were isolated and removed from the data before calculating the trend by removing any pressure data more than \pm 5 dbars of the mean pressure. The trend of the pressure data for the two years was found with the remaining data, and removed linearly from the entire pressure record. We were careful to choose a pressure window (in the case $\pm 5 \mathrm{dbars}$ ) that did not affect the calculation of the actual trend. As a test, we also calculated $\delta \mathrm{P} / \delta \mathrm{T}$ for two time periods far apart in the mooring record that were recorded during quiescent times, and calculated a linear trend in pressure between those two time periods. This procedure yielded similar results as the method above. Both the original and de-trended pressure records were saved in the MATLAB structure for each instrument (Tables A7-A9).

Quality control and calibration procedures specific to instrument sensor type are detailed below. After all quality control and calibration described in Sections 3.1 through 3.3, the mooring data were low-passed filtered to remove tides using a 40-hour Butterworth filter. The original data were sampled as follows: SALP: hourly, microcats: 15-minute; current meters: 30-minute intervals. The data were resampled in time to a uniform hourly time step. The data at the original sampling rates are available in each instrument's structure file (Tables A7-A9).

\subsection{Submerged Autonomous Lagrangian Profilers (SALPs) T/P Modules}

No further processing was done on the temperature and pressure records from the SALPs after the clock correction and pressure de-trending described above, as there were no obviously erroneous spikes. The thermistor had been calibrated before the instrument was deployed. A complete review of the SALP performance may be found in Furey et al. (2013). SALP temperature and pressure data plots may be found in Appendix B. 


\subsection{Aanderaa Current Meters (RCM11s)}

After the clock correction and pressure de-trending described above, these

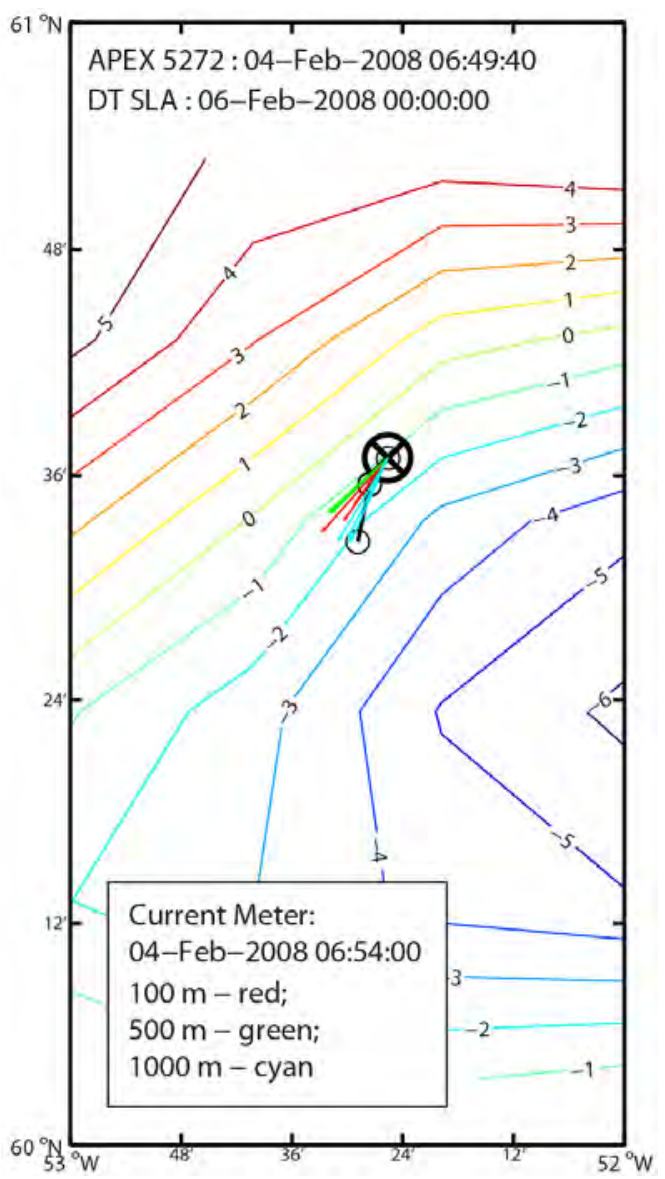

Figure 4. Qualitative check of velocity direction measured by the current meters using APEX float positions. Mooring site is drawn as a bold circle-x. APEX first and second surface positions are plotted as circles connected by a black line. Current meter velocity vectors are plotted at the closest available time to the first APEX position. After release, the APEX dropped from 500 to about 1600 meters depth and then surfaced to get a position fix. Therefore, the velocity vector from the float represents a depthaveraged value. AVISO merged sea level anomaly (MSLA) data for the nearest date to the float release are contoured every 1 centimeter. MSLA data rarely agreed with the current meter or APEX displacement vectors, both because of smoothing of the MSLA data in space and time, and because SLA can only be used to estimate the surface geostrophic velocity anomaly. instruments were processed as follows: Geomagnetic corrections were applied linearly over time using routines written by D. Torres (WHOI), and the most recent International Geomagnetic Reference Field ( IGRF11) data set. Speed data were modified by a scale factor of the ratio in-situ sound velocity/standard sound velocity (where standard sound velocity is $1500 \mathrm{~m} / \mathrm{sec}$ ), as recommended by AADI. Hogg and Frye (2007) suggest scaling all RCM11 speed data by a factor of 1.1. This correction was not applied based on information provided by $\mathrm{D}$. Torres (WHOI) and Ivan Victoria (AADI). Both felt that since the Hogg and Frye study was based on a single instrument, the Hogg and Frye results were not necessarily applicable to all RCM instruments.

The current meter velocities were qualitatively checked against the independent information provided by the APEX floats immediately after release, using the mooring position and first APEX position, recorded within six hours of the float release, to construct a velocity vector that could be used to qualitatively assess the current meter information. One example of this comparison is shown in Figure 4. The current meter velocities generally agreed with the APEX displacement vectors near the times of APEX releases throughout the two year course of the 
mooring record. Temperature data required no editing or correction; the data were free of spikes and the thermistors had been calibrated before the instrument was deployed. A synthetic pressure record was constructed for each RCM-11 according to the method described in Section 3.3 and included in the final structure data for each current meter. Individual current meter data plots may be found in Appendix C.

\subsection{Sea-Bird MicroCATs (SBE37s)}

After the clock correction and pressure de-trending described above, these instruments were processed as follows: The temperature data required no editing, as there were no obviously erroneous spikes.

Synthetic pressure records were constructed for all instruments without pressure sensors. Pressures were recorded by the microcats at $\sim 100$ and $750 \mathrm{~m}$ depth as well as by the SALPs at $\sim 500 \mathrm{~m}$. Predicted profiles of mooring blow down for several velocity profiles were supplied by the mooring's designer (George Tupper, WHOI). The predicted blow down matched the blow down recorded by the instruments at 100, 500 and 750 $\mathrm{m}$ depth. Therefore, this blow down profile was used to construct pressure records for the instruments that lacked a pressure sensor. In fact, the blow down profile of the mooring is such that the upper $500 \mathrm{~m}$ of cable remains nearly vertical even during maximum blow down (Figure 5). Thus, the synthesized pressure records of the instruments in the upper $500 \mathrm{~m}$ of the water column contain very little error.

The conductivity measured by the microcats without pressure sensors assumes a constant reference pressure when converting frequency counts to conductivity.

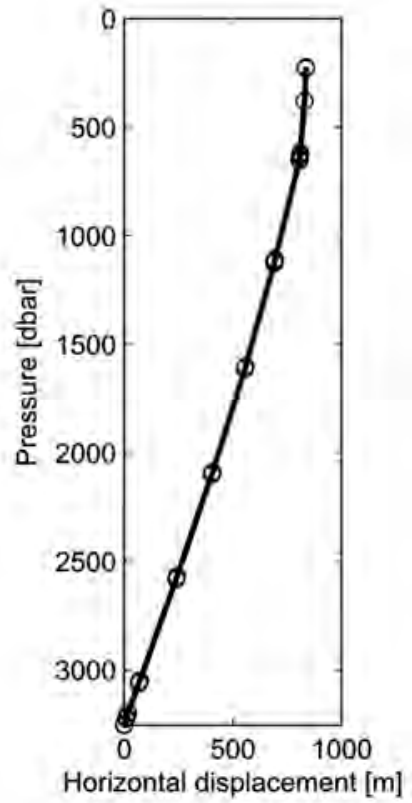

Figure 5. Modeled mooring blow down at a current speed of $75 \mathrm{~cm} / \mathrm{s}$ at the surface decreasing to $0 \mathrm{~cm} / \mathrm{s}$ at the bottom. This mooring profile was used for the reconstruction of pressure time series.

Seabird considers this a negligible error under normal circumstances (minimal pressure variability), but in this case, the large excursions of the mooring (up to 800 meters) meant that this was no longer negligible and needed to be corrected. This was done as advised by Carol Janzen (SeaBird, Inc.) by modifying the conductivity data, not by recalculating conductivity from the frequency data. We computed a time dependent multiplier using recorded temperature $(\mathrm{T})$ and the synthetic pressure data $(\mathrm{P})$ and $\delta$ and $\varepsilon$ calibration coefficients specific to each instrument and provided by SeaBird, Inc. as follows: 
$\mathrm{C}_{\mathrm{P}}=[(10+10 * \delta * \mathrm{~T}) /(10+10 * \delta * \mathrm{~T}+10 * \varepsilon * \mathrm{P})] * \mathrm{C}_{\mathrm{O}}$

where $C_{P}$ is the pressure corrected conductivity, Co is the conductivity output by the instrument. Co is calculated using a preset reference pressure set before deployment, in these instruments 0 dbars. We used the pressure-corrected conductivity, along with the synthetic pressure, to calculate salinity according to the Gibbs Seawater Toolbox 2010 MATLAB routine ' $g s w \_S P \_f r o m \_c . m$ '. The difference between using corrected and uncorrected conductivity in salinity space ( $\mathrm{S}$ calculated with $\mathrm{C}$ corrected minus $\mathrm{S}$ calculated using $\mathrm{C}$ uncorrected) ranged from $0.001-0.003$ practical salinity units at 200 meters depth. The larger values occurred when the mooring was blown to deeper pressures. Although the offset when the mooring is upright can be corrected by using an appropriate reference pressure, blowdown does cause variability in the conductivity (in addition to the variability in salinity calculated from conductivity and synthetic pressure) that results in salinity differences up to 0.002 .

The conductivity time series contained some obviously bad data that needed to be removed (instruments s/ns 163720292037 2043) and replaced with NaNs, or adjusted ( $\mathrm{s} / \mathrm{n}$ 2037), the gross adjustments are detailed in Table A3. Once these adjustments were made, all conductivity data were processed to remove outliers using a 12-hour (49-point) window with a 2.0 standard deviation cut-off, done twice. (This is similar to the procedure done by R. Curry for HydroBase, http://www.whoi.edu/hydrobase/.)
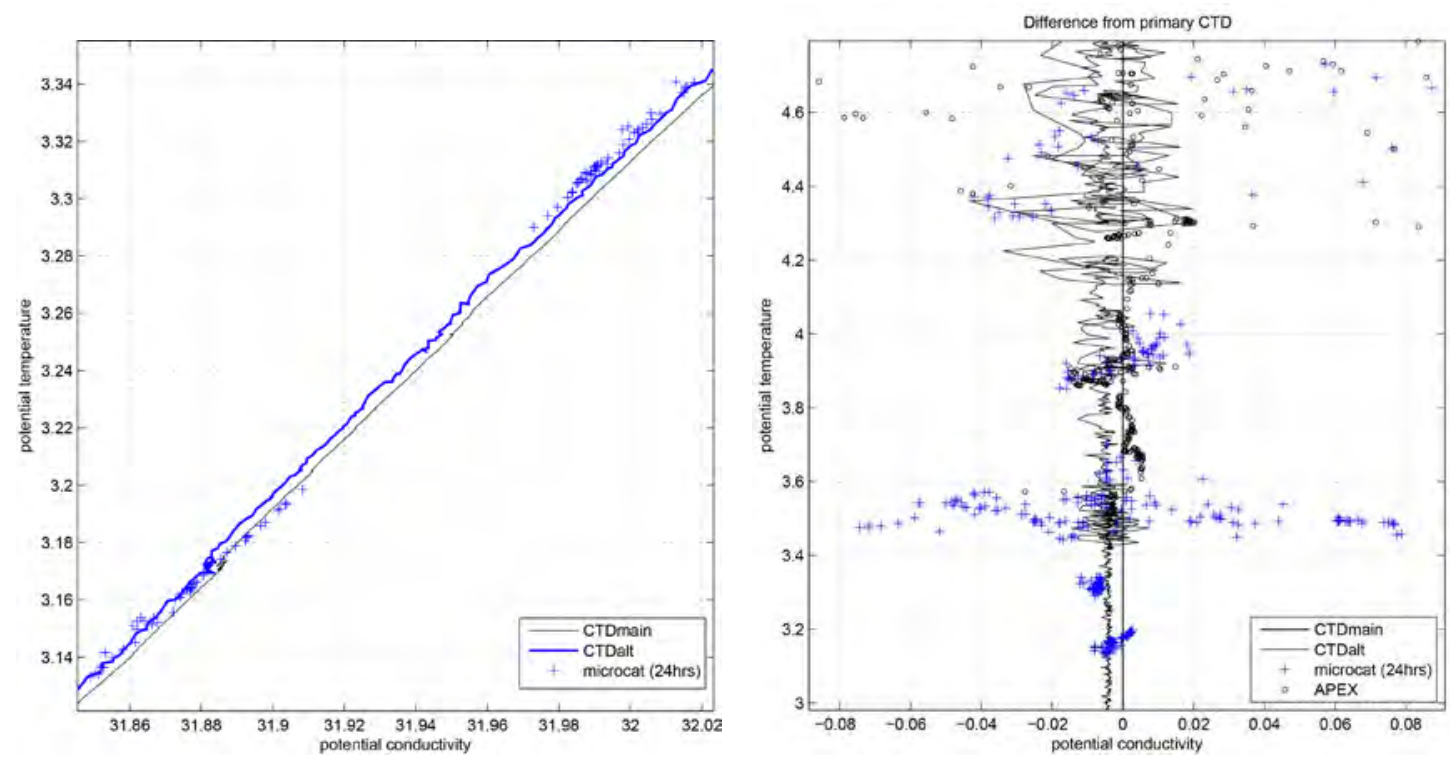

Figure 6. (left) Deep CTD conductivity (primary (main) and secondary (alt) probes) for the CTD taken at the mooring site when the mooring was recovered and microcat conductivity for the final 24 points versus $T$. The secondary probe is noisy, but the microcat conductivity agrees better with these data than that of the primary probe. (right) Difference between microcat, secondary CTD, and nearby APEX potential conductivity from the primary CTD conductivity probe, plotted in T-C space. 
Finally, the conductivity data were calibrated using the post-recovery Seabird calibration coefficients. The final microcat conductivity was not adjusted to the recovery CTD conductivity values (see Figure 6). The CTD conductivity values were suspect - the CTD contained two conductivity probes, and the probe values were offset from each other. The secondary probe, though noisier than the primary, had deep values that generally matched the deep microcat conductivity data. Therefore, we did not adjust the microcat records to the primary CTD values at this site. Further investigation revealed that the primary CTD conductivity sensor was replaced after this research cruise, for unknown reasons. We considered calibrating the microcat conductivity data using the historical deep CTD conductivity in this region (as suggested by J. Toole), but the available data were too sparse to perform this operation.

The final agreement ('fit') between temperature (RCM11s, SALP, SBE37s) and conductivity (SBE37s) data and the CTD cast performed at mooring recovery are near or within the manufacturer stated instrument accuracy (CTD accuracy + mooring instrument accuracy; Table A2) for the deep values (below $1000 \mathrm{~m}$ ), and some shallow values. Individual microcat data plots may be found in Appendix D.

\subsection{Data gridding}

The recorded data were interpolated vertically in order to get full profiles of temperature, salinity and velocity. A shape preserving spline function was used to grid the data to 25 dbar intervals. At every time step this spline fitting was applied to the temperature and salinity at the depths of the microcats. Because of the non-monotonic vertical profiles of temperature and salinity in the Labrador Sea, a control on the fitting was needed. This was especially true for salinity, which has a local minimum at mid-depth associated with Labrador Sea Water. As a control, density profiles were derived both from the newly fitted 25 dbar interval profiles of temperature and salinity as well as by spline fitting the density observations at the original instrument depths (which is necessarily monotonic because of the inherently stable water column). The spline shape parameters were then adjusted to get the best match between the two density profiles. The same spline fitting function was also applied to the $\mathrm{u}$ and $\mathrm{v}$ velocity measurements.

\section{APEX Float quality control and calibration}

The twelve APEX floats deployed during this experiment were built and ballasted at Teledyne Webb Research. The APEX were programmed to park at 300 dbars, profiling 0-1000 meters once every 5 days. An issue with float ballasting put the floats initially 
deeper than planned (near 600-800 meters). Adjustment to the programmed park depth ( $\sim 300$ dbar) took on average 2.75 days (Table A5). Two SALP cages were mounted on the mooring, with six bays per cage, and loaded with 11 APEX floats. The SALP released APEX based on ambient oceanographic conditions that signaled a passing Irminger Ring. One float (\#5263) was deployed off the ship before mooring deployment. Ten floats were successfully deployed from the cages, and one float was stuck in the cage. This stuck float (\#5270) was launched off the ship during the recovery cruise. Eleven APEX successfully completed their missions, one float, \#5268, stopped transmitting after a single cycle for unknown reasons. Three APEX were affected by defective Druck pressure sensors and had Negative Pressure Drift, but not of the Truncated variety. This meant that the pressure drift could be corrected as outlined in Barker et al. (2011). The park point of APEX \# 5263 was adjusted while in mission to try to redirect the float from its northward trajectory towards the shallow Davis Strait back into deeper water. This was unsuccessful, and the float got stuck in shallow water on the continental shelf west of Greenland for most of its mission. Further review of APEX performance may be found in Furey et al. (2013). A summary of APEX release type, positions, and dates may be found in Table A5.

APEX quality control and calibration were done according to the procedures used on WHOI ARGO data as follows. The profile data were visually inspected to identify and flag bad points. This process included visual comparison to nearby historical data and a check for density inversions (see Appendix $\mathrm{F}$ for historical data positions used in this procedure). Next, we applied a thermal-mass correction to the conductivity data based on the Johnson et al. (2007) analysis of the SeaBird 41CP. Finally, the long-term stability of the conductivity sensor was examined using the Owens and Wong (2009) method, which compares the conductivity measured by the float with nearby historical data objectivelymapped to the location of the float observations. Comparison was made with both climatology of historical CTD casts and climatology of high-quality Argo profiles. Adjustments were only made to the reported conductivity if there was clear evidence from the historical comparisons of a drift or offset greater than 0.01 PSU. Only one of the floats (4901945) had a detectable trend in conductivity calibration with the float measuring too salty by up to 0.04 PSU. All data may be found at the Argo GDACs: http://www.usgodae.org/argo/argo.html or ftp://ftp.ifremer.fr/ifremer/argo/. APEX identification numbers, URLS, and quality control and calibration notes for individual floats may be found in Table A6. A composite APEX 'spaghetti' diagram and individual float plots may be found in Appendix F.

\section{Conductivity-Temperature-Depth Station quality control and calibration}

The CTD data were obtained as ancillary data for the project. CTD station locations may be found in Figure 2. CTD data were processed by Jane Dunworth, WHOI, according to 
standard practices of the Physical Oceanography Department. No bottle data were taken on the cruise, so the salinity data were not corrected against in-situ water samples. The primary conductivity sensor on the CTD was replaced after the cruise for unknown reasons. There was an offset between the primary and secondary conductivity sensors which makes the data suspect (also see Section 3.3). Plots of the individual CTD casts may be found in Appendix E.

\section{Acknowledgements}

The authors would like to thank David Fratantoni for generously allowing us to build upon his prototype SALP design. We would also like to thank Fiamma Straneo, Mike Spall, Jonathan Lilly, George Tupper and Dana Swift for help with instruments, processing software, and mooring design and deployment related to this experiment. The authors wish to thank WHOI engineer Rick Trask for mooring design, and Will Ostrom, John Lund, and the crews of the R/V Knorr for expert mooring deployment and recovery. This work was funded by the National Science Foundation Grant OCE-0623192.

\section{References}

Barker, P. M., J. R. Dunn, C. M. Domingues, S. E. Wijffels, 2011: Pressure Sensor Drifts in Argo and Their Impacts. J. Atmos. Oceanic Technol., 28, 1036-1049.

doi: http://dx.doi.org/10.1175/2011JTECHO831.1

De Jong, M.F., A. S. Bower, H. Furey \& J. Lilly. Two years of observations of warm core anti-cyclones in the Labrador Sea. Submitted to Journal of Physical Oceanography, 2013.

Fratantoni, D. M., 2010. Environmentally Adaptive Deployment of Lagrangian Instrumentation using a Submerged Autonomous Launch Platform. Poster Presentation at AGU Ocean Sciences Meeting, February 2010, Portland, OR.

Furey, H., M. F. de Jong, J. Valdes, and A. Bower. Eddy seeding in the Labrador Sea: a Submerged Autonomous Launch Platform application. Accepted, Journal of Ocean and Atmospheric Technology, 2013.

Gelderloos, R., C.A. Katsman and S.S. Drijfhout (2011): Assessing the Roles of Three Eddy Types in Restratifying the Labrador Sea after Deep Convection, J. Phys.

Oceanogr., 41, 2102-2119.

Hátún, H., C.C. Eriksen, P.B. Rhines, 2007. Buoyant eddies entering the Labrador Sea observed with gliders and altimetry. J. Phys. Oceanogr., 37, 2838-2854. 
Hogg, N. G., and D. E. Frye, 2007. Performance of a new generation of acoustic meters. J. Phys. Oceanogr. 36, 148-161.

Johnson, G. C., J. M. Toole, and N. G. Larson. 2007. Sensor corrections for Sea-Bird SBE-41CP and SBE-41 CTDs. Journal of Atmospheric and Oceanic Technology, 24, 1117-1130, doi:10.1175/JTECH2016.1.

Katsman, C. A., M. A. Spall, and R. S. Pickart, 2004. Boundary current eddies and their role in the restratification of the Labrador Sea. J. Phys. Oceanogr., 34, 1967-1983.

Lazier, J. R. N., 1980. Oceanographic conditions at Ocean Weather Ship Bravo, 19641974. Atmosphere-Ocean, 18, 227-228.

---, R. Hendry, A. Clarke, I. Yashayaev, and P. Rhines, 2002. Convection and restratification in the Labrador Sea. Deep-Sea Res. I, 49, 1819-1835.

Lilly, J. M.,, P. B. Rhines, F. Schott, K. Lavender, J. R. N. Lazier, U. Send, E. D'Asaro, 2003. Observations of the Labrador Sea eddy field. Prog. Oceanogr., 59, 75-176.

Owens, W.B., A.P.S. Wong, "An improved calibration method for the drift of the conductivity sensor on autonomous CTD profiling floats by theta-s climatology", DeepSea Research Part I: Oceanographic Research Papers, 56(3), 450-457, 2009.

Pickart, R. S., D. J. Torres, and R. A. Clarke, 2002. Hydrography of the Labrador Sea during active convection. . J. Phys. Oceanogr., 32, 428-457.

Rykova, T., F. Straneo, J. M. Lilly, I. Yashayaev, 2009. Irminger Current Anticyclones in the Labrador Sea observed in the hydrographic record, 1990-2004. J. of Mar. Res., 67,361-384.

Spall, M. A., 2004. Boundary currents and water mass transformation in marginal seas. J. Phys. Oceanogr., 34, 1197-1213.

Straneo, F., 2006: Heat and Freshwater Transport through the Central Labrador Sea. J. Phys. Ocean., 36(4), 606-628.

---, 2006: On the connection between dense water formation, overturning, and poleward heat transport in a convective basin. J. Phys. Ocean. 36(9), 1822-1840. 
Appendix A: Mooring diagram (Figure A1), instrument measurement simple statistics (Table A1), instrument metadata tables (Tables A2-A6) and mooring data structure format (Tables A7-A9). 


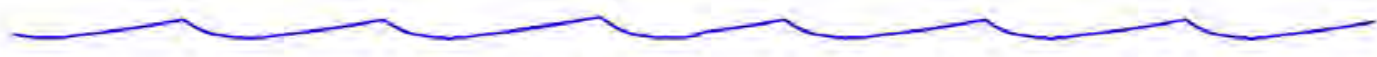

\section{Nominal Location \\ 60.6 Degrees North \\ 52.4 Degrees West}

HARDWARE DESGCNATOW

(A) $1 / 2^{*}$ Ancher Shackle, $5 / 8^{*}$ sing

(B) $1 / 2^{*}$ Anchor Shackle, 5/8* Sling Link,

(B) $5 / 8^{\circ}$ Anchor Shockle

(C) $1 / 2^{*}$ Anchor Shockle, $5 / 8^{*}$ Sling Link,

$3 / 4^{*}$ Anchor Shackle

(D) $1 / 2^{*}$ Anchor Shackle, $5 / 8^{*}$ Sing Unk,

(D) $7 / 8^{\circ}$ Anchor Shocklo

(2) $5 / 8^{*}$ Anchor Shockle, $5 / 8^{\prime \prime}$ Sling Link

$7 / 8^{*}$ Anchor Shockle

(11) 5/8" Anchor Shockle, 5/8" Sling Link,

8. Anchor Shackle

(4) $1-1 / 4^{*}$ Mastor Link
DEPTH $95 \mathrm{M}$

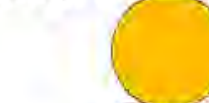

64" Sphere with Argos Transmitter

$2832 \mathrm{lb}$. baoyancy and Light

$5 \mathrm{M}, 3 / \mathbf{d}^{*}$ Mooring Chain

Aanderan RCM-11
SBE 37 w/gressure clamped to wire below Term

SBE 37 w/gressure clamped to wire below Term

$147 \mathrm{M}$. 1/4 Wire-asarked $99 \mathrm{~m}$ from

Asuderas RCM-11

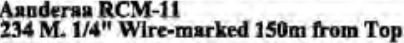

SBE 37 clamped to wire at mark

$250 \mathrm{~m}$

$400 \mathrm{~m}$

(4)

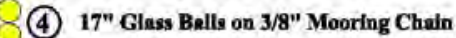

(i) $10 \mathrm{M} .1 / 4^{n}$ Wire

$500 \mathrm{~m}$

$11 \mathrm{~m}$

(C)

Aanderan RCM-11

10 M. 1/4" Wire

(C)

SALP Frame

5 M. 3/8" Mooring Chain W/Communleationx Cable

$518 m$

(C)

BALP Frame

459 M. 1/4" Wire-marked 236m from top

SBE 37 w/pressure clamped to wire at mark

(7) 17" Glass Balls on 3/8" Mooring Chaia

(2) M. 1/4" Wire

$1000 \mathrm{~m}$ (B) Asnderas RCM-11

$1001 \mathrm{~m}$

$1250 m$

SBE 37 clamped to wire below Term
483 M. 1/4" Wire-marliced $249 \mathrm{~m}$ from Top

$2(2)$

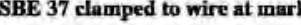

$1500 \mathrm{~m}$ (8) $10 \mathrm{M}$ 1/4" Wire

(2) 17" Glass Balls on 3/8" Mooring Chain

$1501 \mathrm{~m}$

Annderas RCM-11

SBE 37 clamped to wire below Term

$483 \mathrm{M}$. 1/4" Wire-marked $249 \mathrm{~m}$ from Top

$1750 \mathrm{~m}$ SBE 37 clamped to wire at mark

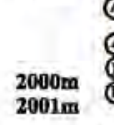

(2) 17" Glass Balls on 3/8" Mooring Chain

(4)

(1)

(4)

Annderan RCM-11

SBE 37 cinmped to wire below Term

483 M. 1/4" Wire

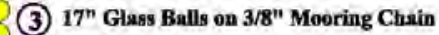

$10 \mathrm{M} .1 / 4^{"}$ Wire

2500m Aanderan RCM-11

A83 M. 1/4" Wire

(3) 17" Glass Balls on $3 / \mathbf{8}^{n}$ Mooring Chain

(1)

$10 \mathrm{M.} \mathrm{1/4"} \mathrm{Wire}$

$3000 \mathrm{~m}$ (Q) Aanderan RCM-11

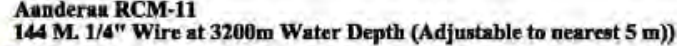

(14) 17" Gless Balls on 3/8" Mooring Chain

5 M. 3/8" Mooring Chain

Dusled Acoustic Relesse EGG Moded 8242

1 M. 1/2" Trswler Dualting Chaln

5 M. 3/8" Mooring Chain

20 M. 3/4" Nylon

5 M. 3/8" Mooring Chain

Mace Anchor Wet Wt $4400 \mathrm{Ib}$

4 3/8" mooring chain

\& $22 \mathrm{LB}$ danforth

(A) (D)

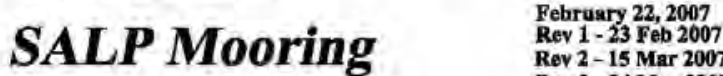

Rev 3 - 24 May 2007

Figure A1. Mooring diagram drawn by George Tupper, WHOI. 
Table A1. Instrument property simple statistics.

\begin{tabular}{|c|c|c|c|c|c|c|}
\hline Property & $\begin{array}{c}\text { Instrument Type } \\
\# s / n\end{array}$ & Depth $(\mathrm{m})$ & Mean & Maximum & Minimum & $\begin{array}{c}\text { Standard } \\
\text { Deviation }\end{array}$ \\
\hline
\end{tabular}

\begin{tabular}{|c|c|c|c|c|c|c|}
\hline \multirow{4}{*}{$P$} & SBE37 \#5291 & 101 & 141 & 734 & 118 & 46 \\
\cline { 2 - 7 } & SALP master & 511 & 553 & 1139 & 530 & 46 \\
\cline { 2 - 7 } & SALP slave & 518 & 561 & 1146 & 538 & 46 \\
\cline { 2 - 7 } & SBE37 \#5290 & 750 & 806 & 1372 & 784 & 45 \\
\hline
\end{tabular}

\begin{tabular}{|c|c|c|c|c|c|c|}
\hline \multirow{5}{*}{} & RCM11 \#147 & 100 & 4.60 & 7.02 & 1.52 & 0.85 \\
\cline { 2 - 7 } & SBE37 \#5291 & 101 & 4.634 & 7.083 & 1.475 & 0.847 \\
\cline { 2 - 7 } & SBE37 \#2043 & 200 & 4.723 & 6.443 & 2.741 & 0.569 \\
\cline { 2 - 7 } & SBE37 \#2029 & 400 & 4.391 & 5.904 & 3.305 & 0.417 \\
\cline { 2 - 7 } & RCM11 \#160 & 500 & 4.20 & 5.64 & 3.24 & 0.38 \\
\cline { 2 - 7 } & SALP master & 511 & 4.18 & 5.58 & 3.36 & 0.37 \\
\cline { 2 - 7 } & SALP slave & 518 & 4.18 & 5.56 & 3.38 & 0.37 \\
\cline { 2 - 7 } & SBE37 \#5290 & 750 & 3.855 & 4.973 & 3.298 & 0.275 \\
\cline { 2 - 7 } & RCM11 \#128 & 1000 & 3.63 & 4.54 & 3.35 & 0.17 \\
\cline { 2 - 7 } & SBE37 \#1649 & 1001 & 3.650 & 4.554 & 3.372 & 0.167 \\
\cline { 2 - 7 } & SBE37 \#1644 & 1250 & 3.591 & 4.186 & 3.318 & 0.102 \\
\cline { 2 - 7 } & RCM11 \#162 & 1500 & 3.60 & 3.86 & 3.14 & 0.06 \\
\hline & SBE37 \#2037 & 1501 & 3.601 & 3.870 & 3.139 & 0.057 \\
\hline & SBE37 \#1637 & 1750 & 3.430 & 3.768 & 2.993 & 0.077 \\
\cline { 2 - 7 } & RCM11 \#374 & 2000 & 3.22 & 3.59 & 2.82 & 0.07 \\
\hline SBE37 \#2030 & 2001 & 3.2281 & 3.591 & 2.818 & 0.068 \\
\hline & RCM11 \#159 & 2500 & 2.84 & 3.10 & 2.44 & 0.06 \\
\hline RCM11 \#156 & 3000 & 2.19 & 2.67 & 1.71 & 0.10 \\
\hline
\end{tabular}

\begin{tabular}{|c|c|c|c|c|c|c|}
\hline \multirow{4}{*}{} & SBE37 \#5291 & 101 & 34.828 & 35.254 & 34.151 & 0.116 \\
\cline { 2 - 7 } & SBE37 \#2043 & 200 & 34.906 & 35.093 & 34.617 & 0.057 \\
\cline { 2 - 7 } & SBE37 \#2029 & 400 & 34.908 & 35.031 & 34.713 & 0.039 \\
\cline { 2 - 7 } & SBE37 \#5290 & 750 & 34.828 & 35.254 & 34.151 & 0.116 \\
\cline { 2 - 7 } & SBE37 \#1649 & 1001 & 34.865 & 34.976 & 34.799 & 0.021 \\
\cline { 2 - 7 } & SBE37 \#1644 & 1250 & 34.876 & 34.945 & 34.808 & 0.019 \\
\cline { 2 - 7 } & SBE37 \#2037 & 1501 & 34.899 & 34.931 & 34.836 & 0.012 \\
\cline { 2 - 7 } & SBE37 \#1637 & 1750 & 34.904 & 34.925 & 34.877 & 0.005 \\
\cline { 2 - 7 } & SBE37 \#2030 & 2001 & 34.902 & 34.922 & 34.878 & 0.005 \\
\hline
\end{tabular}


Table A1. Instrument property simple statistics, continued.

\begin{tabular}{|c|c|c|c|c|c|c|}
\hline Property & $\begin{array}{c}\text { Instrument Type } \\
\text { \#s/n }\end{array}$ & Depth $(\mathrm{m})$ & Mean & Maximum & Minimum & $\begin{array}{c}\text { Standard } \\
\text { Deviation }\end{array}$ \\
\hline \multirow{4}{*}{} & RCM11 \#147 & 100 & 2.1 & 76.4 & -59.3 & 15.5 \\
\cline { 2 - 7 } & RCM11 \#160 & 500 & 2.8 & 65.6 & -50.9 & 12.9 \\
\cline { 2 - 7 } & RCM11 \#128 & 1000 & 3.3 & 53.4 & -43.1 & 11.8 \\
\cline { 2 - 7 } & RCM11 \#162 & 1500 & 3.2 & 43.7 & -37.4 & 11.8 \\
\cline { 2 - 7 } & RCM11 \#374 & 2000 & 2.0 & 45.0 & -33.4 & 10.1 \\
\cline { 2 - 7 } & RCM11 \#159 & 2500 & 1.1 & 46.0 & -35.3 & 9.8 \\
\cline { 2 - 7 } & RCM11 \#156 & 3000 & -0.5 & 29.3 & -40.4 & 9.7 \\
\hline
\end{tabular}

\begin{tabular}{|c|c|c|c|c|c|c|}
\hline \multirow{4}{*}{} & RCM11 \#147 & 100 & 0.0 & 65.6 & -67.0 & 16.2 \\
\cline { 2 - 7 } & RCM11 \#160 & 500 & 0.0 & 50.5 & -52.5 & 13.0 \\
\cline { 2 - 7 } & RCM11 \#128 & 1000 & 0.6 & 50.7 & -45.9 & 11.9 \\
\cline { 2 - 7 } & RCM11 \#162 & 1500 & 0.6 & 45.5 & -43.1 & 11.2 \\
\cline { 2 - 7 } & RCM11 \#374 & 2000 & 1.4 & 40.4 & -40.3 & 10.0 \\
\cline { 2 - 7 } & RCM11 \#159 & 2500 & 2.3 & 38.8 & -38.8 & 9.5 \\
\cline { 2 - 7 } & RCM11 \#156 & 3000 & 3.7 & 45.8 & -43.7 & 9.4 \\
\hline
\end{tabular}


Table A2. Instrument accuracy and resolution.

\begin{tabular}{|c|c|c|c|c|}
\hline Instrument & Component & Initial accuracy & Typical drift & Resolution \\
\hline \multirow{3}{*}{$\begin{array}{r}\text { Seabird } \\
\text { MicroCAT } \\
\text { SBE } 37-\text { SM* }^{*}\end{array}$} & conductivity & $\begin{array}{c} \pm 0.0003 \mathrm{~S} / \mathrm{m} \\
( \pm 0.003 \mathrm{mS} / \mathrm{cm})\end{array}$ & $\begin{array}{c} \pm 0.0003 \mathrm{~S} / \mathrm{m} \\
( \pm 0.003 \mathrm{mS} / \mathrm{cm}) \\
\text { per month }\end{array}$ & $\begin{array}{c}0.00001 \mathrm{~S} / \mathrm{m} \\
(0.0001 \mathrm{mS} / \mathrm{cm})\end{array}$ \\
\hline & temperature & $\pm 0.002^{\circ} \mathrm{C}$ & $\pm 0.0002^{\circ} \mathrm{C}$ per month & $0.0001^{\circ} \mathrm{C}$ \\
\hline & $\begin{array}{l}\text { Pressure } \\
\text { (Druck) }\end{array}$ & $0.1 \%$ of full scale range & $\begin{array}{l}0.05 \% \text { of full scale range } \\
\text { per year }\end{array}$ & $0.002 \%$ of full scale range \\
\hline \multirow[b]{3}{*}{$\begin{array}{r}\text { Current Meter } \\
\text { Aanderaa } \\
\text { RCM-11** }\end{array}$} & speed & $\pm 0.15 \mathrm{~cm} / \mathrm{s}$ & Not specified. & $0.3 \mathrm{~cm} / \mathrm{s}$ \\
\hline & direction & $\begin{array}{l} \pm 5^{\circ} \text { for } 0-15^{\circ} \text { tilt and } \pm 7.5^{\circ} \\
\text { for } 15-35^{\circ} \text { tilt. }\end{array}$ & Not specified. & $0.35^{\circ}$ \\
\hline & $\begin{array}{c}\text { Temperature } \\
\text { (Fenwall } \\
\text { GB32JM19) }\end{array}$ & $\pm 0.05^{\circ} \mathrm{C}$ & Not specified. & $\begin{array}{l}0.1 \% \text { of full scale range } \\
\text { Note: All RCM11s used the } \\
\text { Low Range }(-2.70 \text { to } \\
\left.21.77^{\circ} \mathrm{C}\right) \text { for temperature } \\
\text { conversion, so resolution for } \\
\text { this mooring is } 0.02^{\circ} \mathrm{C} \text {. }\end{array}$ \\
\hline \multirow[b]{2}{*}{$\begin{array}{r}\text { SALP*** } \\
\text { (Designed and } \\
\text { built at WHOI by } \\
\text { J. Valdes) }\end{array}$} & $\begin{array}{c}\text { Temperature } \\
\text { YSI (YSI 55008) }\end{array}$ & Not specified. & $<0.01^{\circ} \mathrm{C} / 10$ months & Not specified. \\
\hline & $\begin{array}{c}\text { Pressure } \\
\text { Druck (PDCR } \\
\text { 900-4210) } \\
\text { Pressure } \\
\text { transducer } \\
\end{array}$ & $0.1 \%$ of full scale range & $\begin{array}{l}0.05 \% \text { of full scale range } \\
\text { per year }\end{array}$ & $0.002 \%$ of full scale range \\
\hline
\end{tabular}

*http://www.seabird.com/products/spec_sheets/37smdata.htm @ 20 December 2011

**http://www.icm.csic.es/bio/projects/eflubio/RCM11.pdf @ 20 December 2011

***http://datasheet.octopart.com/44011RC-Measurement-Specialties-datasheet-8450905.pdf @ 11 march 2013

Table A3. Microcat conductivity corrections.

\begin{tabular}{|c|c|c|}
\hline Instrument $\mathrm{s} / \mathrm{n}$ & $\begin{array}{l}\text { Conductivity sections } \\
\text { adjusted by mean on } \\
\text { either side }\end{array}$ & $\begin{array}{l}\text { Conductivity sections } \\
\text { cut }\end{array}$ \\
\hline mc1637 & None. & 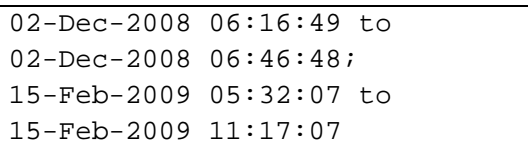 \\
\hline mc2029 & None. & $\begin{array}{l}\text { 28-Mar-2009 } 09: 17: 01 \text { to } 28-\text { Mar- } \\
200920: 47: 03\end{array}$ \\
\hline mc2037 & None. & 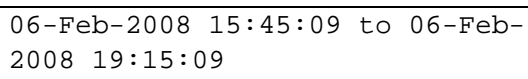 \\
\hline $\mathrm{mc} 2043$ & 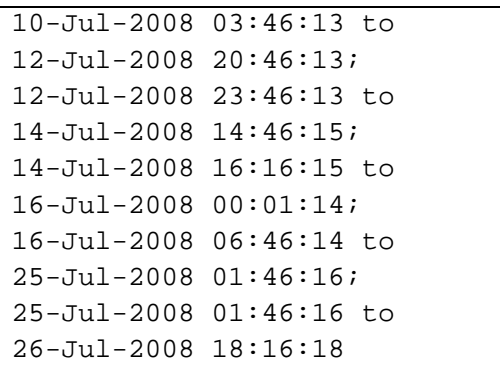 & 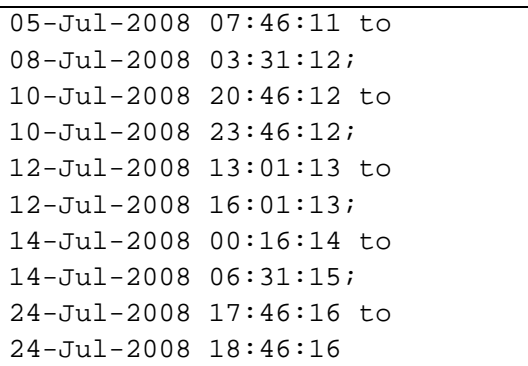 \\
\hline
\end{tabular}


Table A4. Instrument clock drifts.

\begin{tabular}{|c|c|c|}
\hline $\begin{array}{l}\text { Nominal } \\
\text { Depth }(\mathrm{m})\end{array}$ & Instrument Type \#s/n & $\begin{array}{c}\text { Final Clock Offset (mm:ss. } \\
+ \text { means instr. clock fast) }\end{array}$ \\
\hline 100 & RCM11 \#147 & $-11: 55$ \\
\hline 101 & SBE37 \#5291 & $+02: 45$ \\
\hline 200 & SBE37 \#2043 & $+03: 05$ \\
\hline 250 & RCM11 \#345 & Instrument leaked. \\
\hline 400 & SBE37 \#2029 & $+02: 42$ \\
\hline 500 & RCM11 \#160 & $+06: 20$ \\
\hline 511 & SALP master & Unknown, assumed 00:00 \\
\hline 518 & SALP slave & Unknown, assumed 00:00 \\
\hline 750 & SBE37\#5290 & $+09: 10$ \\
\hline 1000 & RCM11 \#128 & $+02: 26$ \\
\hline 1001 & SBE37\#1649 & $+04: 40$ \\
\hline 1250 & SBE37\#1644 & $+14: 00$ \\
\hline 1500 & RCM11 \#162 & $+00: 52$ \\
\hline 1501 & SBE37\#2037 & $+03: 01$ \\
\hline 1750 & SBE37\#1637 & $+04: 50$ \\
\hline 2000 & RCM11 \#374 & $+04: 20$ \\
\hline 2001 & SBE37\#2030 & $+18: 45$ \\
\hline 2500 & RCM11 \#159 & $+14: 00$ \\
\hline 3000 & RCM11 \#156 & \\
\hline & & \\
\hline
\end{tabular}


Table A5. APEX deployments or releases listed in order of launch.

\begin{tabular}{|c|c|c|c|c|}
\hline Float ID/cage & $\begin{array}{l}\text { Release Date/ } \\
\text { Final Transmission } \\
\text { Date/ No. Profiles } \\
\text { Completed }\end{array}$ & Release type & $\begin{array}{l}\text { Days to } \\
\text { adjust to } \\
\text { park } \\
\text { point }\end{array}$ & Notes. \\
\hline \multicolumn{5}{|c|}{ Deployment Cruise. } \\
\hline 5263/slave & $\begin{array}{c}2007-09-26 / \\
2011-04-11 / \\
246\end{array}$ & $\begin{array}{c}\text { Released from } \\
\text { ship prior to } \\
\text { arrival at mooring } \\
\text { site. }\end{array}$ & 2.33 & $\begin{array}{l}\text { Initial park point of } 300 \text { meters. } \\
\text { This float moved northward into } \\
\text { shallow waters of Davis Straits, and } \\
\text { the park point was reset to } \sim 550 \text {, then } \\
100 \text {, then } 250 \text { meters depth, in an } \\
\text { unsuccessful attempt to keep the } \\
\text { float in the central Labrador Sea. }\end{array}$ \\
\hline \multicolumn{5}{|c|}{ Begin SALP Underwater Mission. } \\
\hline 5266/master & $\begin{array}{c}2007-12-08 / \\
2012-01-27 / \\
295\end{array}$ & T-P criteria & 2.46 & - \\
\hline 5272/master & $\begin{array}{c}2008-02-04 / \\
2012-09-26 / \\
331\end{array}$ & T-P criteria & 2.70 & - \\
\hline $5264 /$ slave & $\begin{array}{c}2008-03-23 / \\
2013-01-18 / \\
344\end{array}$ & Timed & 2.62 & - \\
\hline 5271/master & $\begin{array}{c}2008-06-03 / \\
2012-12-06 / \\
321\end{array}$ & T-only criteria & 2.63 & $\begin{array}{l}\text { Negative pressure drift (NPD) from } \\
\text { leaking Druck pressure sensor. }\end{array}$ \\
\hline \multicolumn{5}{|c|}{ Release criteria changed to allow for independent launch. } \\
\hline $5261 /$ slave & $\begin{array}{c}2008-12-28 / \\
2012-12-10 / \\
282\end{array}$ & T-P criteria & 2.82 & - \\
\hline 5269/master & $\begin{array}{c}2008-12-28 / \\
2012-09-30 / \\
270\end{array}$ & T-P criteria & 3.70 & $\begin{array}{l}\text { Bad salinity; NPD from leaking } \\
\text { Druck pressure sensor. }\end{array}$ \\
\hline 5265/master & $\begin{array}{c}2009-03-07 / \\
2013-02-18 / \\
281\end{array}$ & T-P criteria & 2.94 & - \\
\hline $5267 /$ slave & $\begin{array}{c}2009-03-06 / \\
2012-11-04 / \\
261\end{array}$ & T-P criteria & 2.50 & - \\
\hline $5268 /$ slave & $\begin{array}{c}2009-09-27 / \\
2009-09-27 / \\
0\end{array}$ & Timed & - & Died after first transmission. \\
\hline $5262 /$ slave & $\begin{array}{c}2009-07-22 / \\
2012-12-10 / \\
242\end{array}$ & Timed & 3.08 & - \\
\hline \multicolumn{5}{|c|}{ Recovery Cruise. } \\
\hline 5270/master & $\begin{array}{c}2009-09-28 / \\
2012-11-01 / \\
223\end{array}$ & $\begin{array}{l}\text { Launched from } \\
\text { ship at mooring } \\
\text { site. }\end{array}$ & 2.46 & $\begin{array}{l}\text { NPD from leaking Druck pressure } \\
\text { sensor. }\end{array}$ \\
\hline
\end{tabular}


Table A6. APEX Identification numbers for DACs, WHOI URLs, notes.

\begin{tabular}{|c|c|c|c|c|c|}
\hline $\begin{array}{l}\text { APEX } \\
\text { s/n }\end{array}$ & $\begin{array}{l}\text { Trans. } \\
\text { ID \# }\end{array}$ & IMEI & WMO\# & AOML\# & WHOI URL \\
\hline 5261 & 3473 & 300224010810200 & 4901401 & 4470 & http://argo.whoi.edu/wmo/4901401.html \\
\hline \multicolumn{2}{|r|}{ Notes: } & \multicolumn{4}{|c|}{ NPD pressure adjustment applied to profile 269 and higher. } \\
\hline 5262 & 3474 & 300224010817330 & 4901402 & 4471 & http://argo.whoi.edu/wmo/4901402.html \\
\hline \multicolumn{2}{|r|}{ Notes: } & \multicolumn{4}{|c|}{$\begin{array}{l}\text { NPD pressure adjustment applied to profile } 228 \text { and higher. Float spent about } 100 \text { cycles in water } \\
\text { less than } 400 \mathrm{~m} \text { deep but returned to deep water and showed no sign of conductivity drift. }\end{array}$} \\
\hline 5263 & 3475 & 300224010816200 & 4901403 & 4472 & http://argo.whoi.edu/wmo/4901403.html \\
\hline & Notes: & \multicolumn{4}{|c|}{$\begin{array}{l}\text { Drifted onto the shelf at cycle } 19 \text { and didn't come off. Not possible for deep comparison to } \\
\text { calibrate conductivity sensor. Data looks OK but without reference, flagged the last year of salts } \\
\text { as 2: 'probably good'. }\end{array}$} \\
\hline 5264 & 3476 & 300224010814200 & 4901404 & 4473 & http://argo.whoi.edu/wmo/4901404.html \\
\hline & Notes: & \multicolumn{4}{|c|}{$\begin{array}{l}\text { NPD pressure adjustment applied to profile } 322 \text { and higher. Four winters of beautiful deep mixed } \\
\text { layers. Towards end of the record float gets carried by DWBC around Cape Farewell: cycles 330- } \\
338 \text {. }\end{array}$} \\
\hline 5265 & 3477 & 300224010813220 & 4901405 & 4474 & http://argo.whoi.edu/wmo/4901405.html \\
\hline \multicolumn{2}{|r|}{ Notes: } & \multicolumn{4}{|c|}{ NPD pressure adjustment applied to profile 253 and higher. } \\
\hline 5266 & 3478 & 300224010818200 & 4901406 & 4475 & http://argo.whoi.edu/wmo/4901406.html \\
\hline \multicolumn{2}{|r|}{ Notes: } & \multicolumn{4}{|c|}{ Drifted onto the shelf after profile 85 and didn't come off. } \\
\hline 5267 & 3479 & 300224010812200 & 4901407 & 4476 & http://argo.whoi.edu/wmo/4901407.html \\
\hline \multicolumn{2}{|r|}{ Notes: } & \multicolumn{4}{|c|}{ NPD pressure adjustment applied to profile 254 and higher. } \\
\hline 5269 & 3481 & 300224010815330 & 4901449 & 4477 & http://argo.whoi.edu/wmo/4901449.html \\
\hline \multicolumn{2}{|r|}{ Notes: } & \multicolumn{4}{|c|}{ No salvageable conductivity measurements. Temperature appears OK up until profile 189.} \\
\hline 5270 & 3482 & 300224010813200 & 4901445 & 4478 & http://argo.whoi.edu/wmo/4901445.html \\
\hline & Notes: & \multicolumn{4}{|c|}{$\begin{array}{l}\text { Only float to receive a conductivity calibration correction. Float drifts salty with linear trend over } \\
\text { time. CTD sensor goes bad after profile } \# 145 \text {. }\end{array}$} \\
\hline 5271 & 3483 & 300224010815200 & 4901446 & 4479 & http://argo.whoi.edu/wmo/4901446.html \\
\hline \multicolumn{2}{|r|}{ Notes: } & \multicolumn{4}{|c|}{ NPD pressure adjustment applied to profile 308 and higher. } \\
\hline 5272 & 3484 & 300224010810210 & 4901447 & 4480 & http://argo.whoi.edu/wmo/4901447.html \\
\hline & Notes: & \multicolumn{4}{|c|}{ NPD pressure adjustment applied to profile 331 and higher. } \\
\hline
\end{tabular}


Table A7. RCM MATLAB data structure, using \#156 as example.

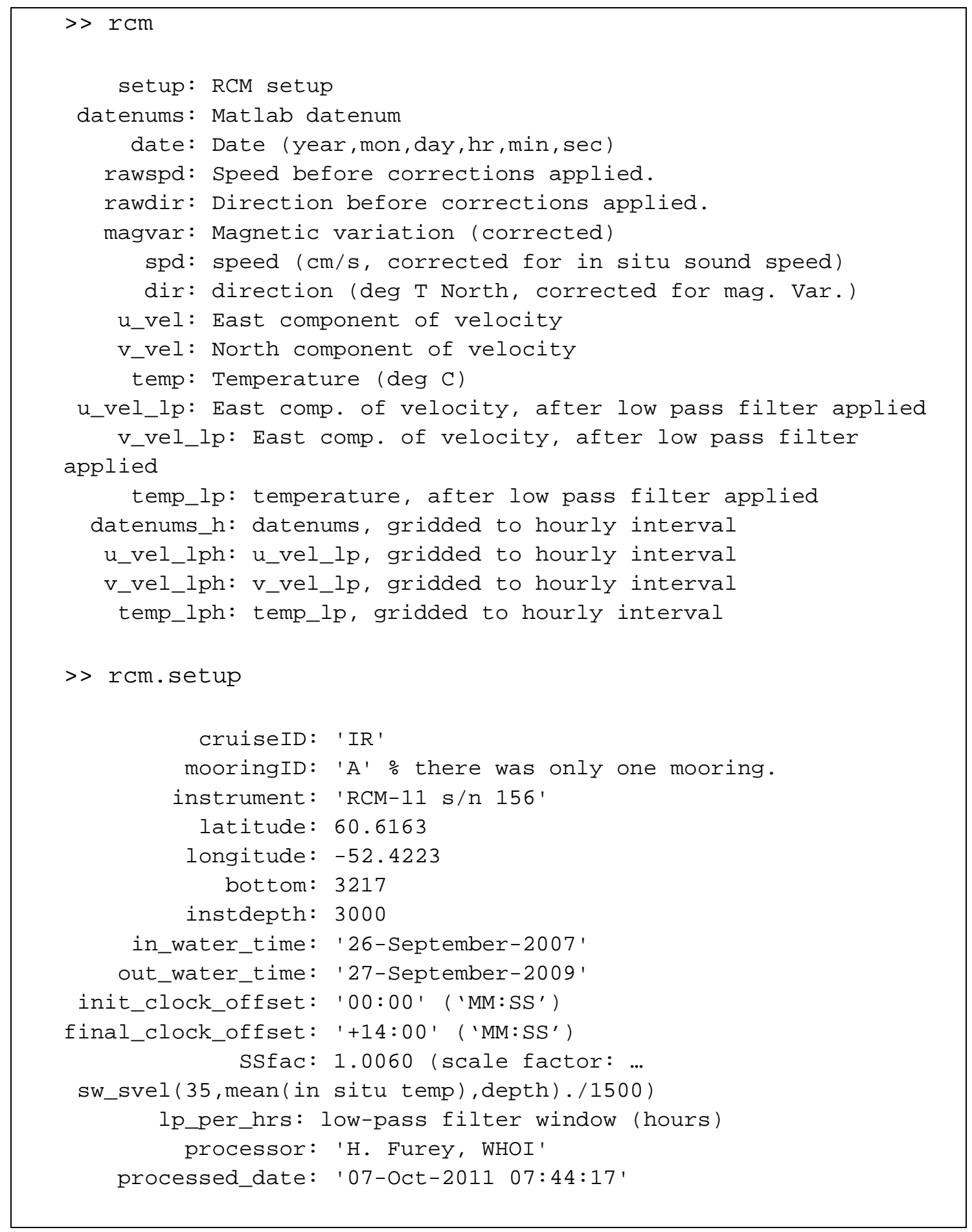


Table A8. Microcat MATLAB data structure, using \#2037 as example.

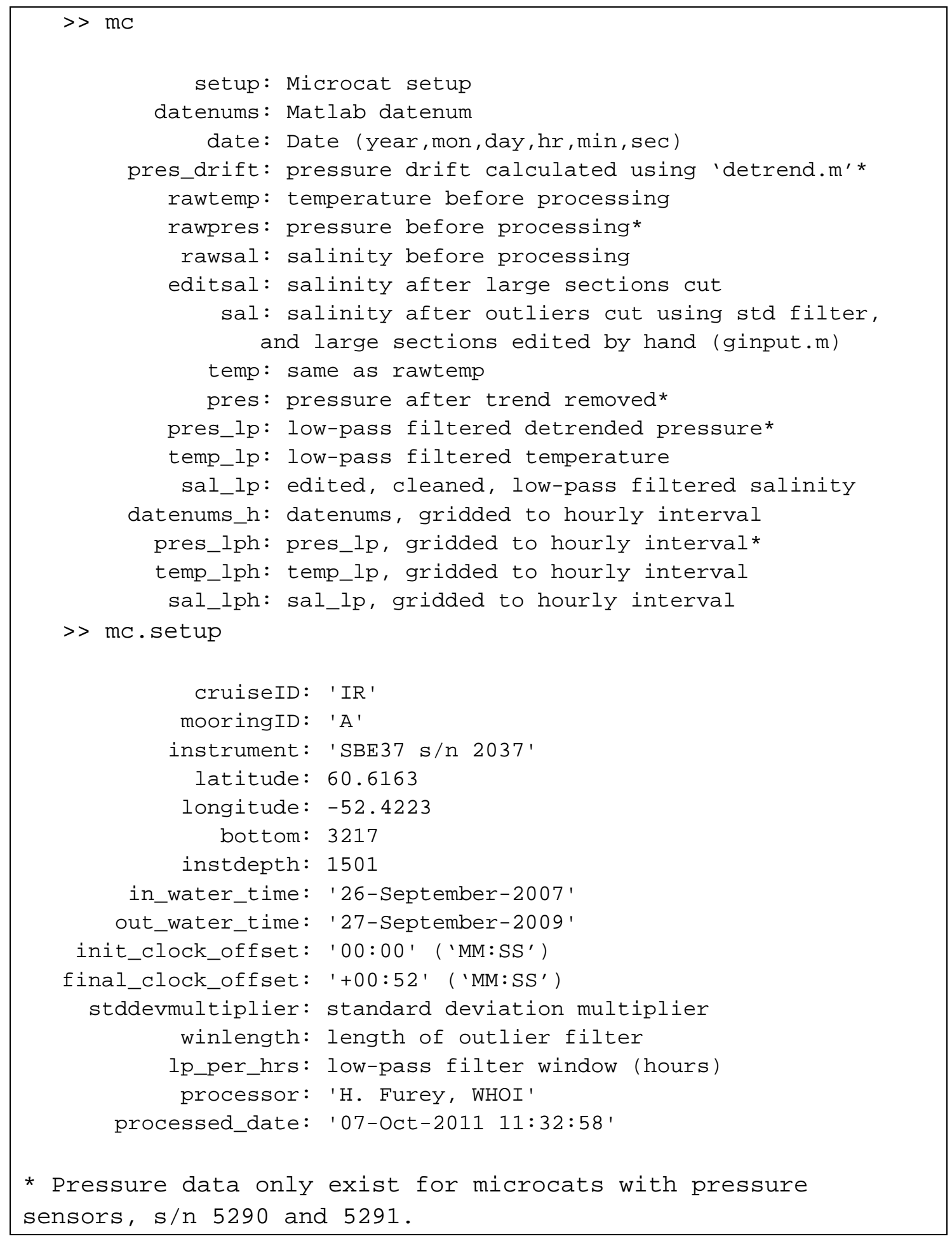


Table A9. SALP MATLAB data structure, using master as example.

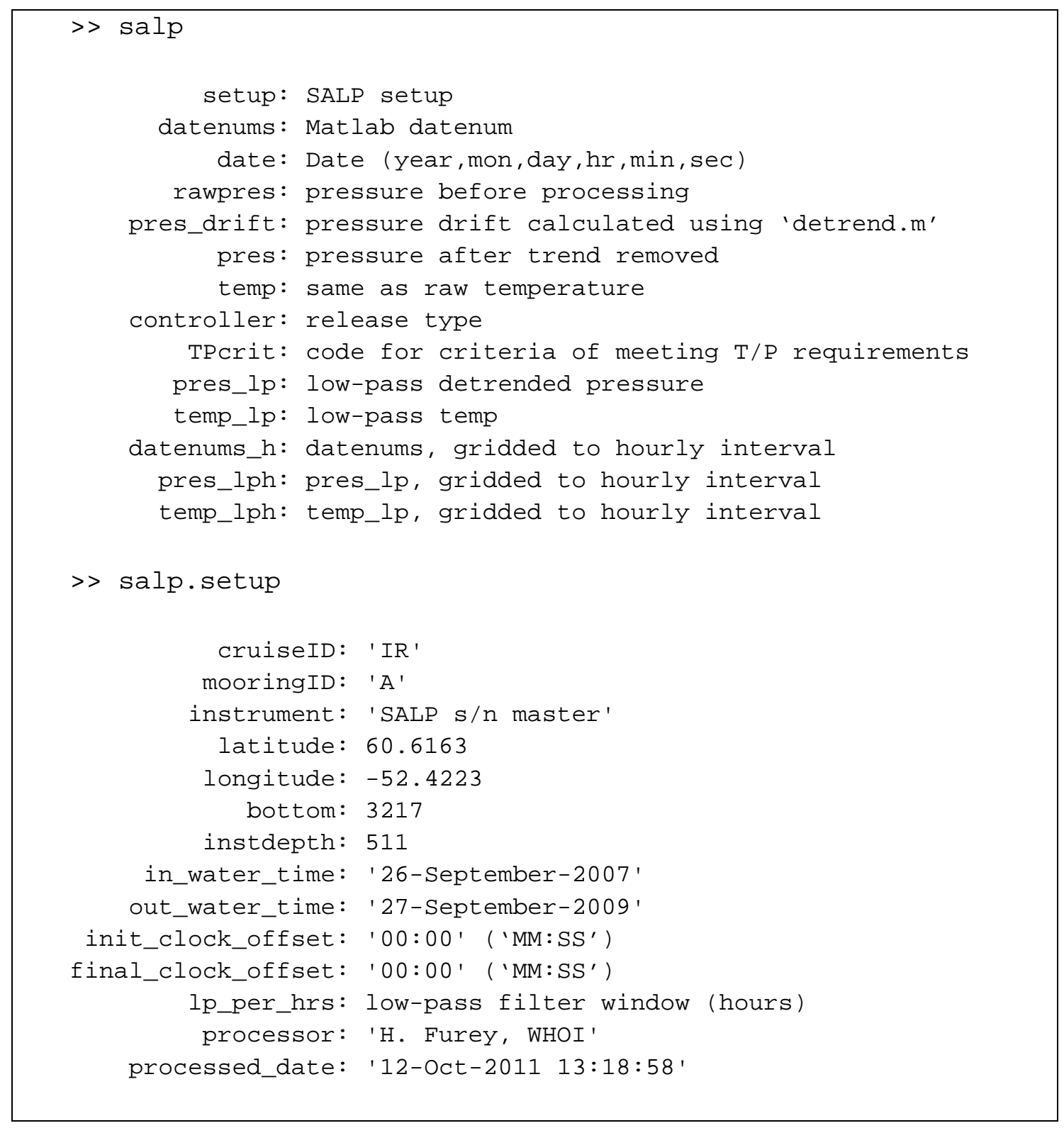


This page left intentionally blank. 
Appendix B: SALP pressure and temperature records. 

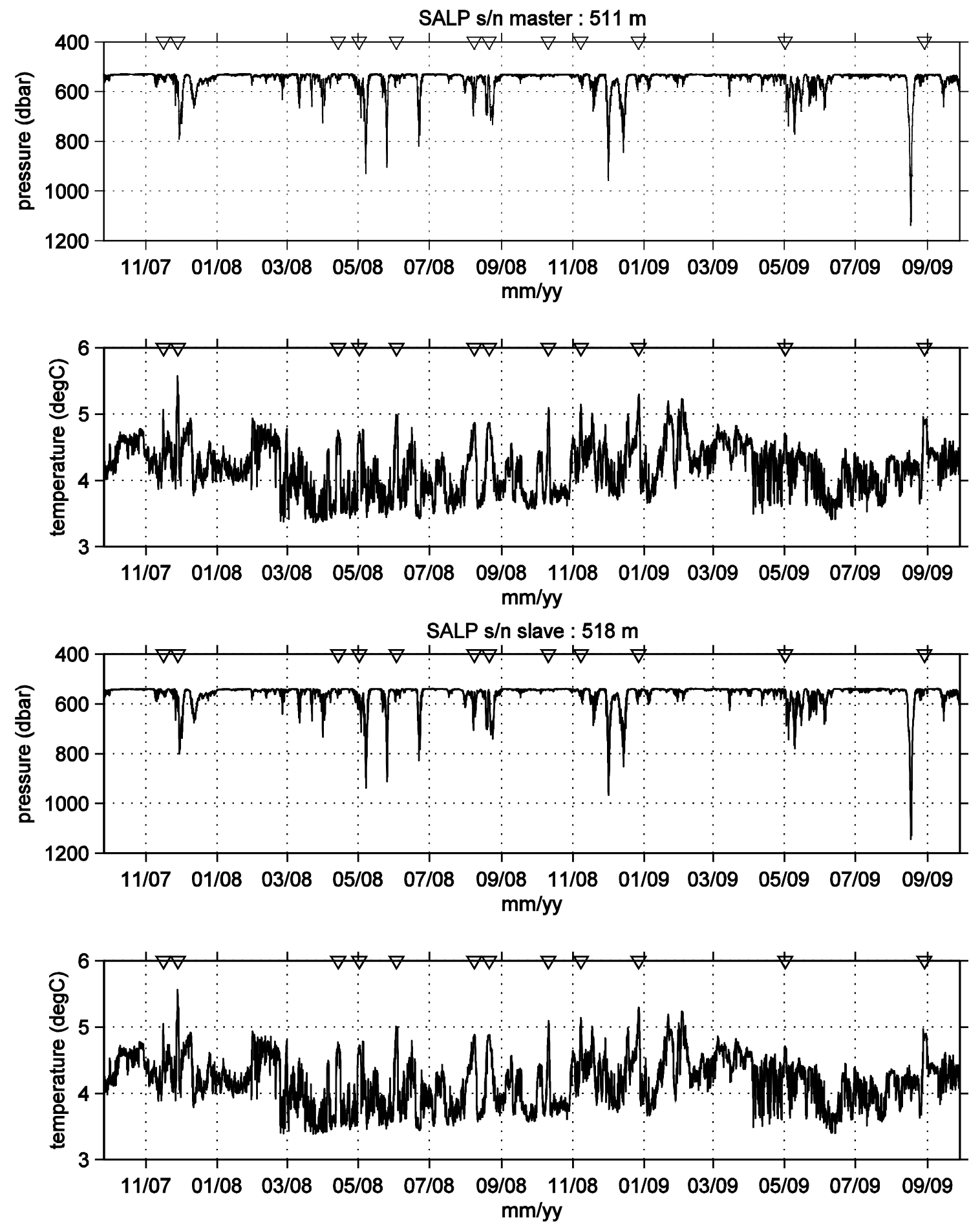

Figure B1. SALP Master (top two panels) and slave (bottom two panels) pressure and in situ temperature records. Triangles designate positions in time of the 12 best anticyclones, see De Jong at al. (submitted) for details. 
Appendix C: Aanderaa RCM11 current meter synthetic pressure (see Section 3.3), in situ temperature, u-velocity and v-velocity records. On all plots, triangles designate positions in time of the 12 best anticyclones in the mooring record, see De Jong at al. (submitted) for details. The current meter positioned at 250 meters leaked, and no data were recovered. 

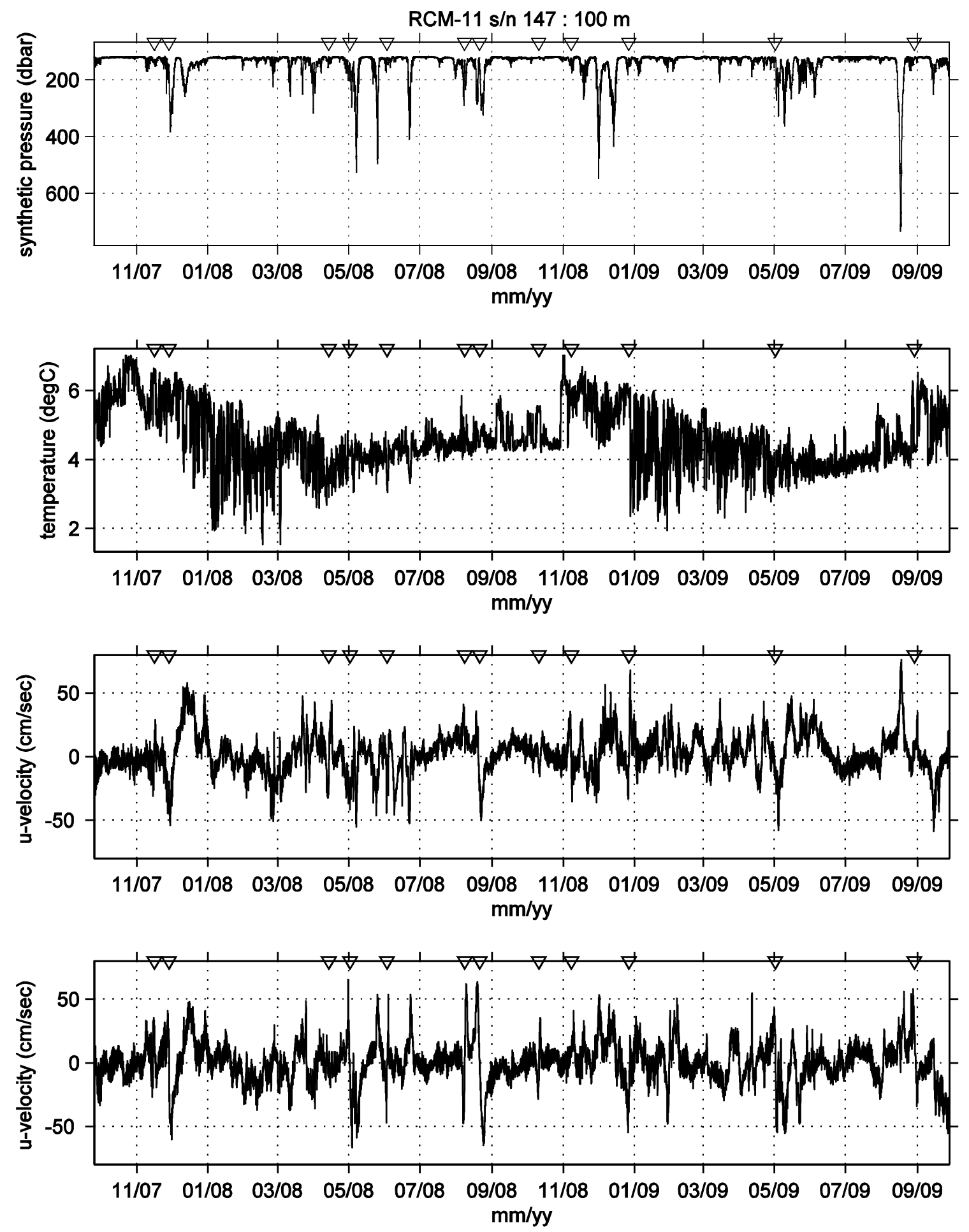

Figure C1. Current meter \#147, positioned at 100 meters. 

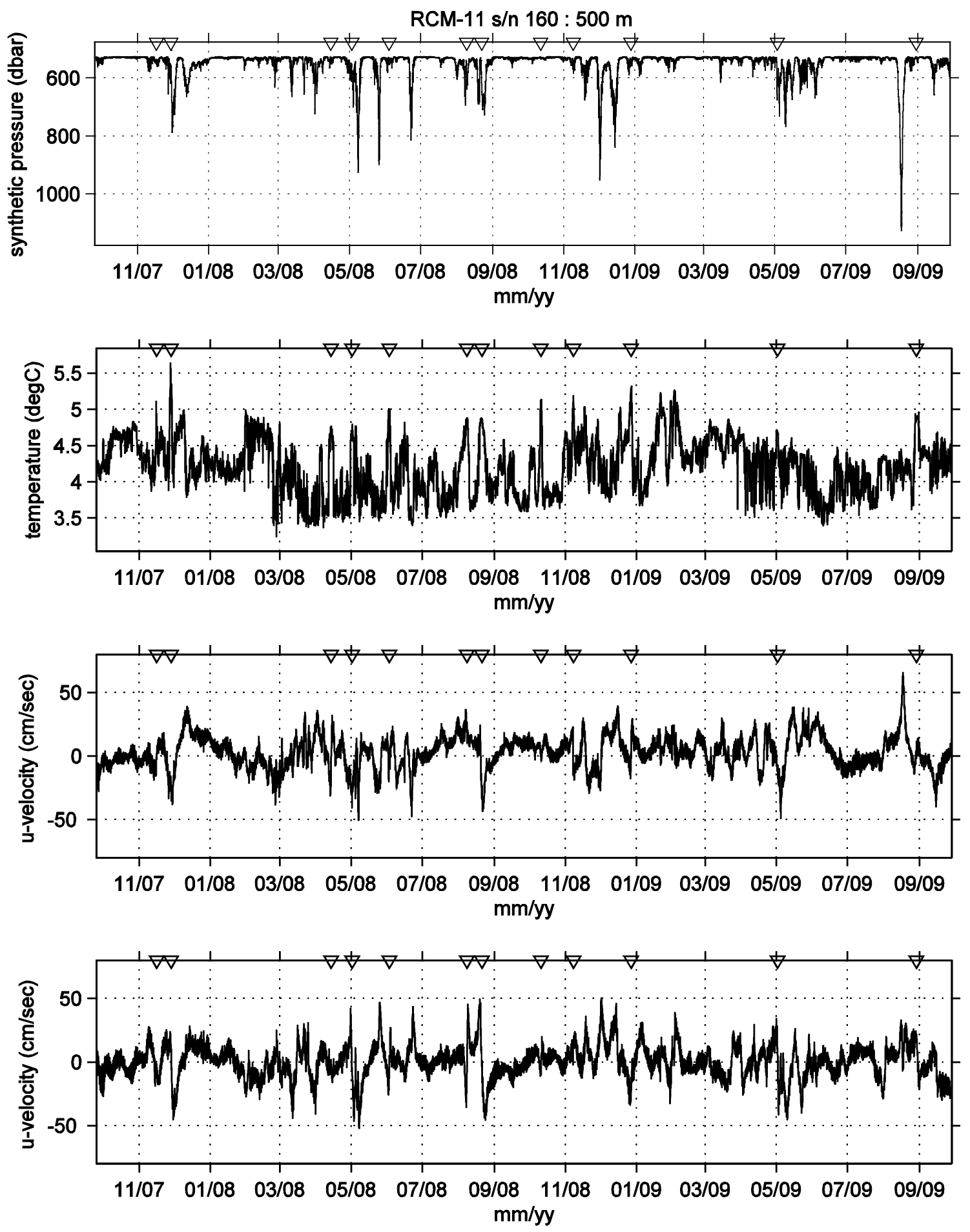

Figure C2. Current meter \#160, positioned at 500 meters. 

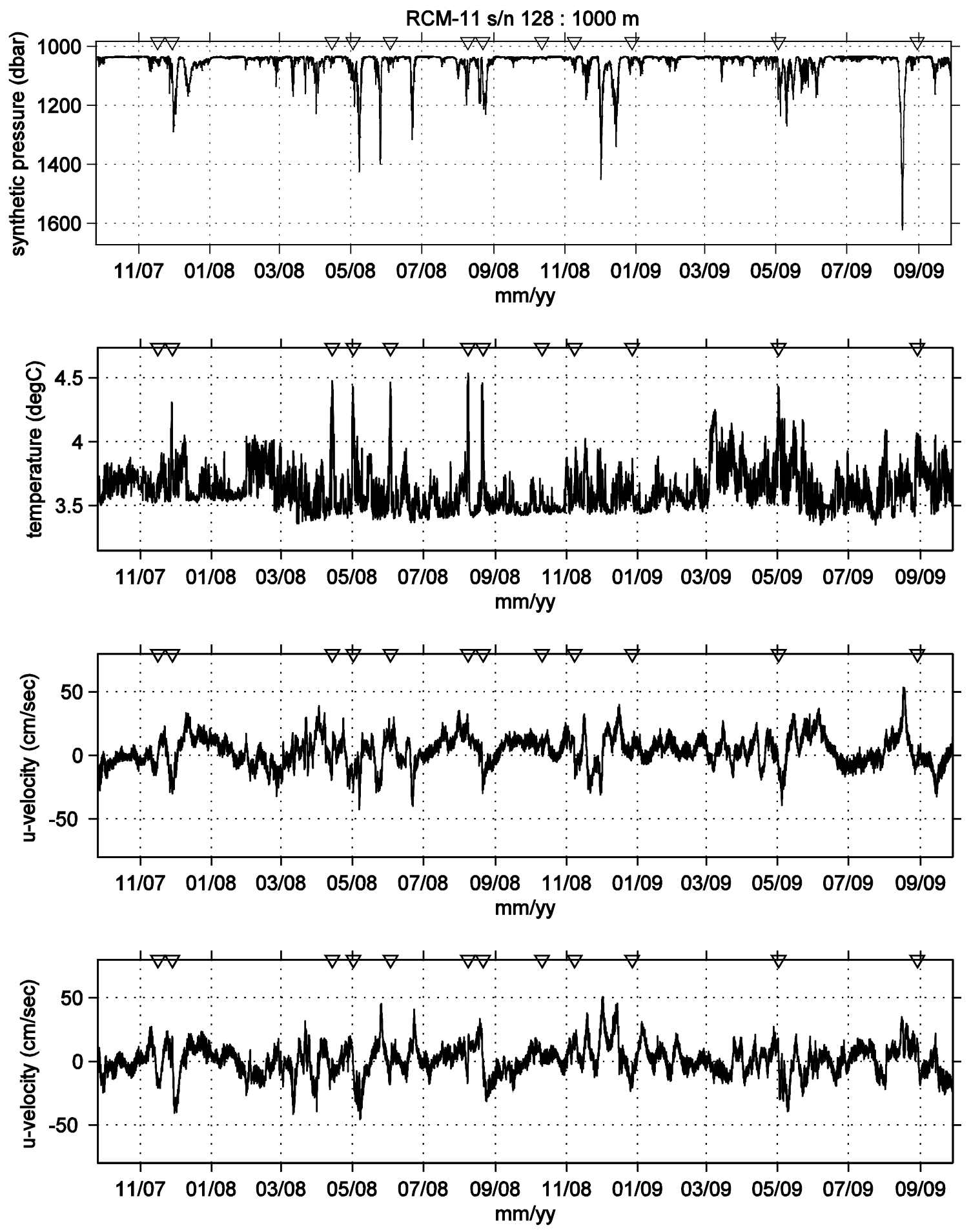

Figure C3. Current meter \#128, positioned at 1000 meters. 

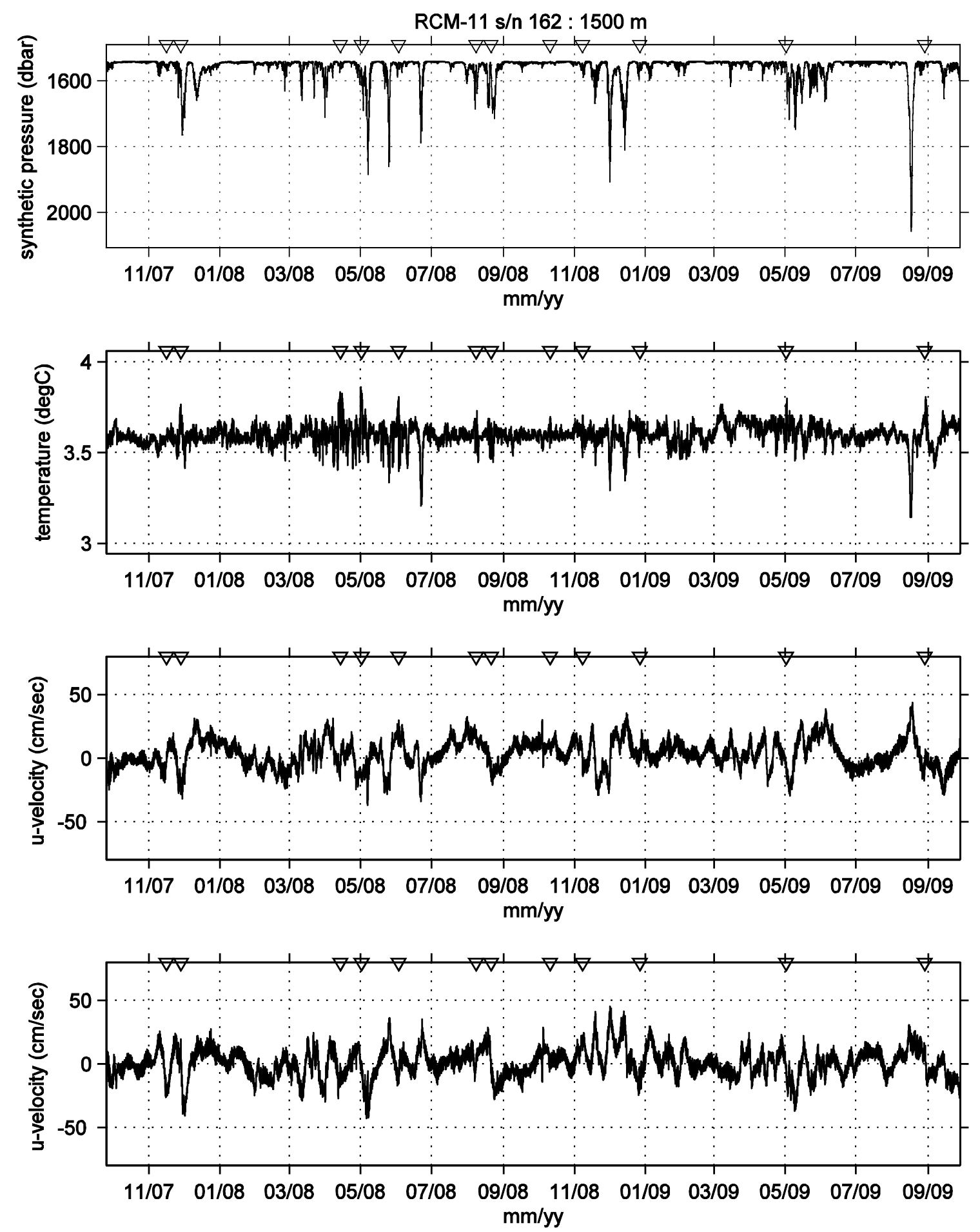

Figure C4. Current meter \#162, positioned at 1500 meters. 

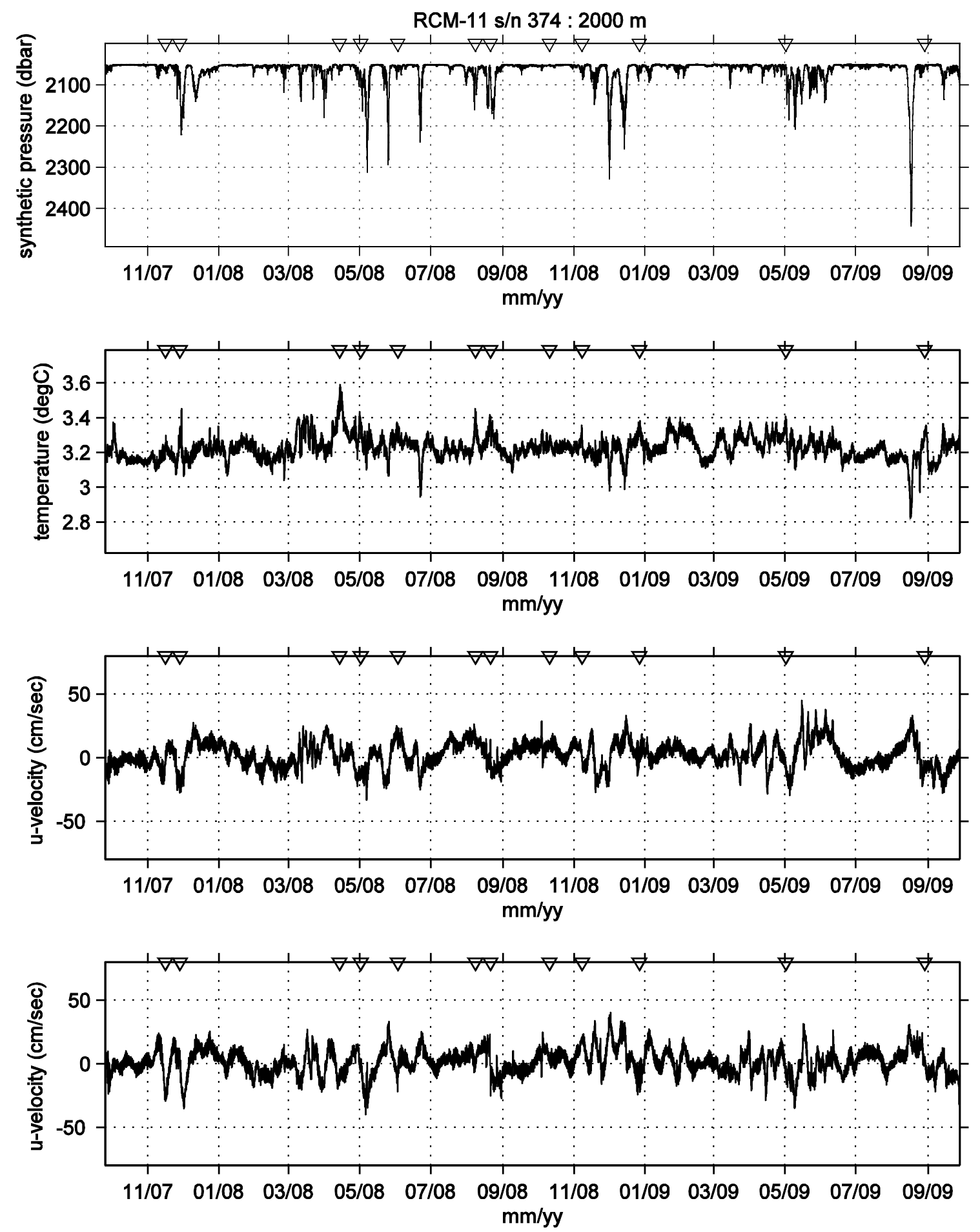

Figure C5. Current meter \#374, positioned at 2000 meters. 

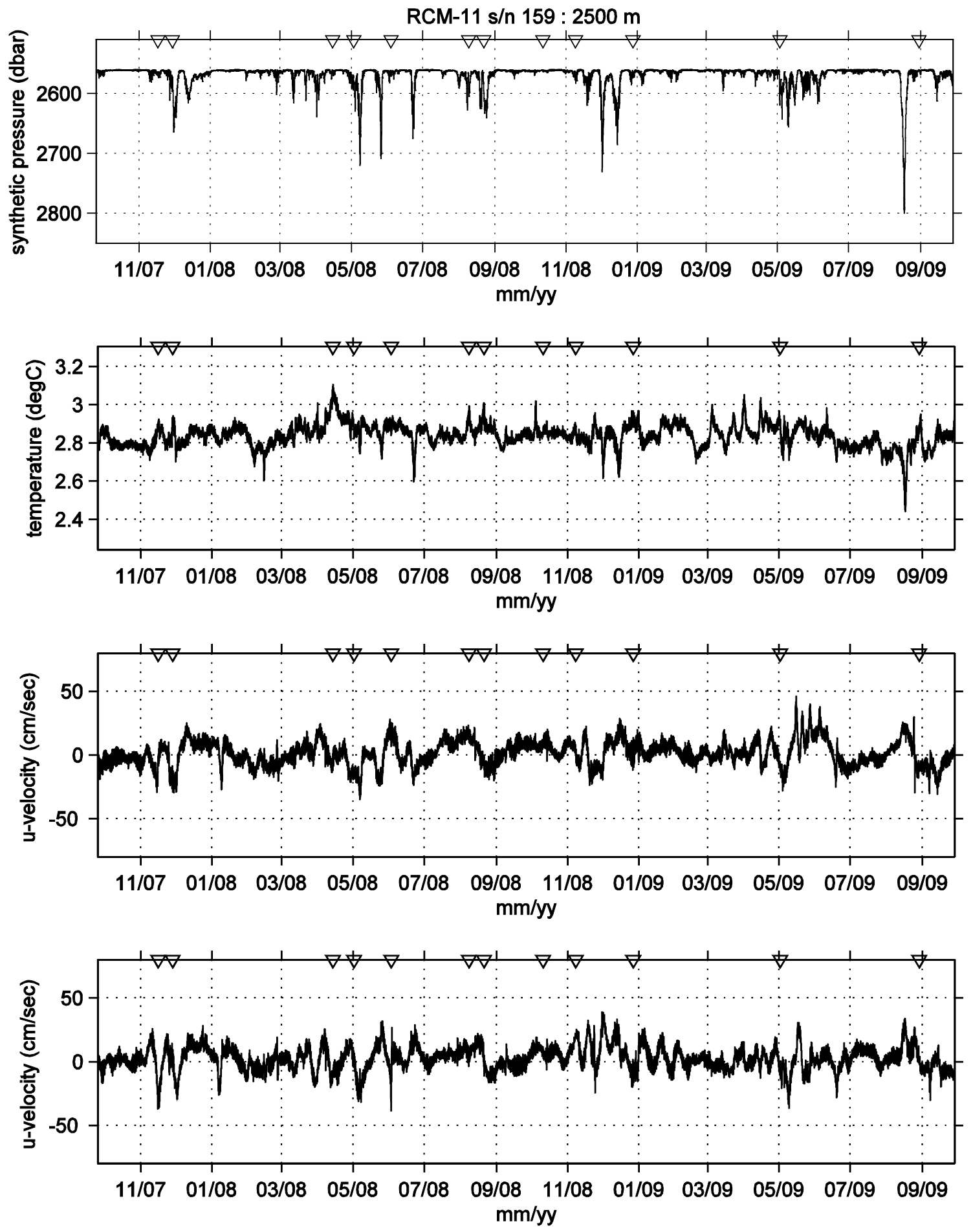

Figure C6. Current meter \#159, positioned at 2500 meters. 

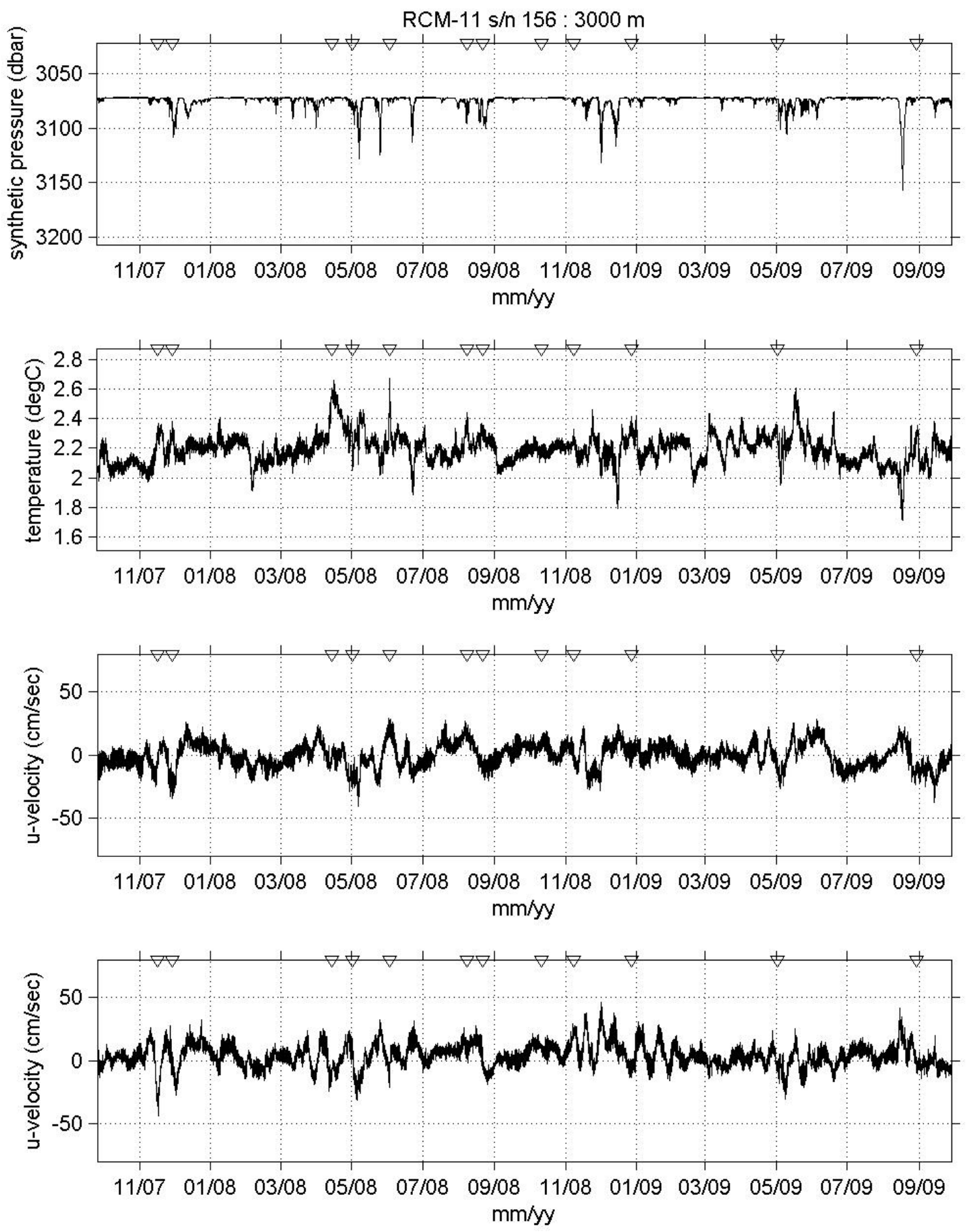

Figure C7. Current meter \#156, positioned at 3000 meters. 
Appendix D: Seabird SBE37 pressure or synthetic pressure (see Section 3.3), in situ temperature, and salinity records. Aanderaa RCM11 current meter synthetic pressure (see Section 3.3), in situ temperature, u-velocity and v-velocity records. On all plots, triangles designate positions in time of the 12 best anticyclones in the mooring record, see De Jong at al. (submitted) for details. 

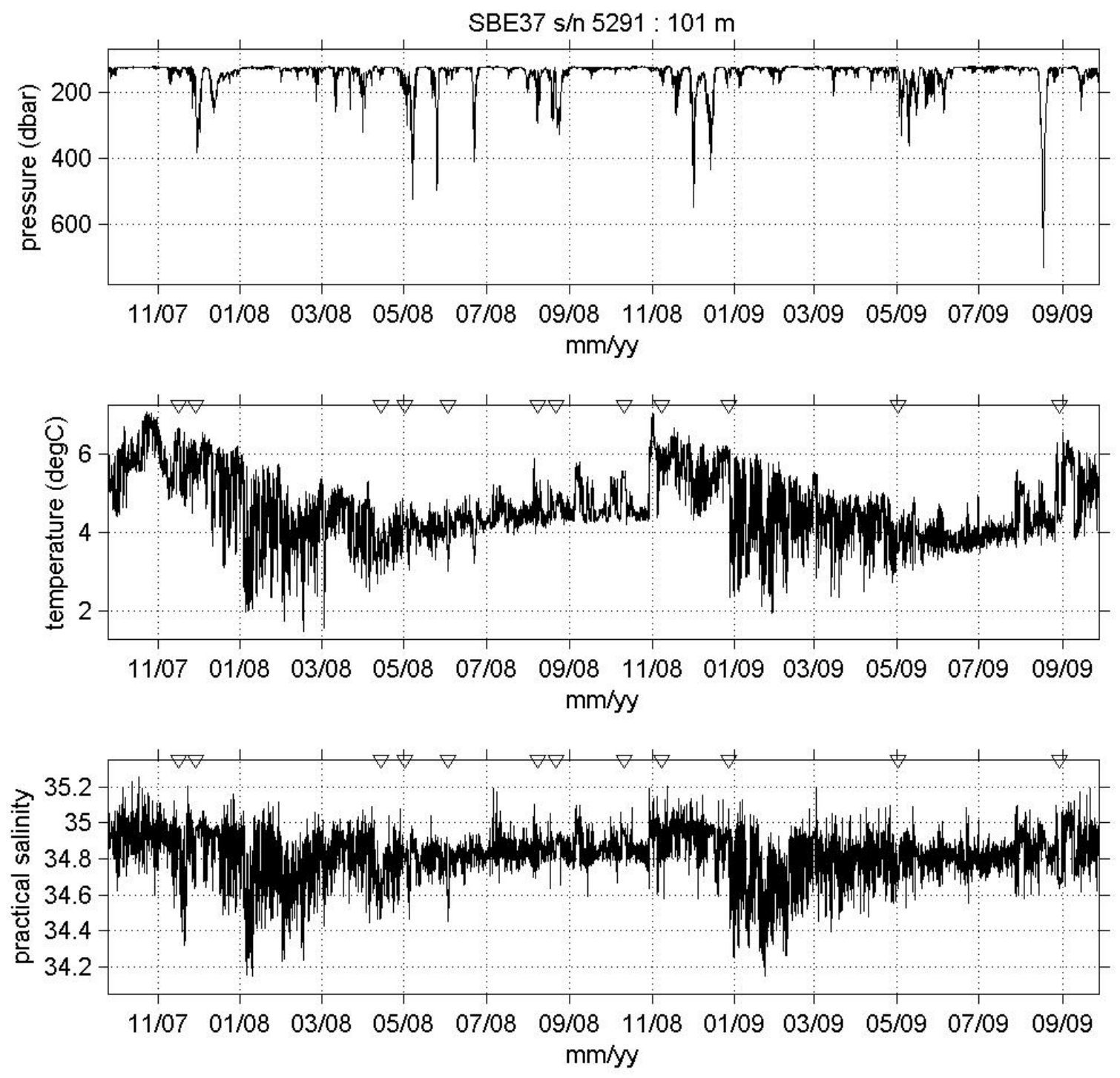

Figure D1. Microcat \#5291, positioned at 101 meters. 

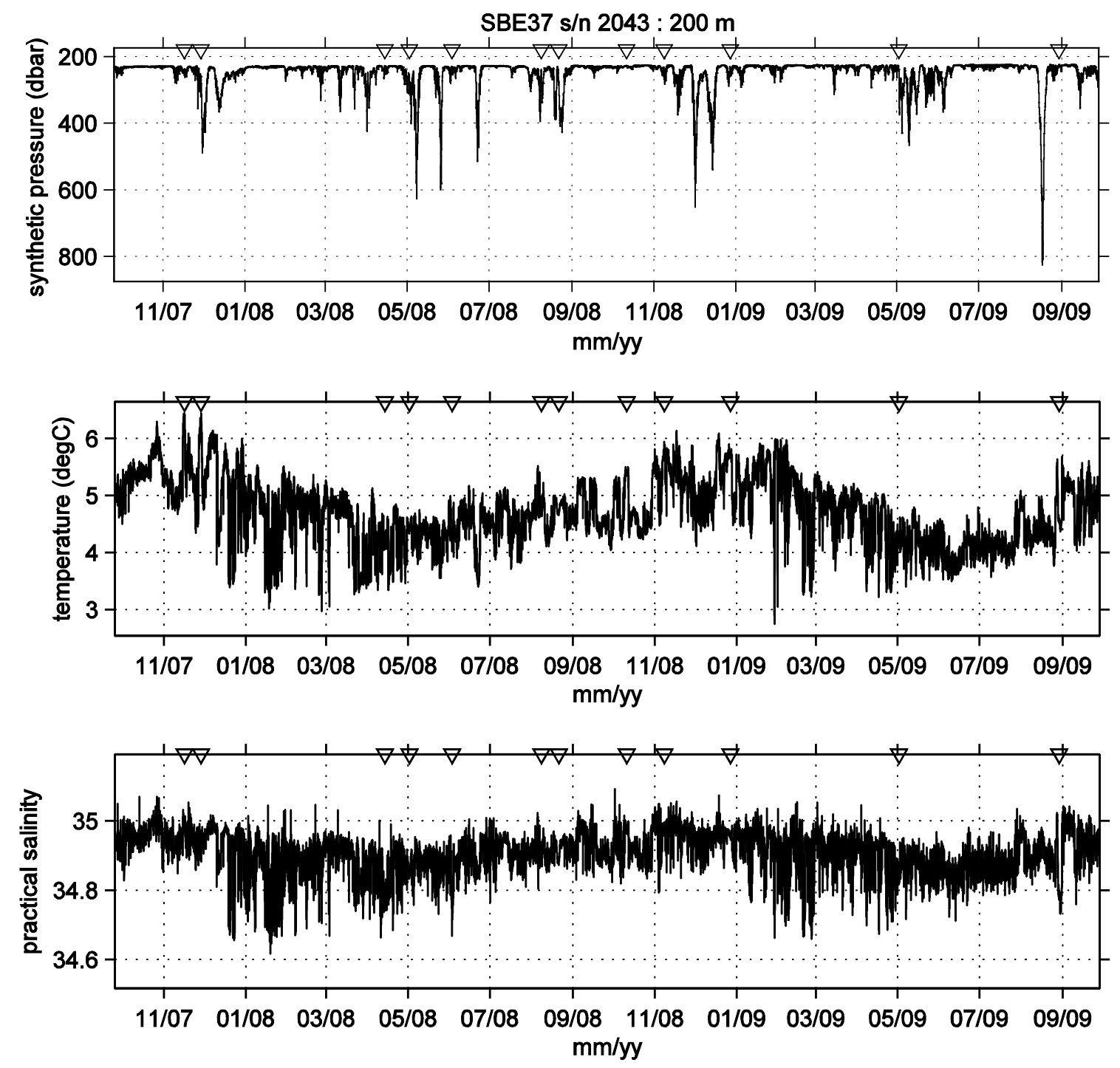

Figure D2. Microcat \#2043, positioned at 200 meters. 

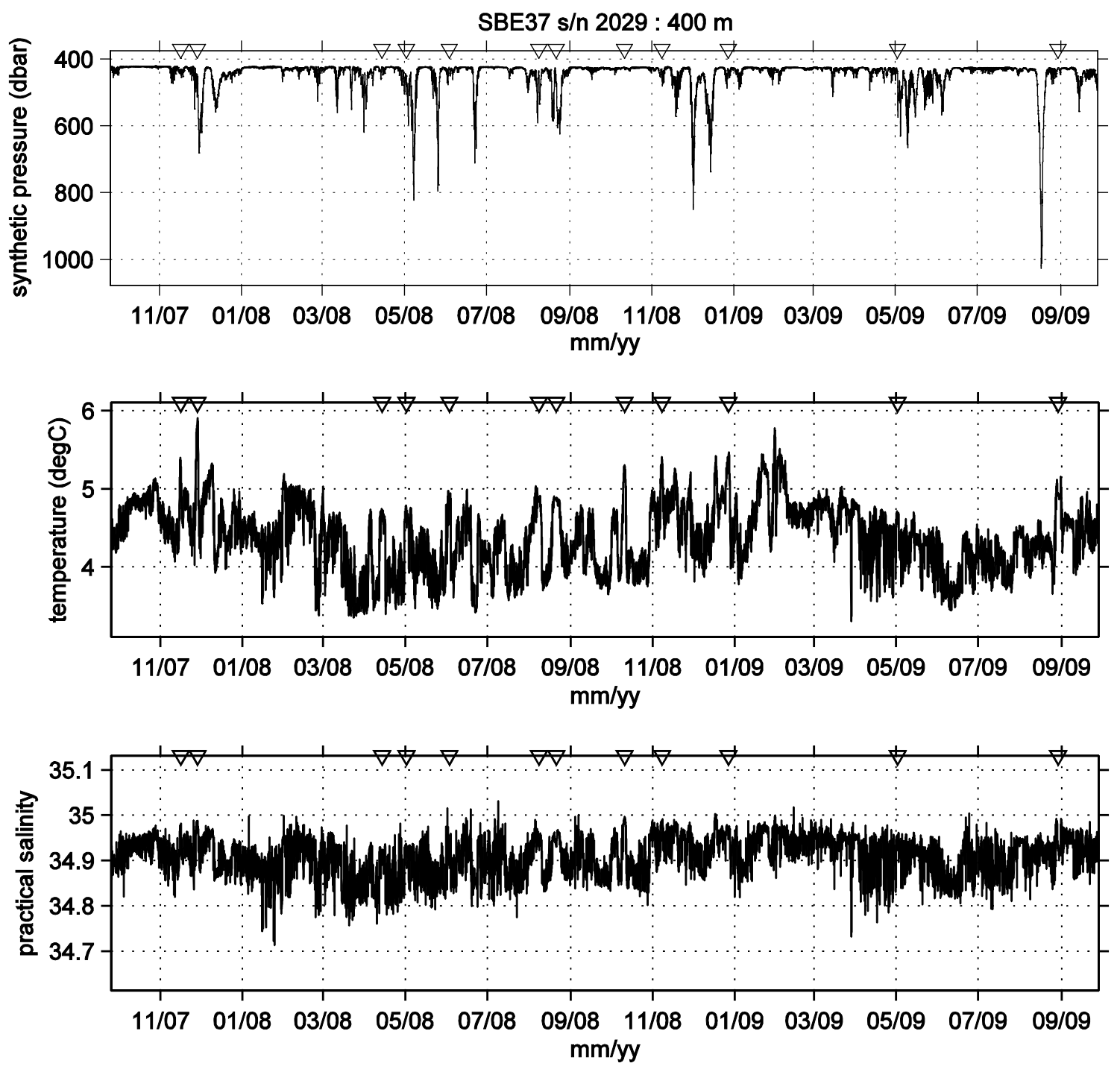

Figure D3. Microcat \#2029, positioned at 400 meters. 

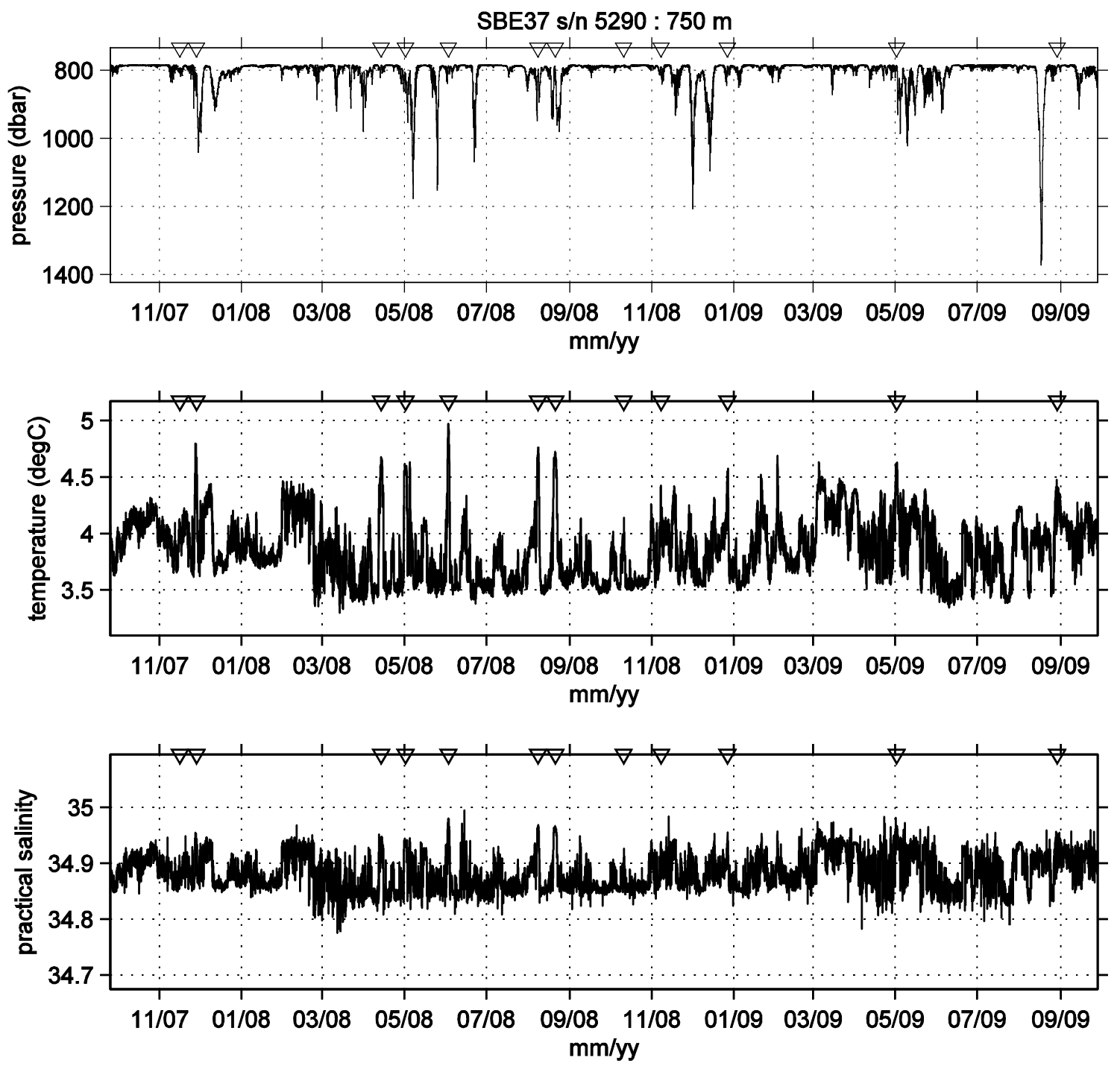

Figure D4. Microcat \#5290, positioned at 750 meters. 

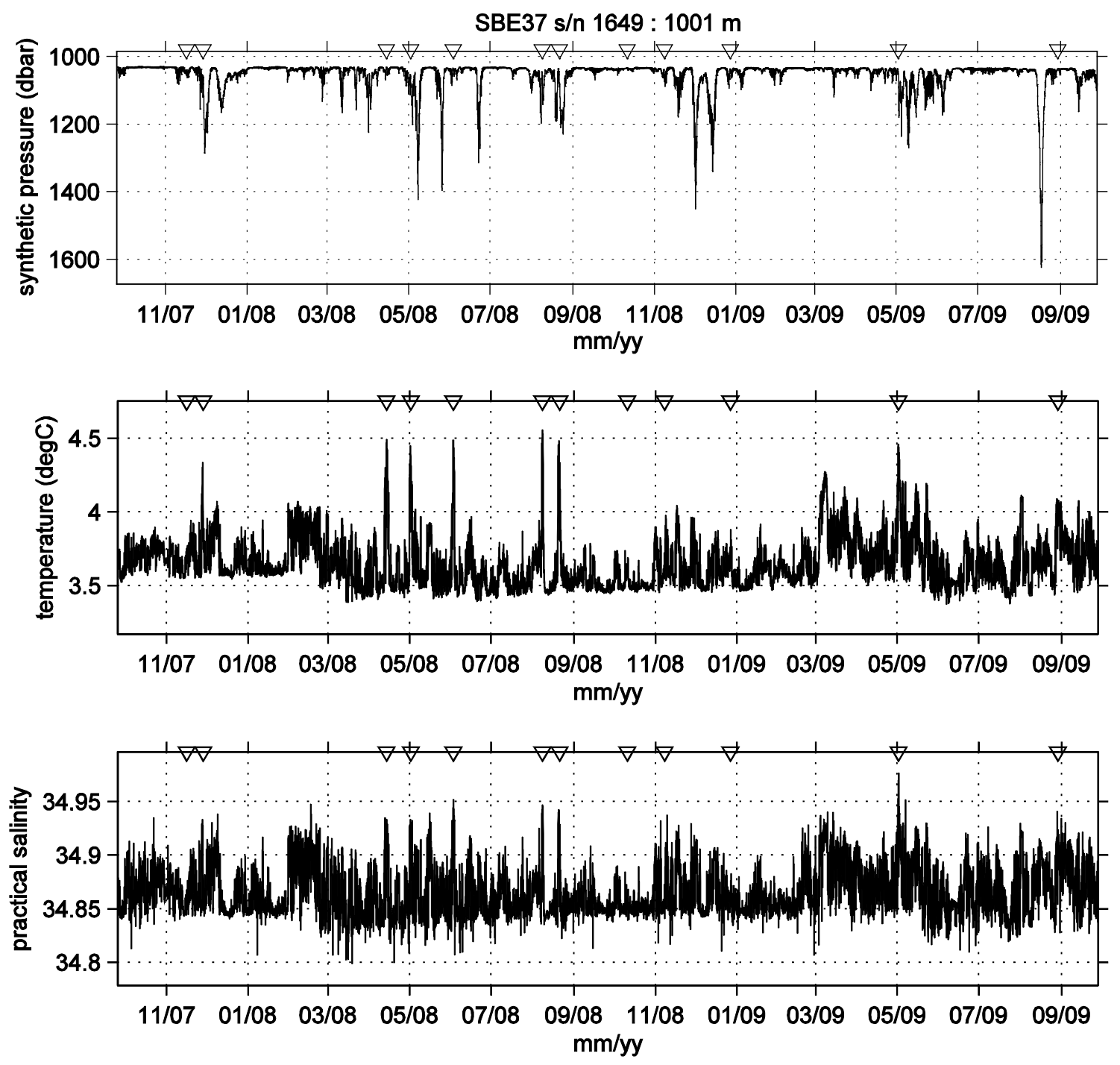

Figure D5. Microcat \#1649, positioned at 1001 meters. 

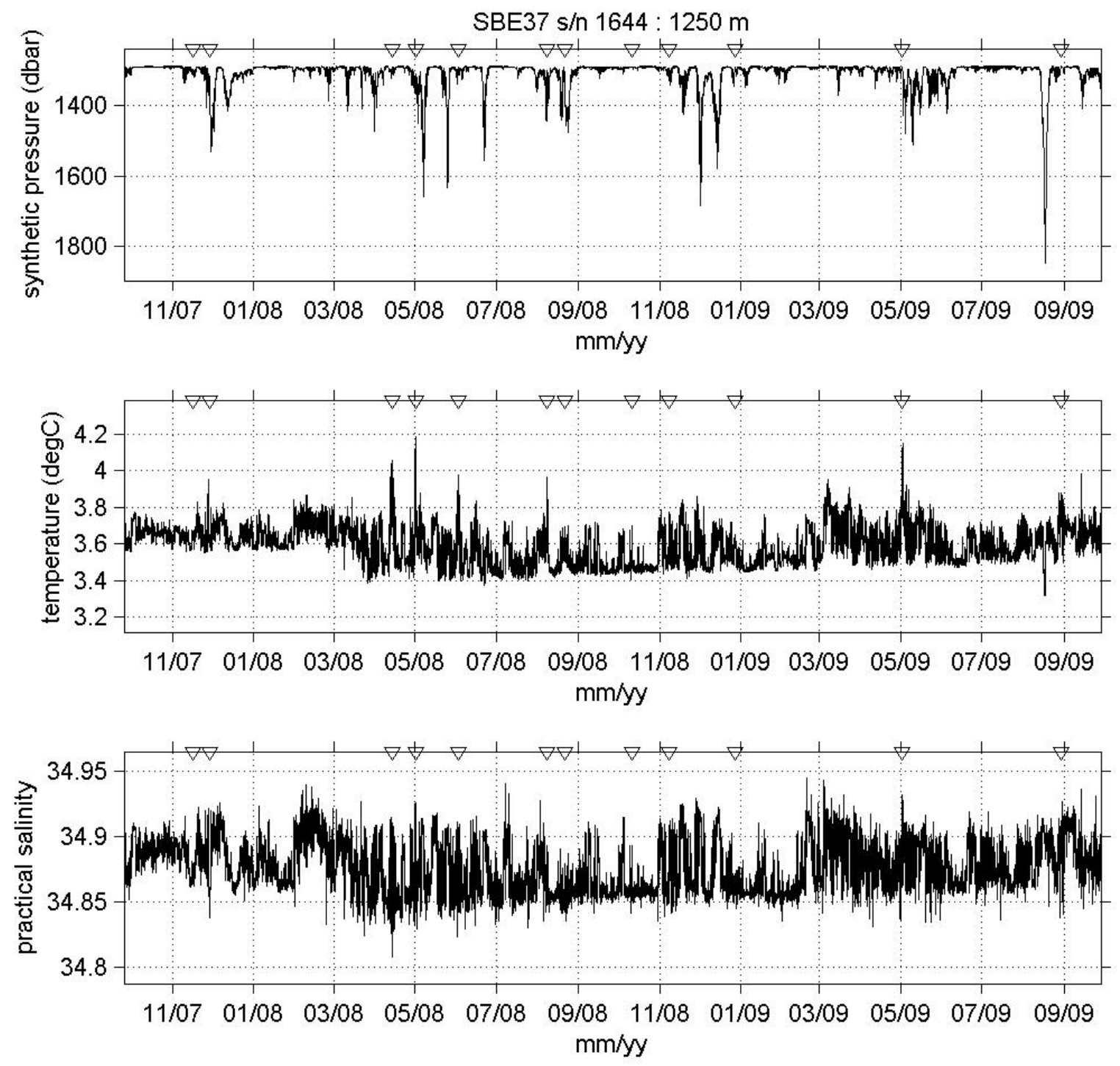

Figure D6. Microcat \#1644, positioned at 1250 meters. 

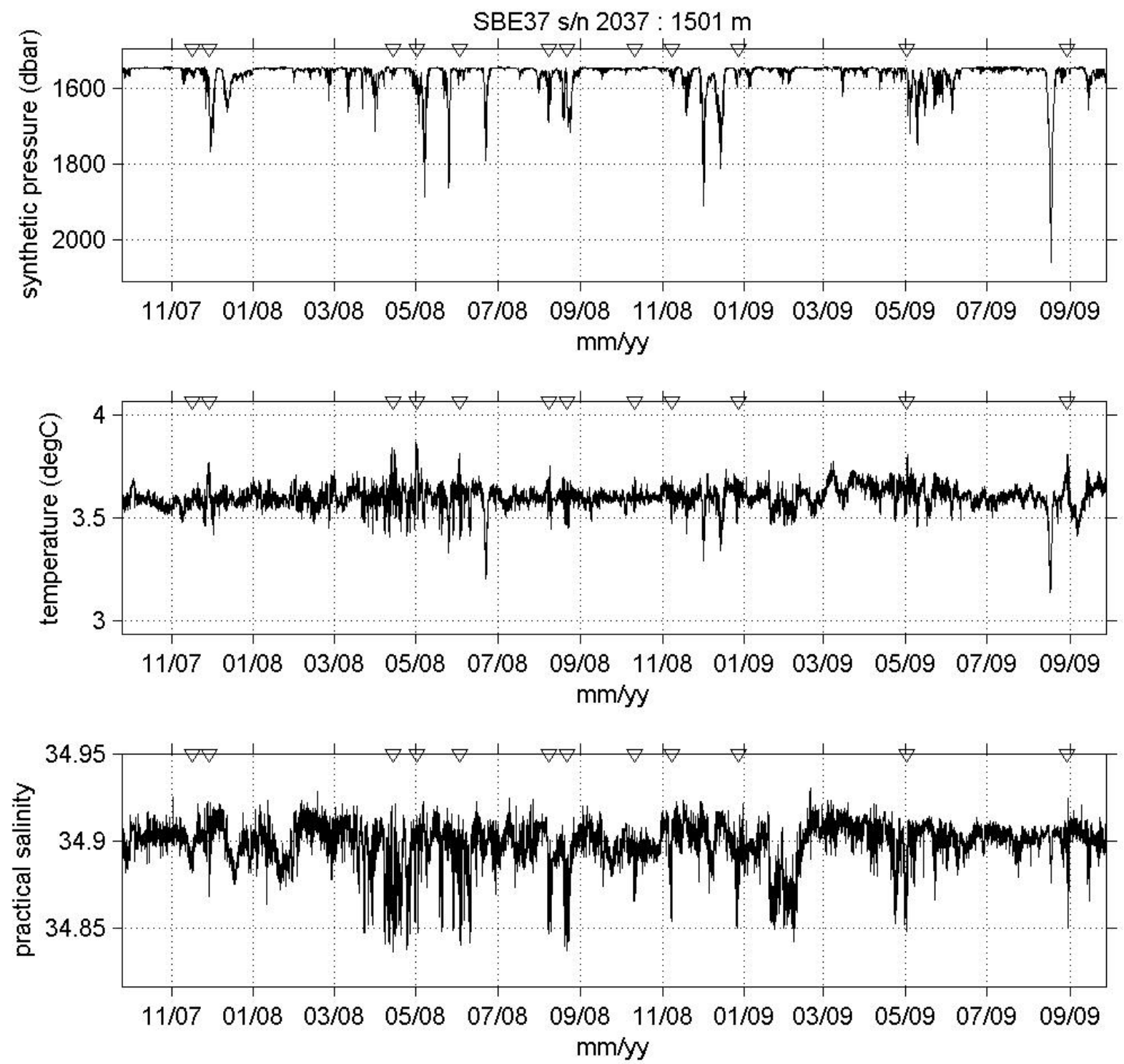

Figure D7. Microcat \#2037, positioned at 1501 meters. 

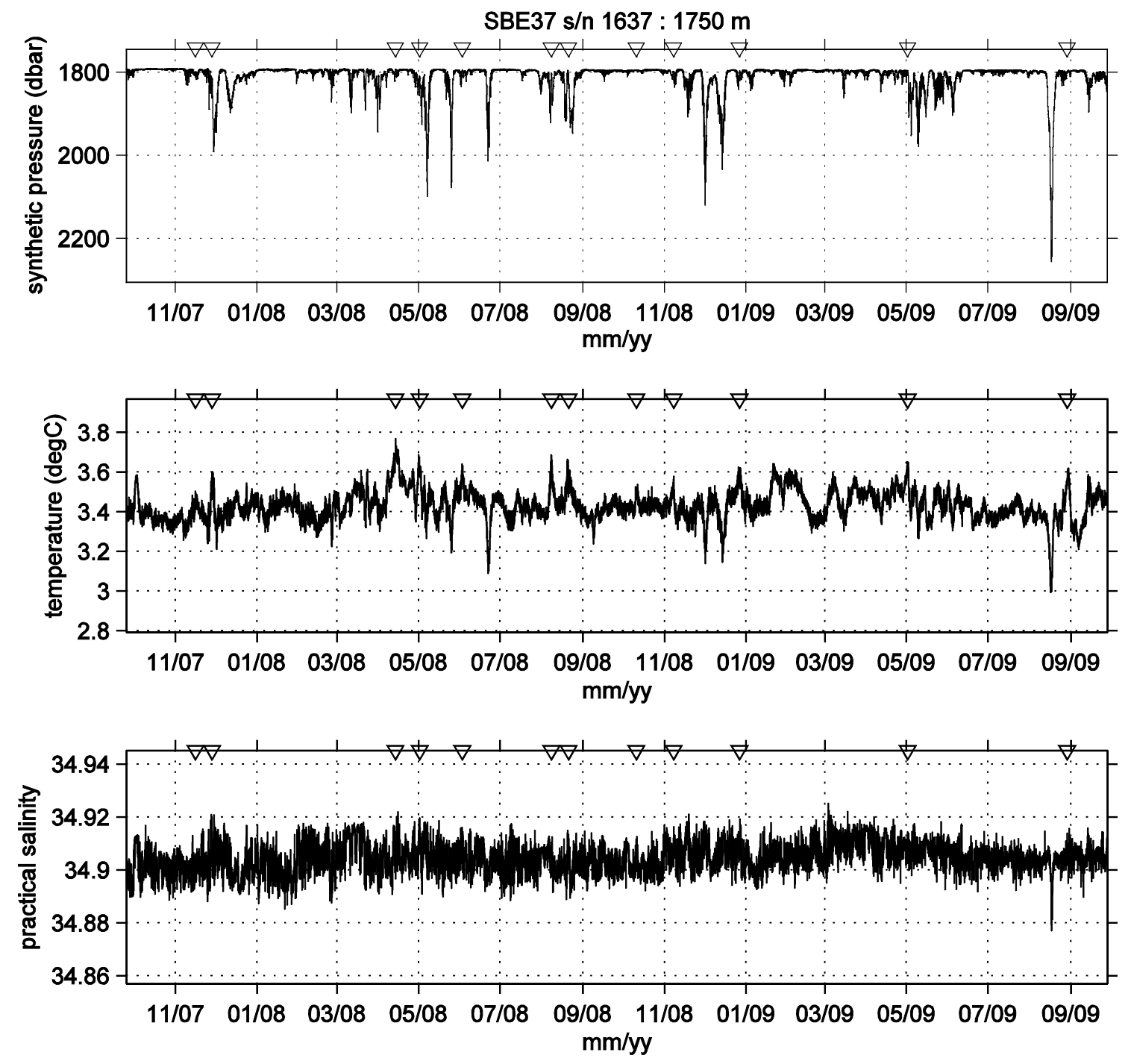

Figure D8. Microcat \#1637, positioned at 1750 meters. 

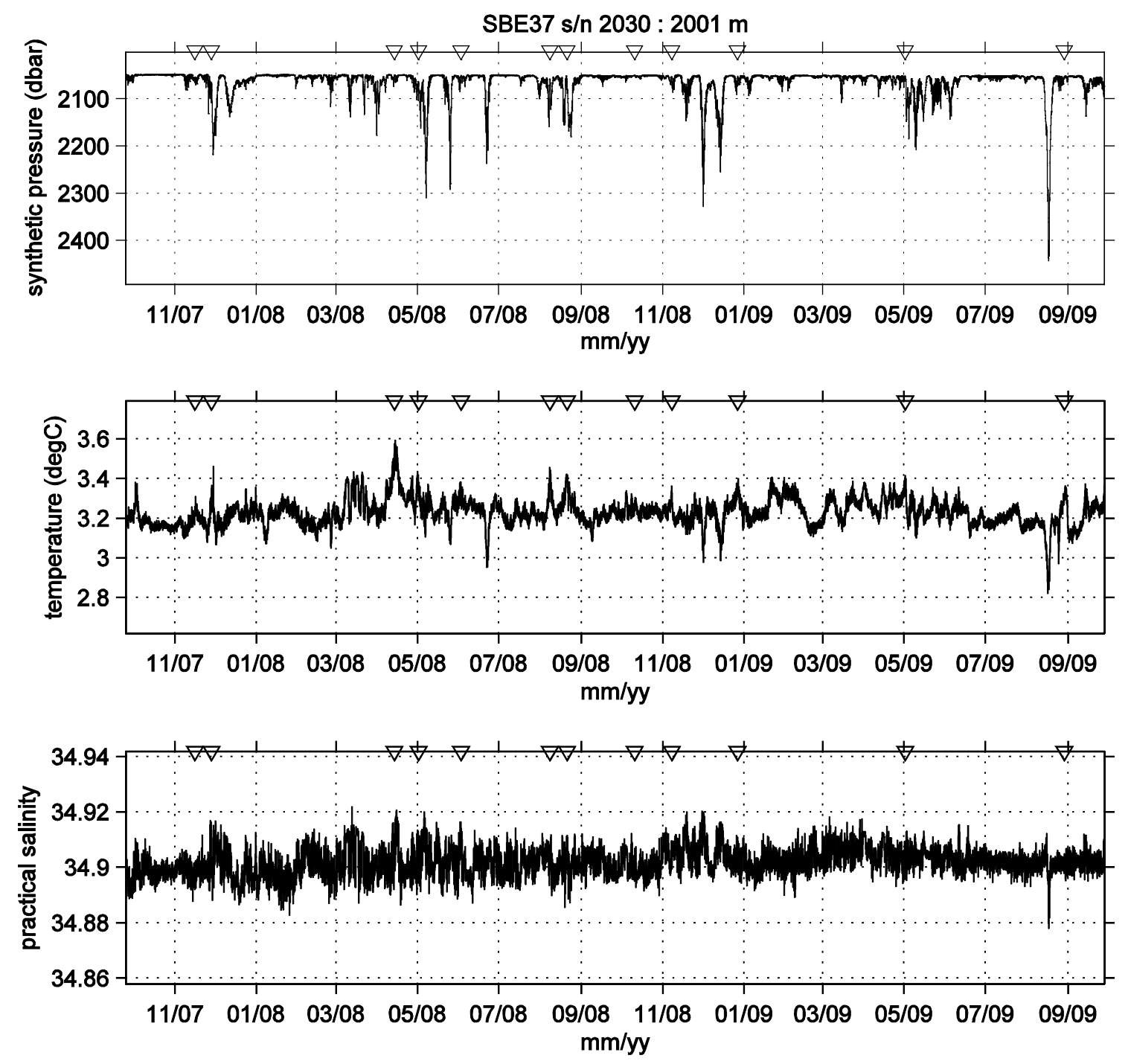

Figure D9. Microcat \#2030, positioned at 2001 meters. 
Appendix E: CTD station data. 
This page left intentionally blank. 

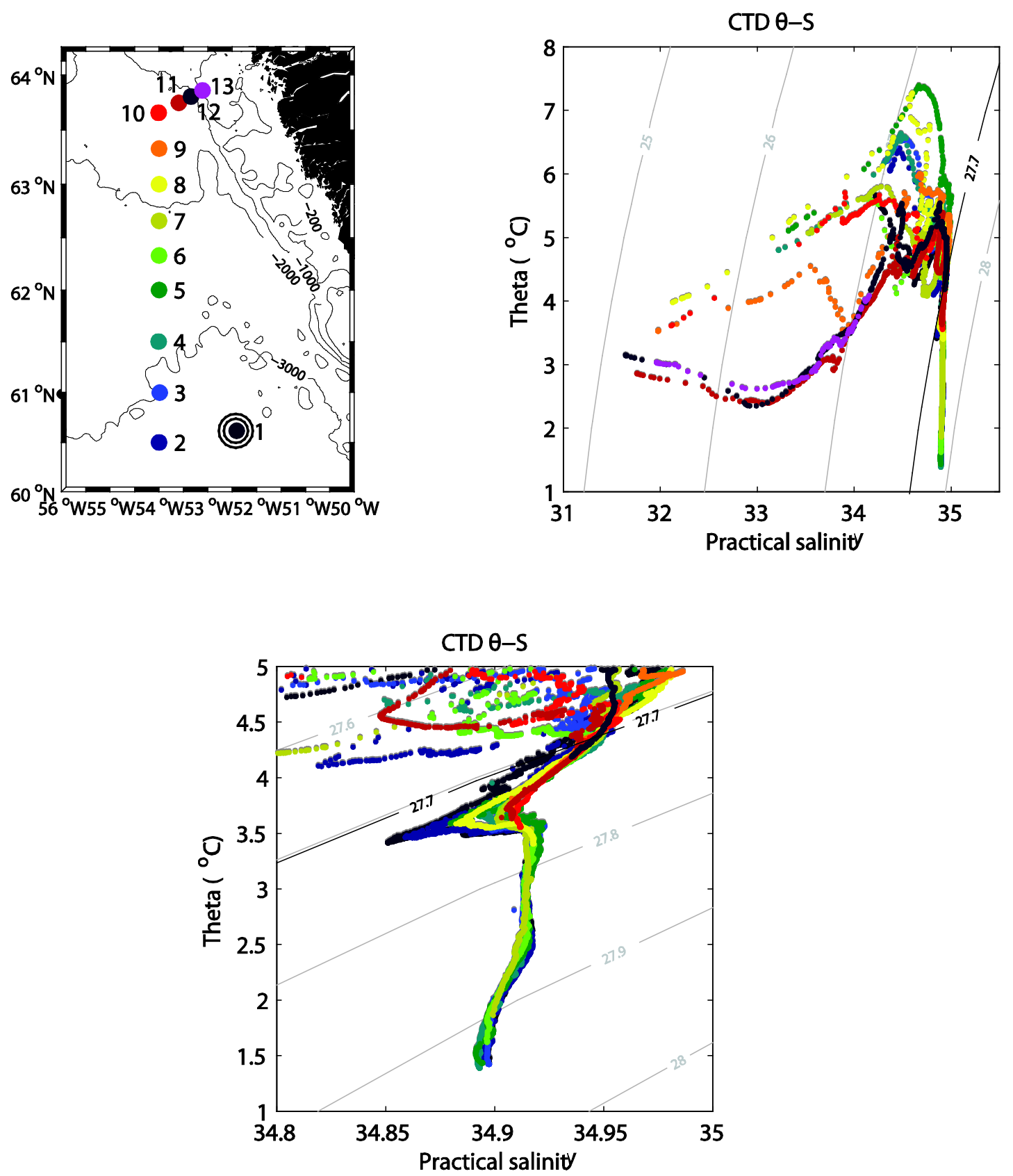

Figure E1. (a) CTD station locations and numbers, (b) $\theta$-S diagram, (c) $\theta$-S with axes pared to isolate deep $\theta-\mathrm{S}$ variability. 

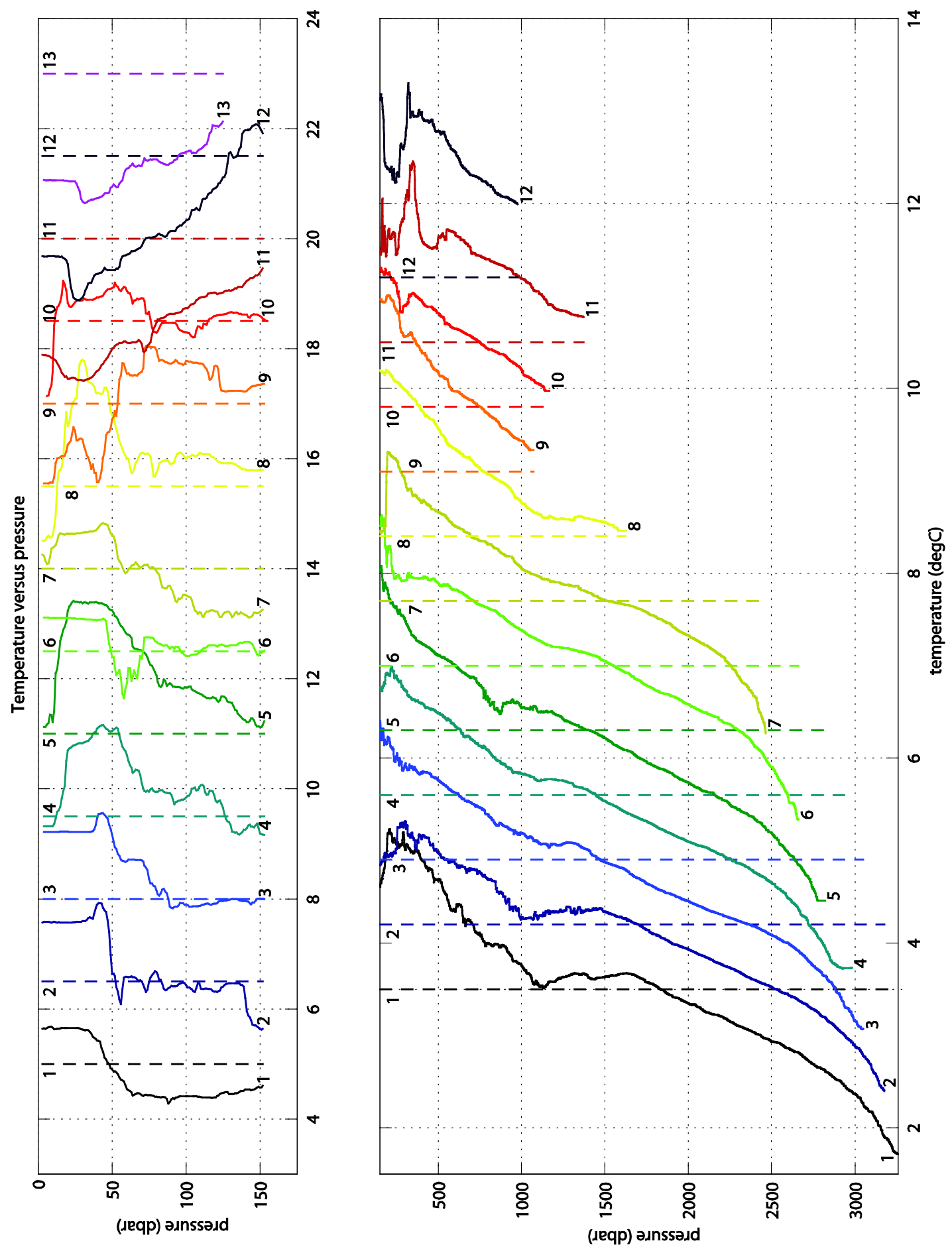

Figure E2. (left, top) Temperature versus pressure: surface - $150 \mathrm{~m}$, (right, bottom) Temperature versus pressure: below $150 \mathrm{~m}$. Numbers refer to stations cast number show in E1, where \#1 is the cast at the mooring site, and \#13 is the cast nearest the coast of Greenland. In the $0-150$ meter ( $150 \mathrm{~m}$ - bottom) data, stations have been offset by $1.5^{\circ} \mathrm{C}\left(0.7^{\circ} \mathrm{C}\right)$, so that $1.5^{\circ} \mathrm{C}\left(0.7^{\circ} \mathrm{C}\right)$ times $\mathrm{N}-1$ has been added to each cast after the cast at station \#1, where $\mathrm{N}$ is the station number. Reference lines have been put in for each cast that show the offset for each cast + a uniform temperature cast of $5^{\circ} \mathrm{C}\left(3.5^{\circ} \mathrm{C}\right)$. The reference casts are annotated with station number at the top of the cast, actual cast is marked at the bottom of the cast. 

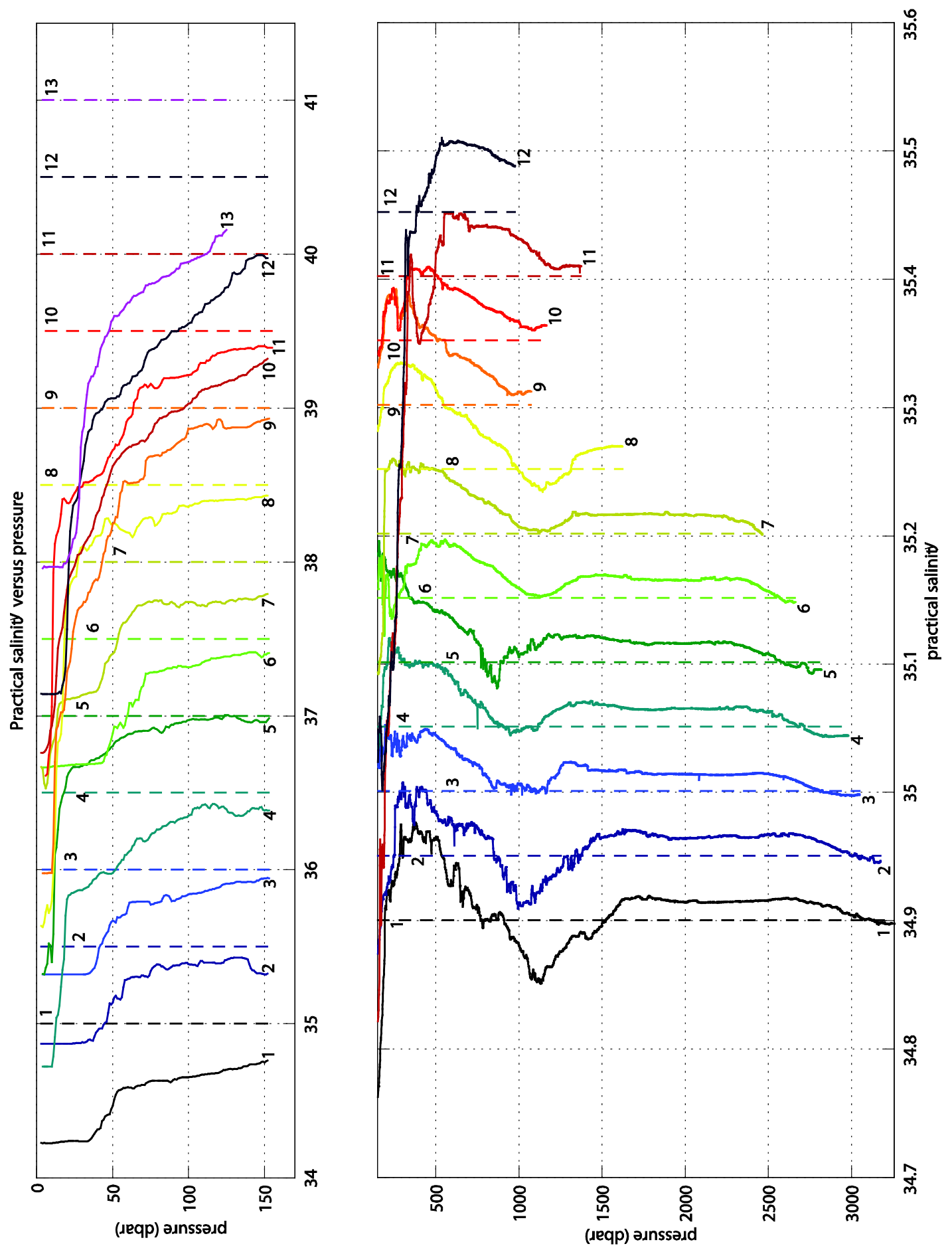

Figure E3. (left, top) Practical salinity versus pressure: surface - $150 \mathrm{~m}$, (right, bottom) Practical salinity versus pressure: below $150 \mathrm{~m}$. Numbers refer to stations cast number show in E1, where \#1 is the cast at the mooring site, and \#13 is the cast nearest the coast of Greenland. In the $0-150$ meter ( $150 \mathrm{~m}$ - bottom) data, stations have been offset by $0.5(0.05)$, so that $0.5(0.05)$ times $\mathrm{N}-1$ has been added to each cast after the cast at station \#1, where $\mathrm{N}$ is the station number. Reference lines have been put in for each cast that show the offset for each cast + a uniform salinity cast of 35.00 (34.90). The reference casts are annotated with station number at the top of the cast, actual cast is marked at the bottom of the cast. 
This page left intentionally blank. 
Appendix F: Summary plot of all APEX trajectories, and a set of four individual plots for each APEX: (a) float trajectory colored by time (blue is the earliest position, red is the most recent position, with positions marked by profile numbers) along with historical data station locations used to calibrate the APEX data; (b) $\theta$-S diagram color coded by time similar to (a); the fit of APEX data compared with historical salinity data, including error estimates, along two $\theta$ surfaces; and (d) drift estimated of the APEX to historical data fits shown in (c) in conductivity and salinity space. All individual APEX plots are references by WMO number, see Table A5. Other plots (such as salinity and temperature versus time) are available at the individual drifter URLs listed in Table A5. 
This page left intentionally blank. 

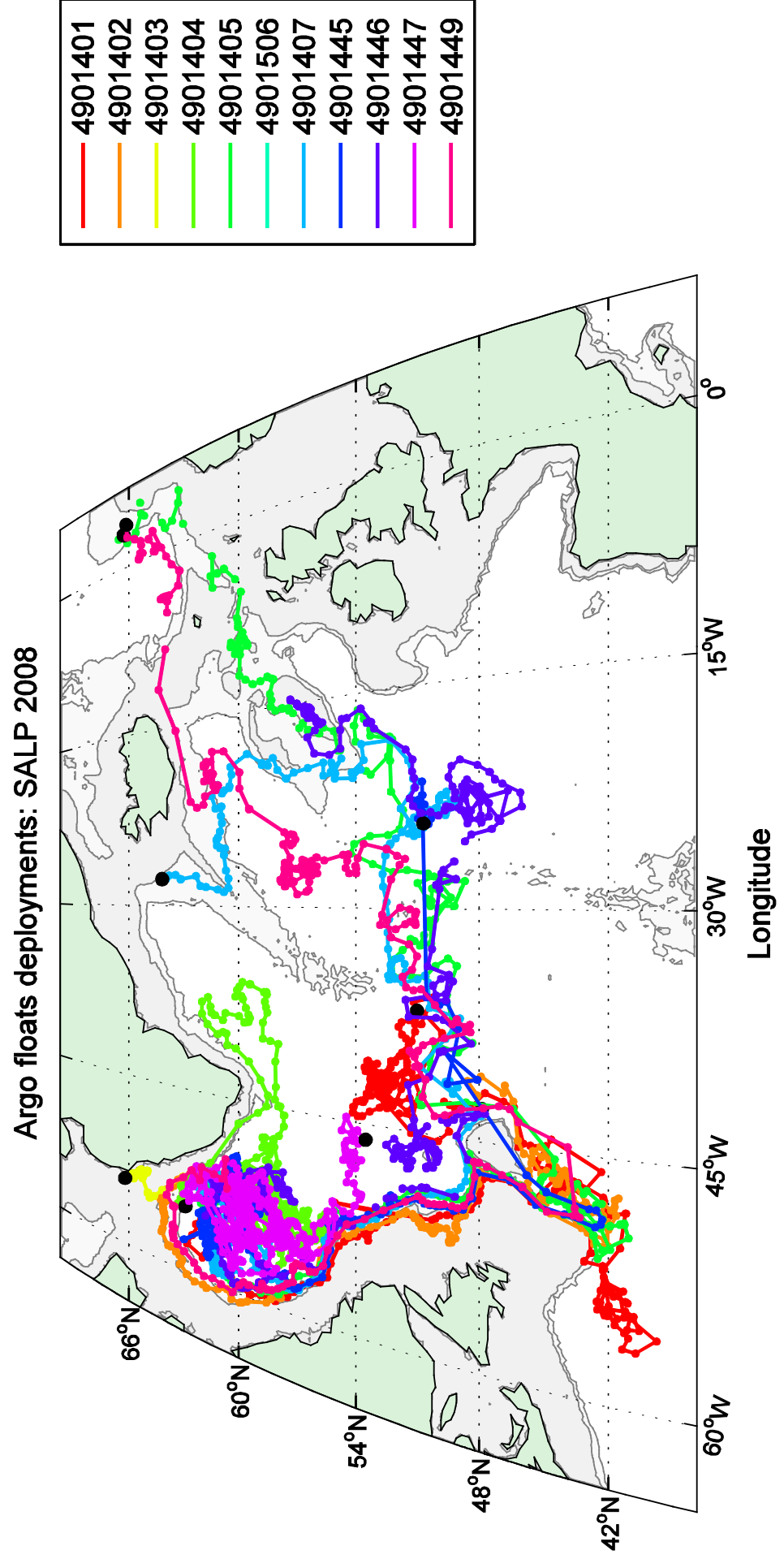

әрnџ!ฺอา

Figure F1. Composite plot of all APEX trajectories collected as a part of this experiment, labeled by WMO ascension number (See Table A5). 


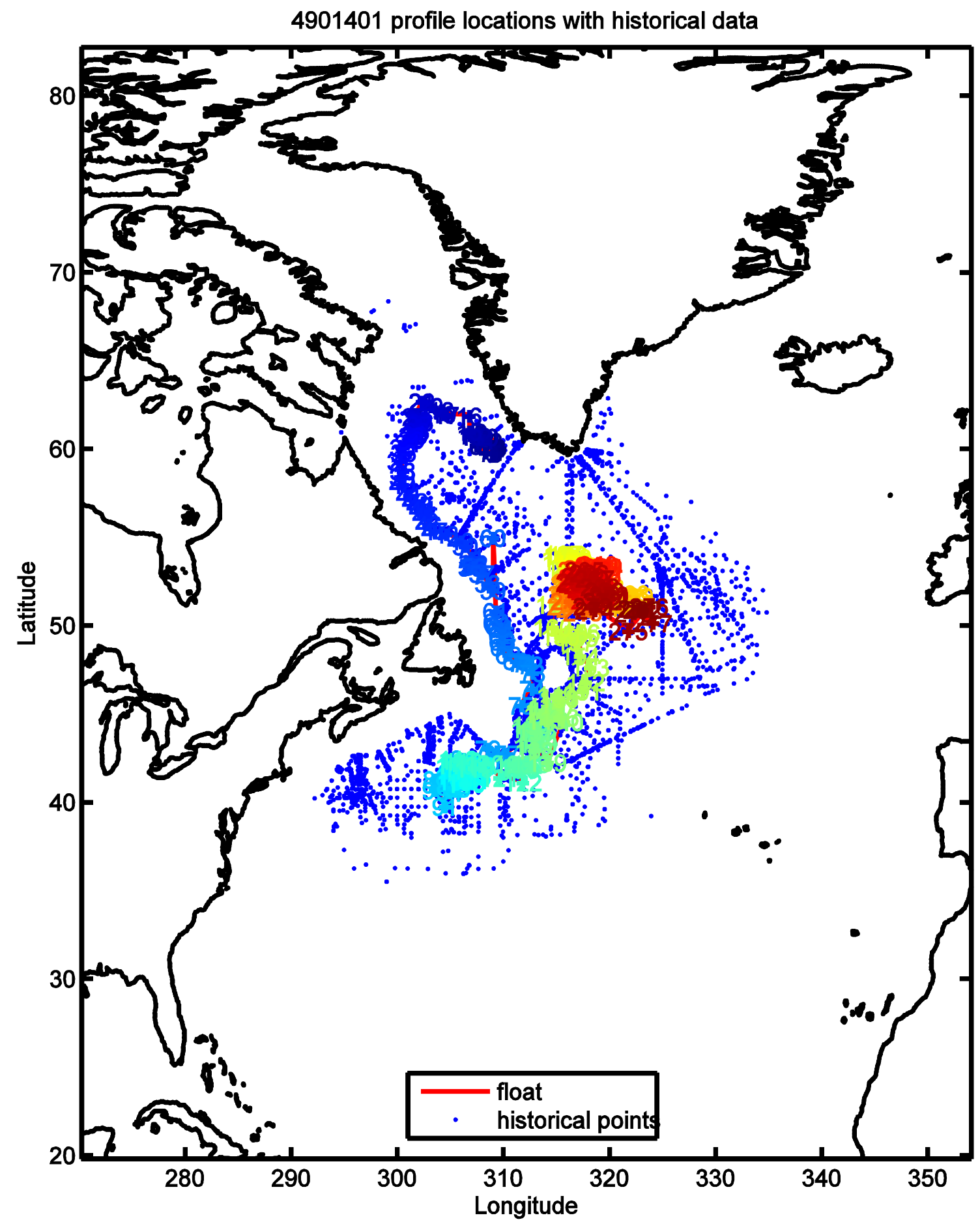

Figure F2a. APEX s/n 5261 / WMO \#4901401. 


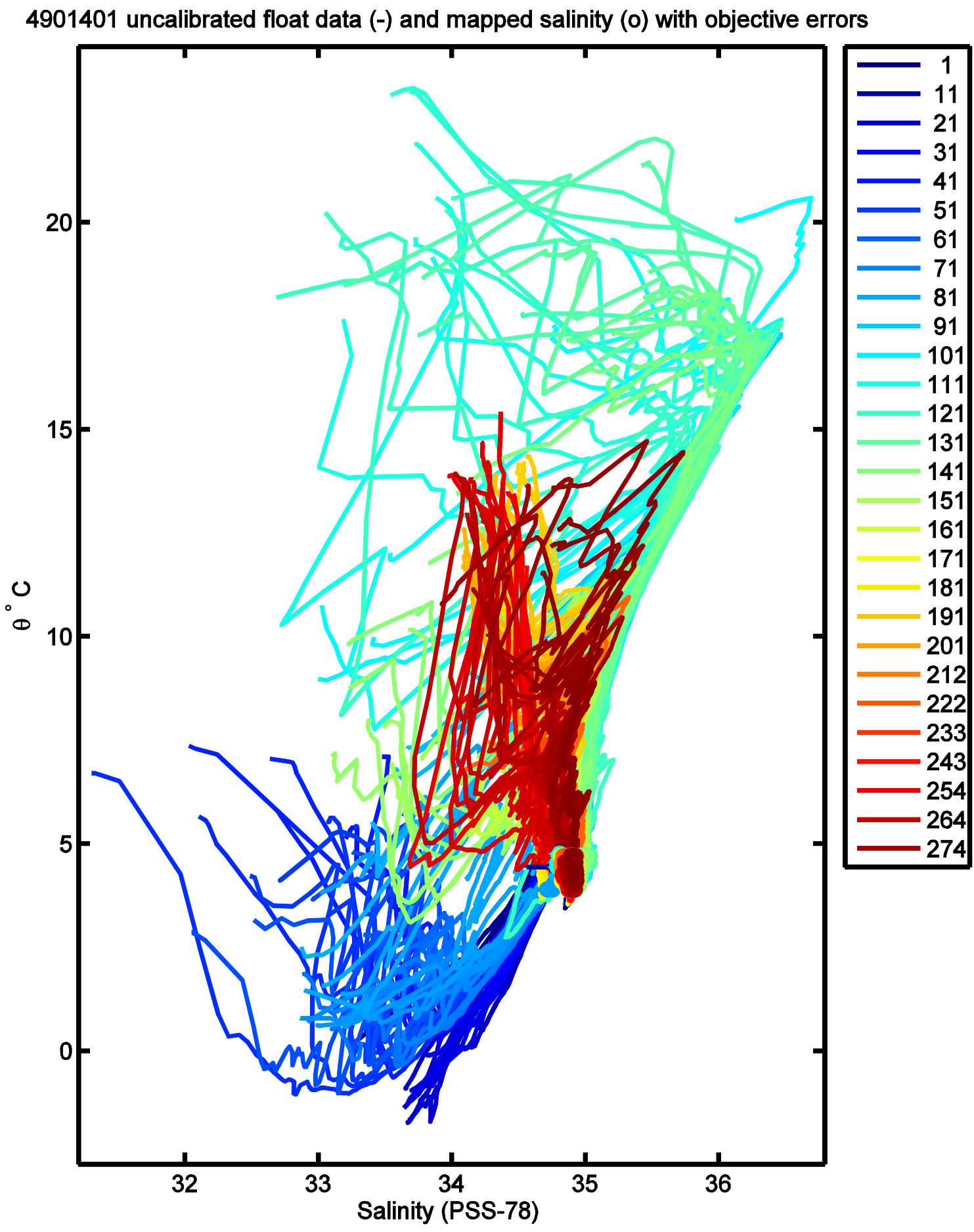

Figure F2b. APEX s/n 5261 / WMO \#4901401. 

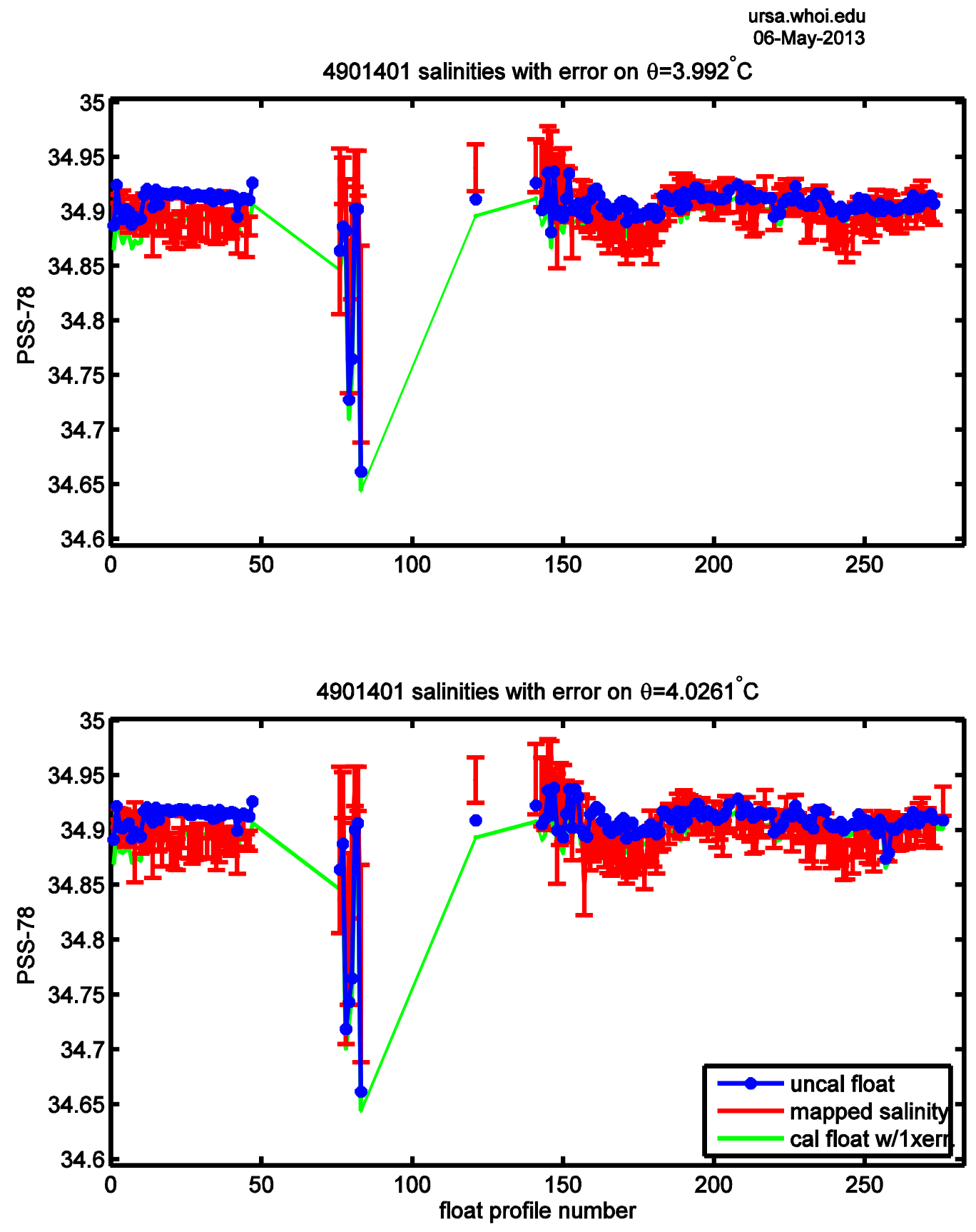

Figure F2c. APEX s/n 5261 / WMO \#4901401. 

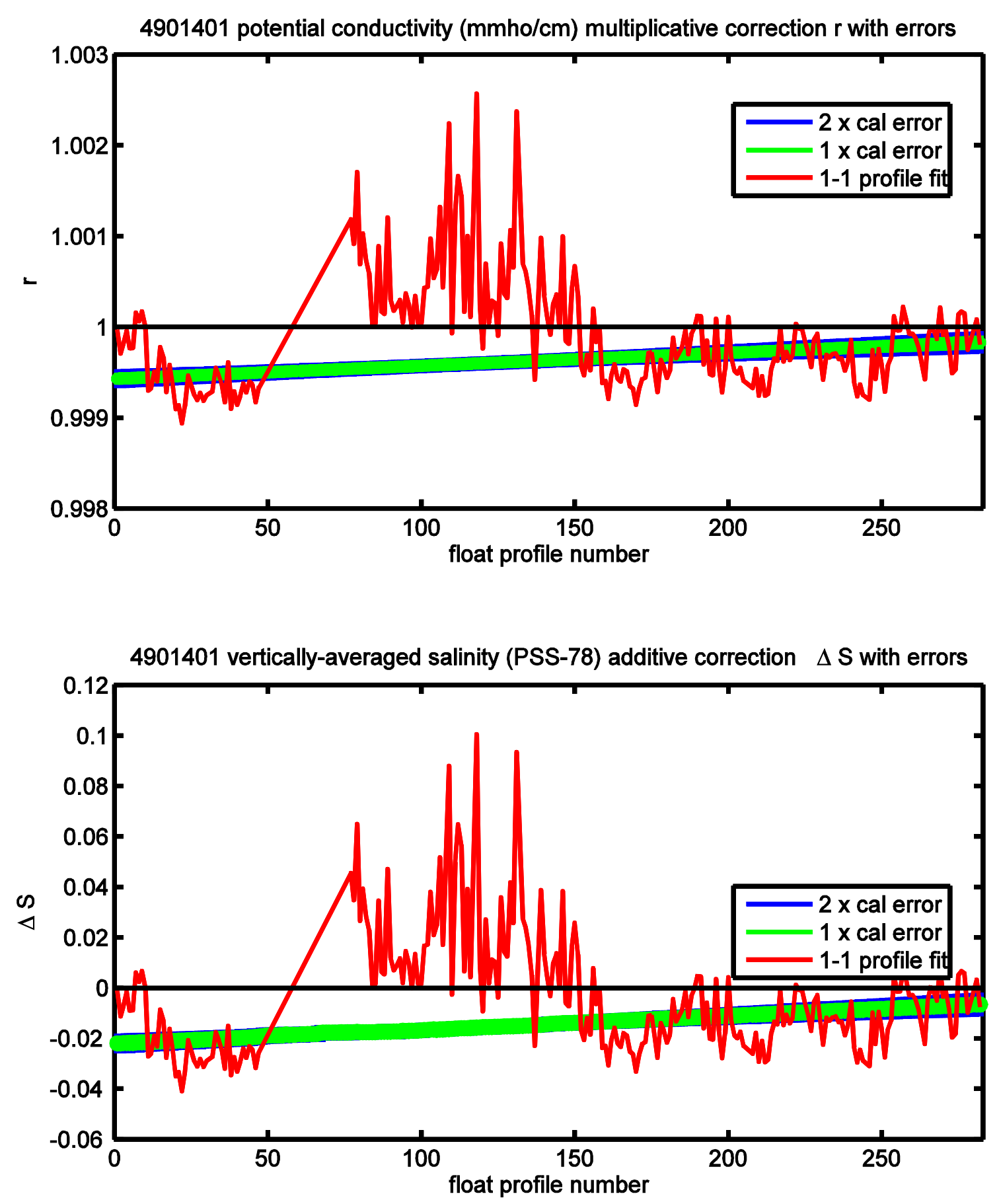

Figure F2d. APEX s/n 5261 / WMO \#4901401. 


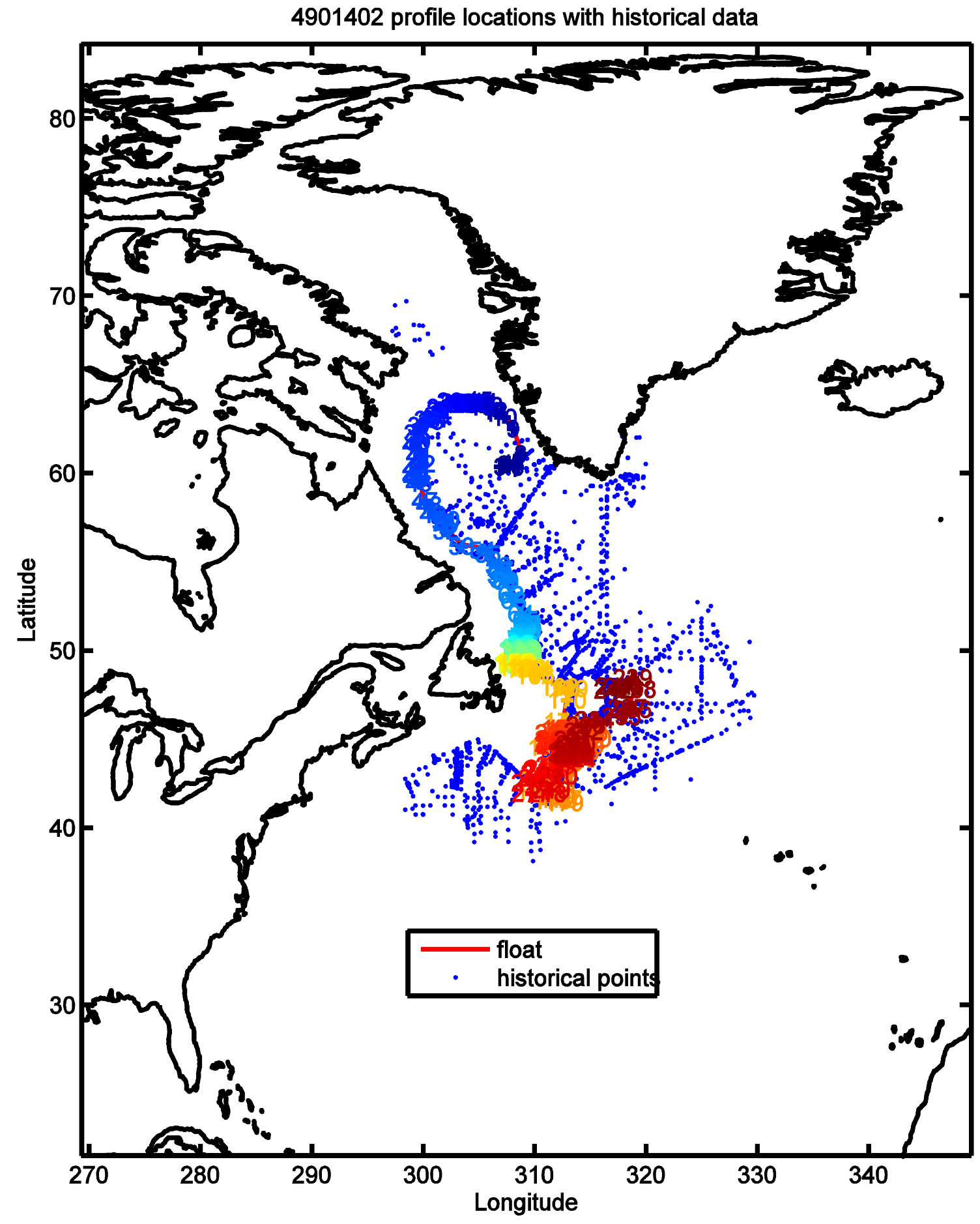

Figure F3a. APEX s/n 5262 / WMO \#4901402. 


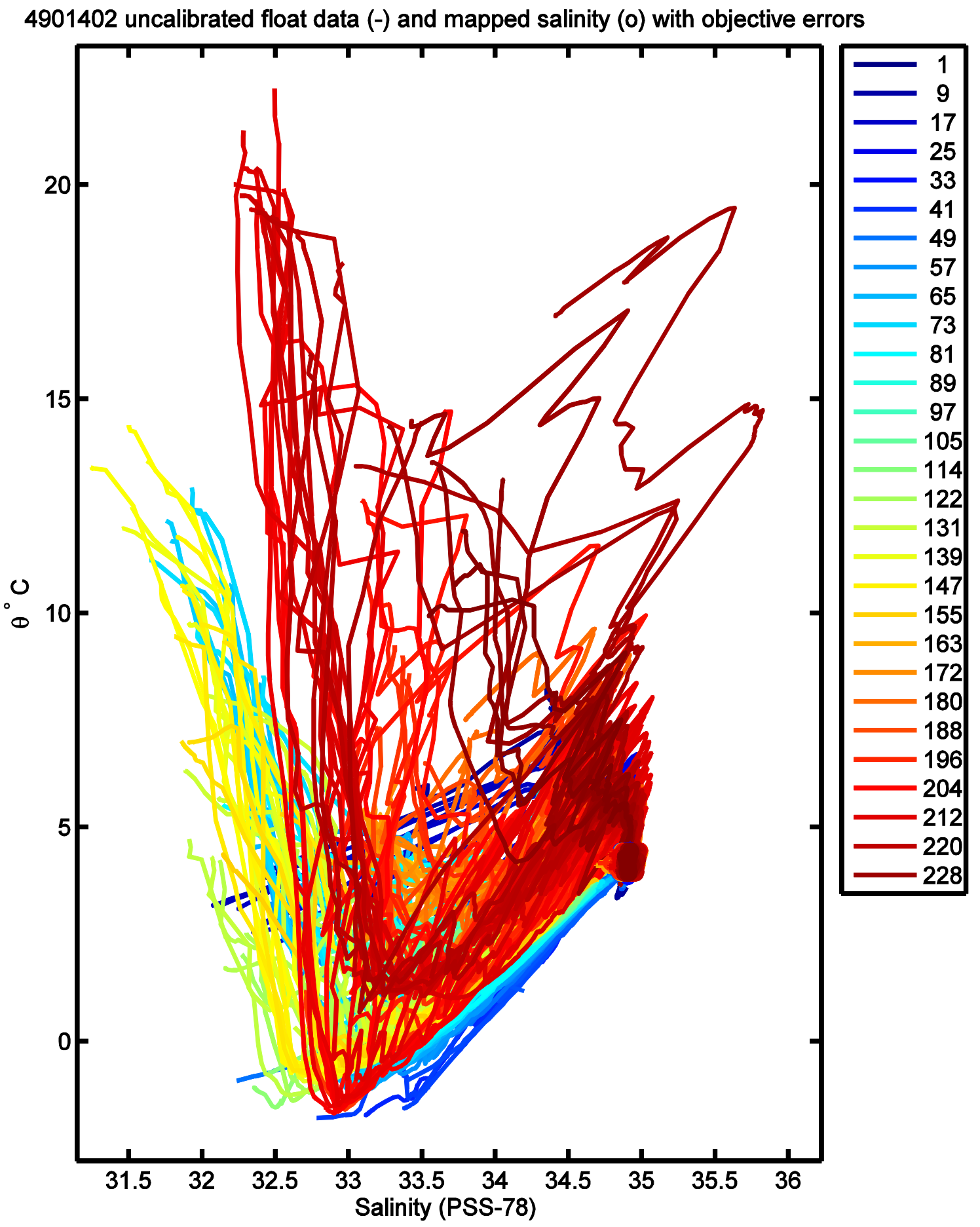

Figure F3b. APEX s/n 5262 / WMO \#4901402. 

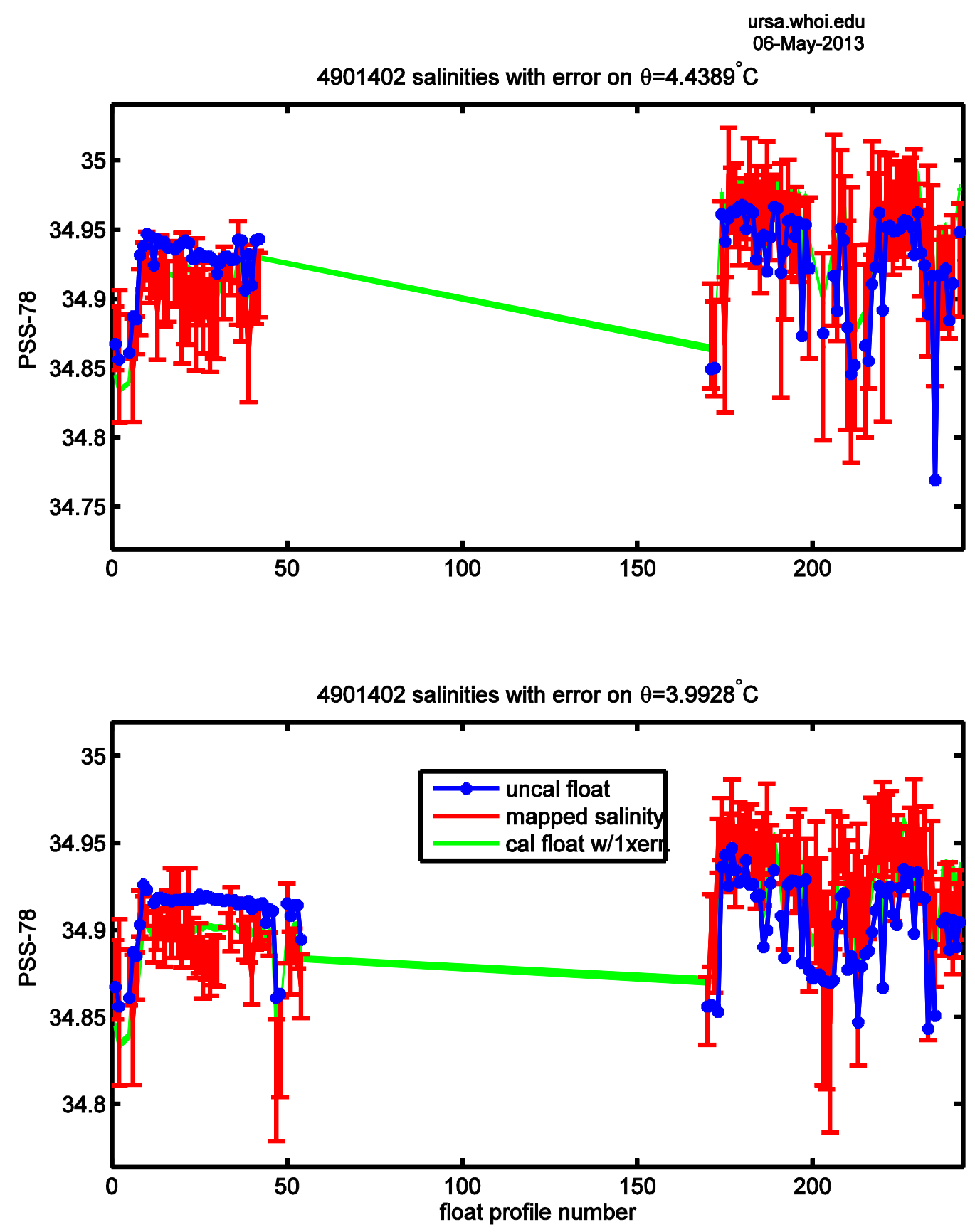

Figure F3c. APEX s/n 5262 / WMO \#4901402. 

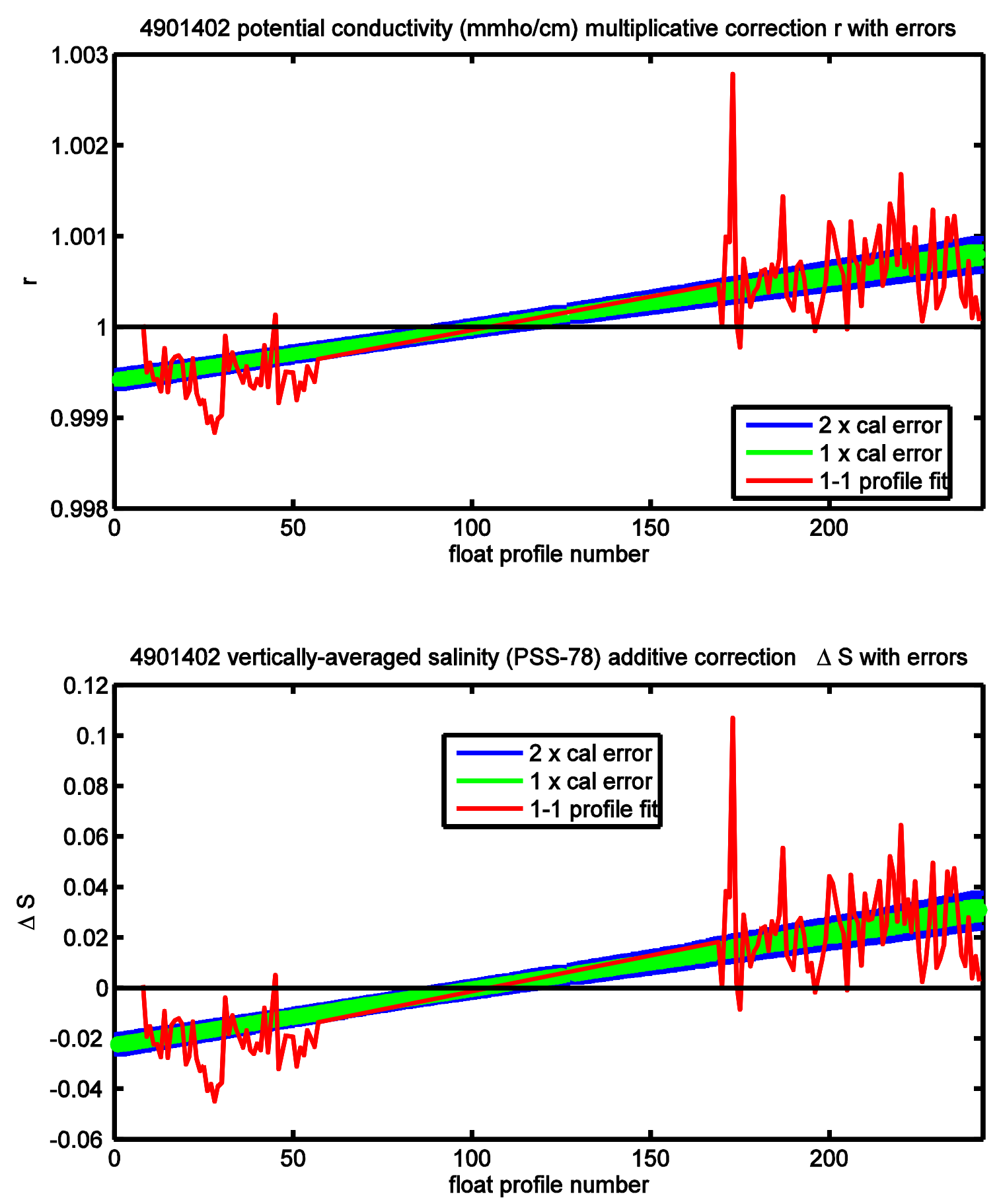

Figure F3d. APEX s/n 5262 / WMO \#4901402. 


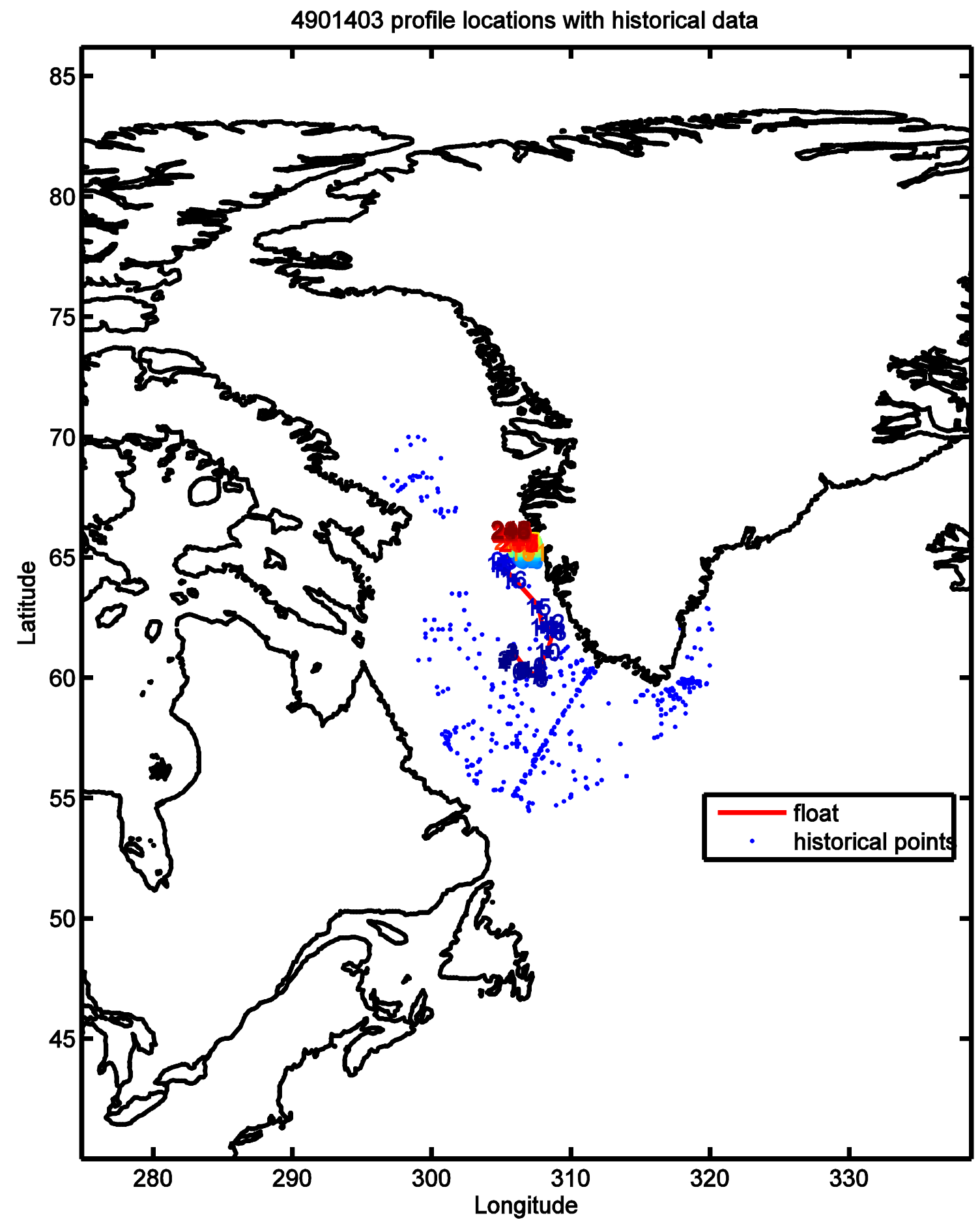

Figure F4a. APEX s/n 5263 / WMO \#4901403. 


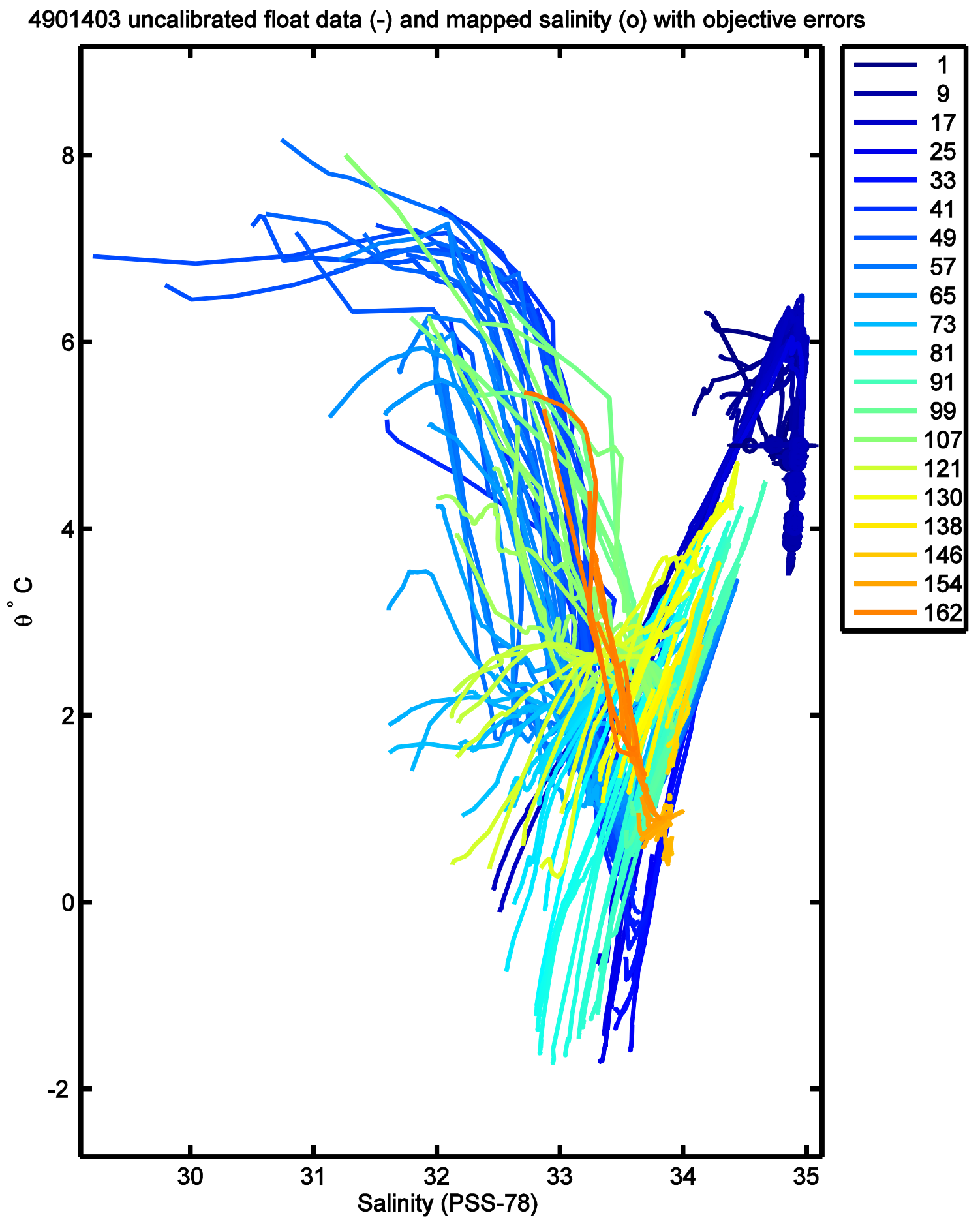

Figure F4b. APEX s/n 5263 / WMO \#4901403. 

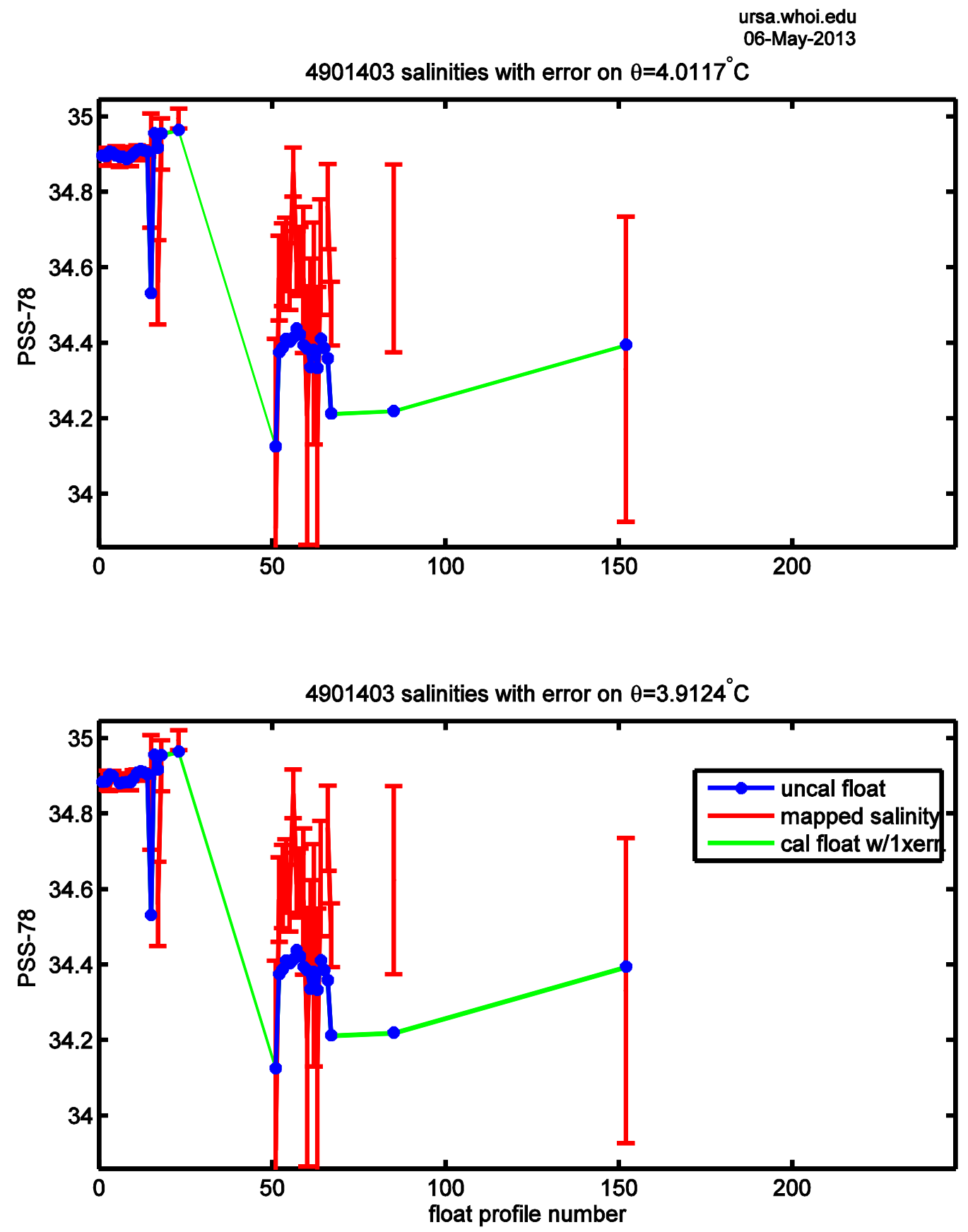

Figure F4c. APEX s/n 5263 / WMO \#4901403. 

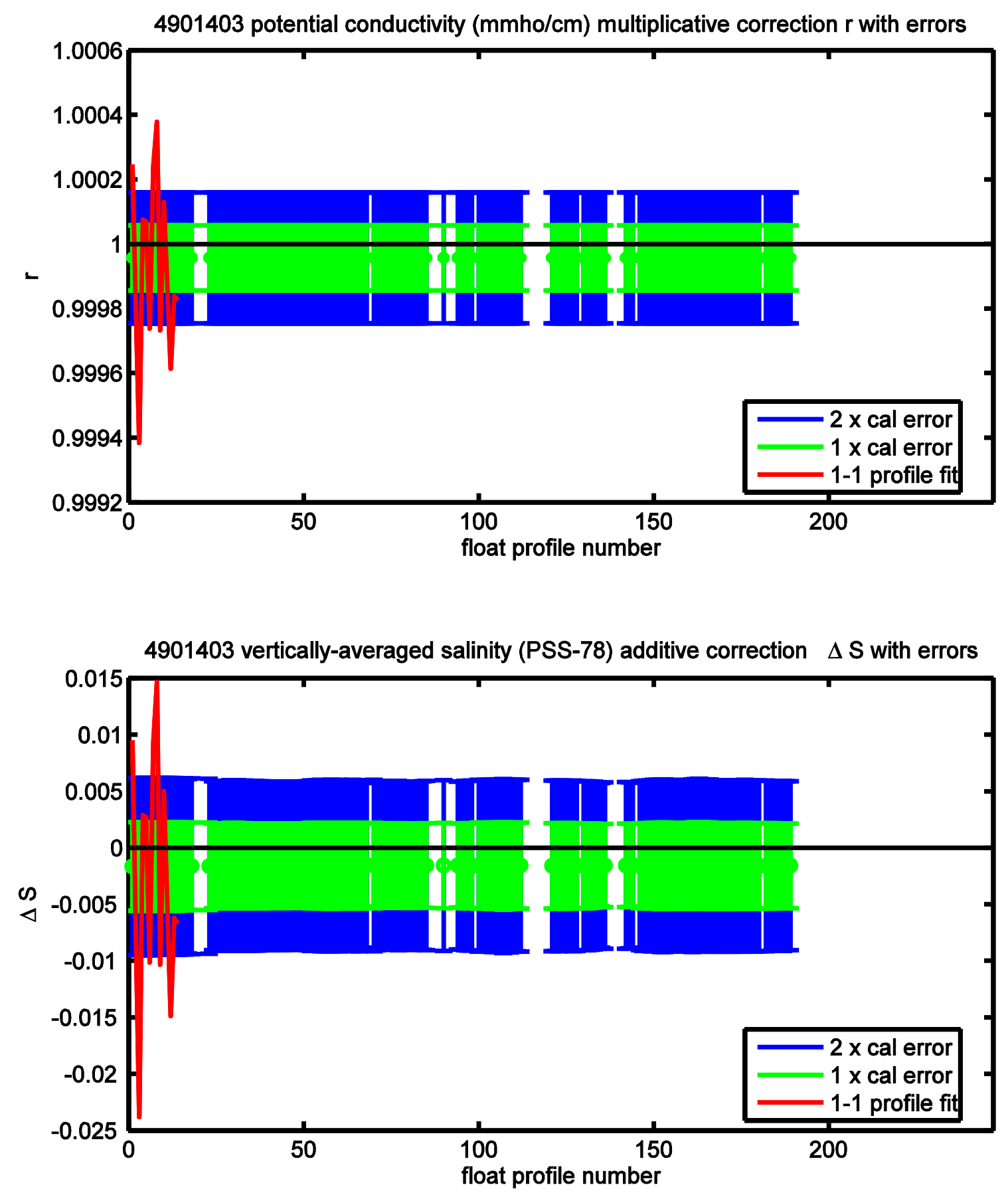

Figure F4d. APEX s/n 5263 / WMO \#4901403. 


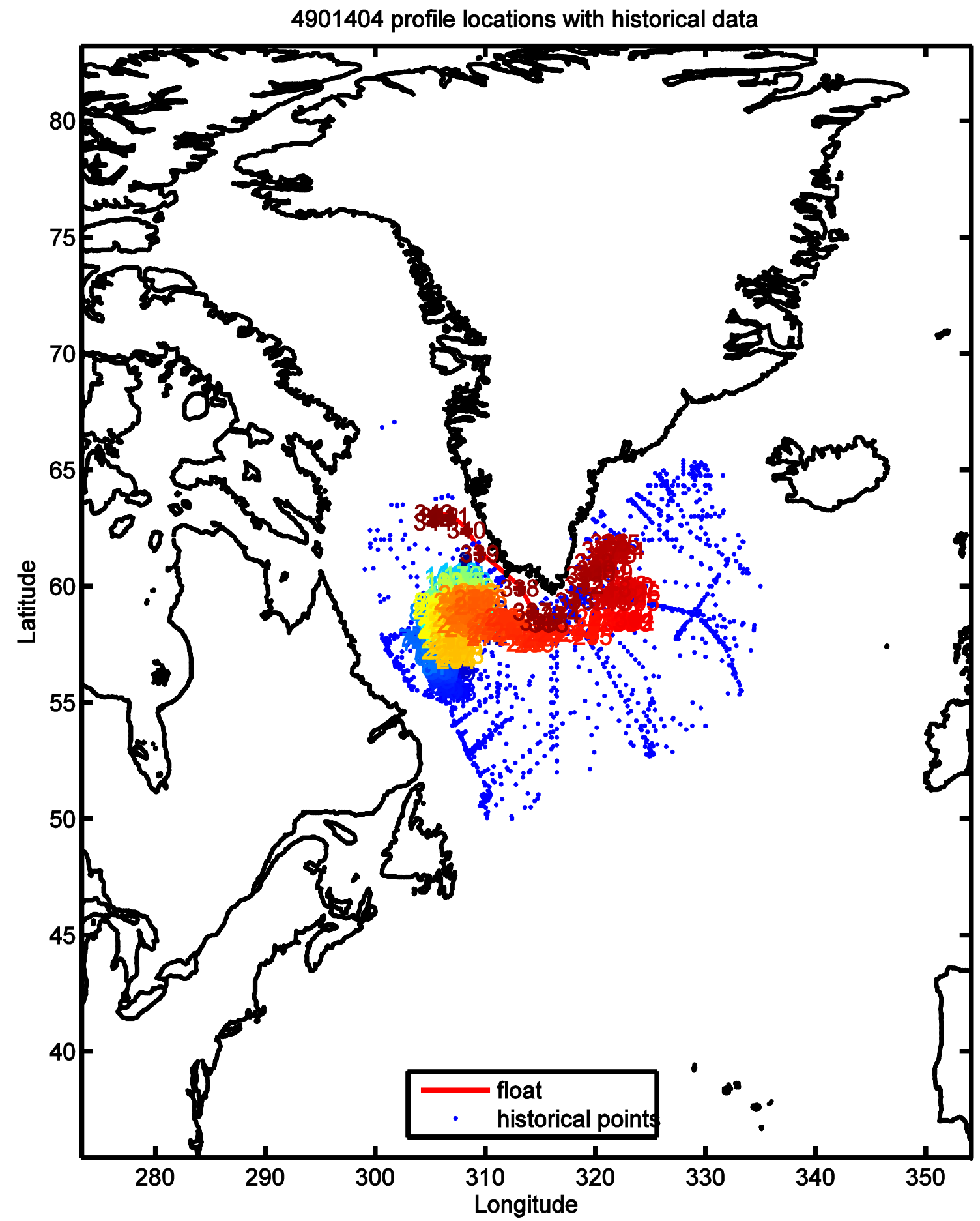

Figure F5a. APEX s/n 5264 / WMO \#4901404. 


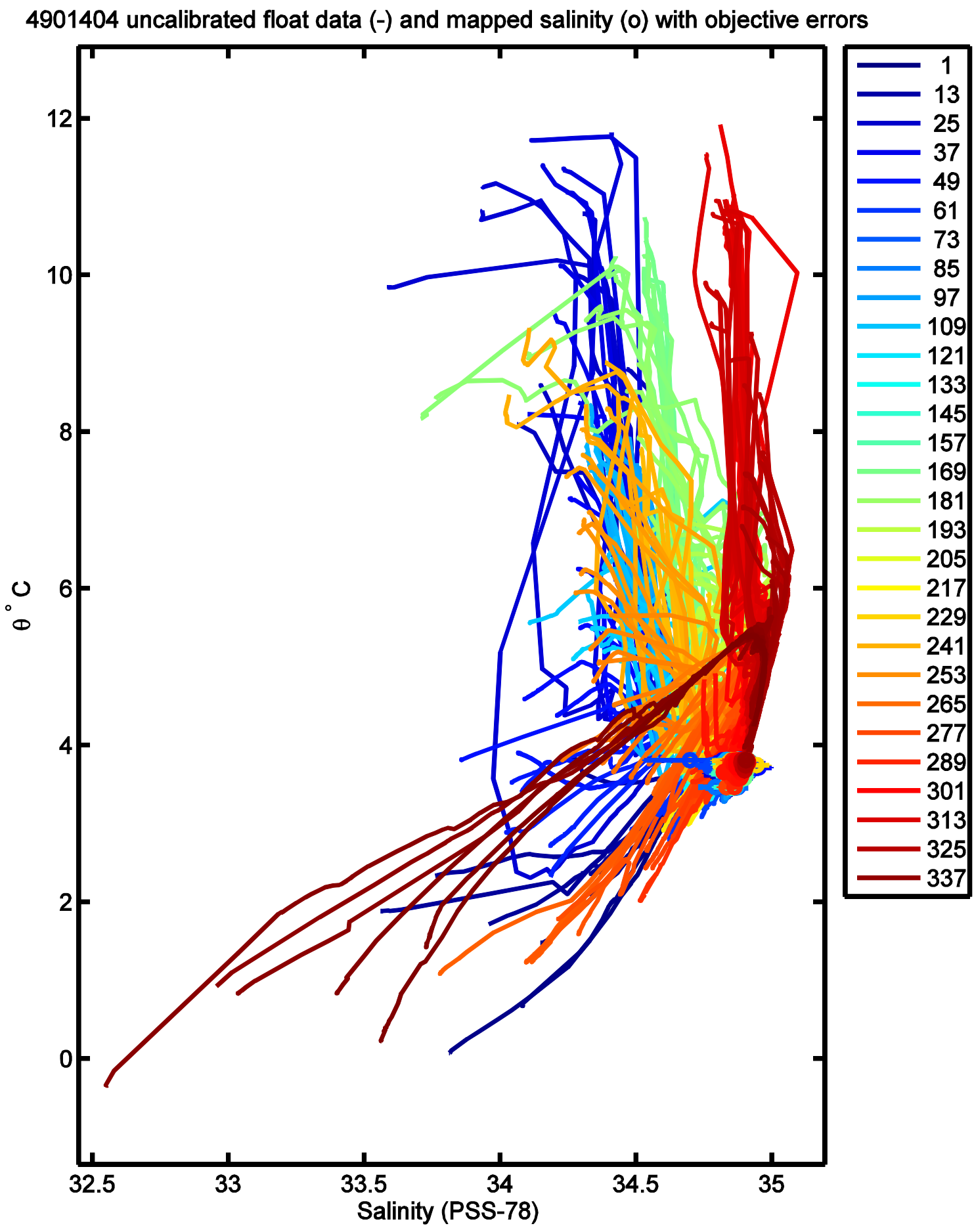

Figure F5b. APEX s/n 5264 / WMO \#4901404. 

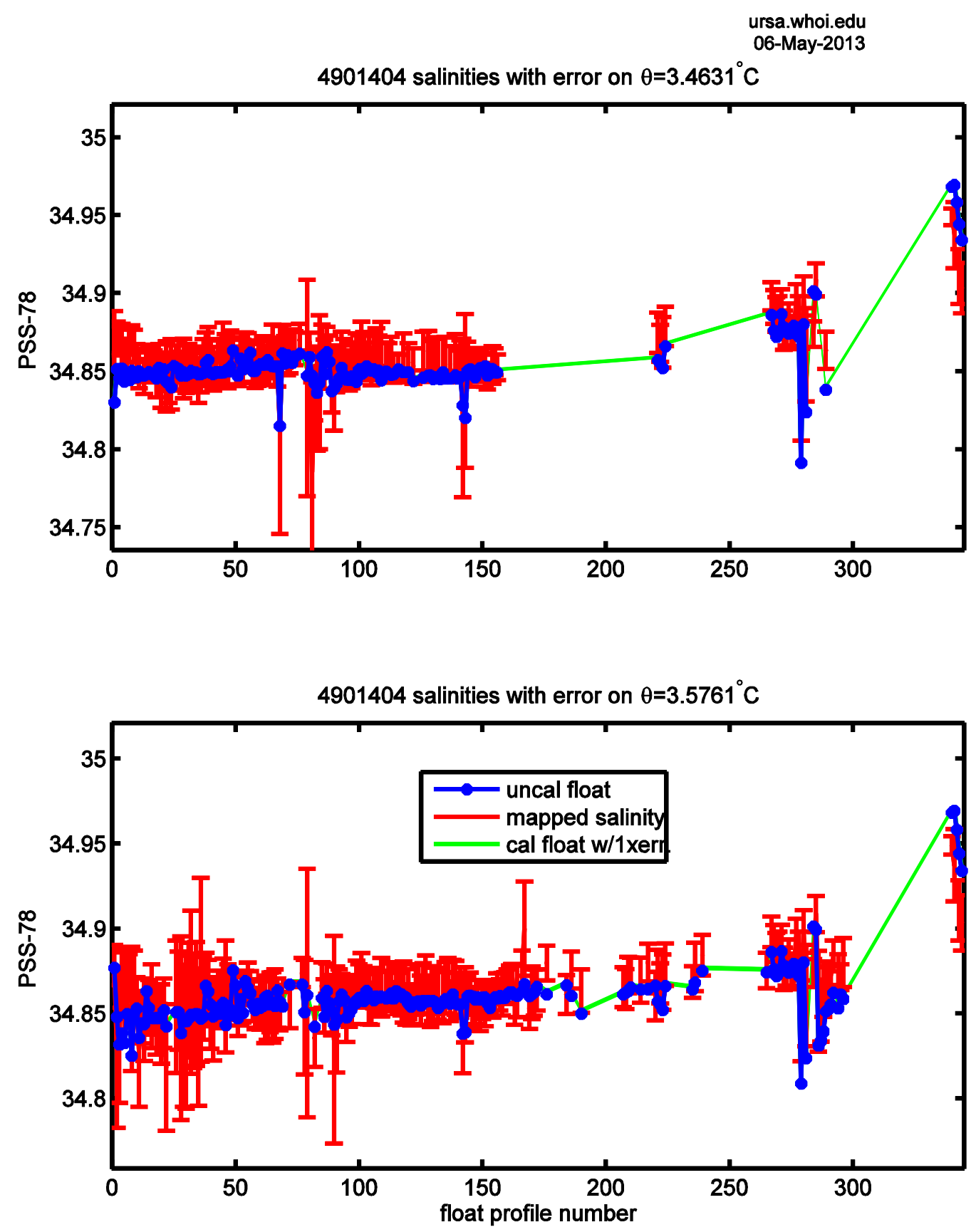

Figure F5c. APEX s/n 5264 / WMO \#4901404. 

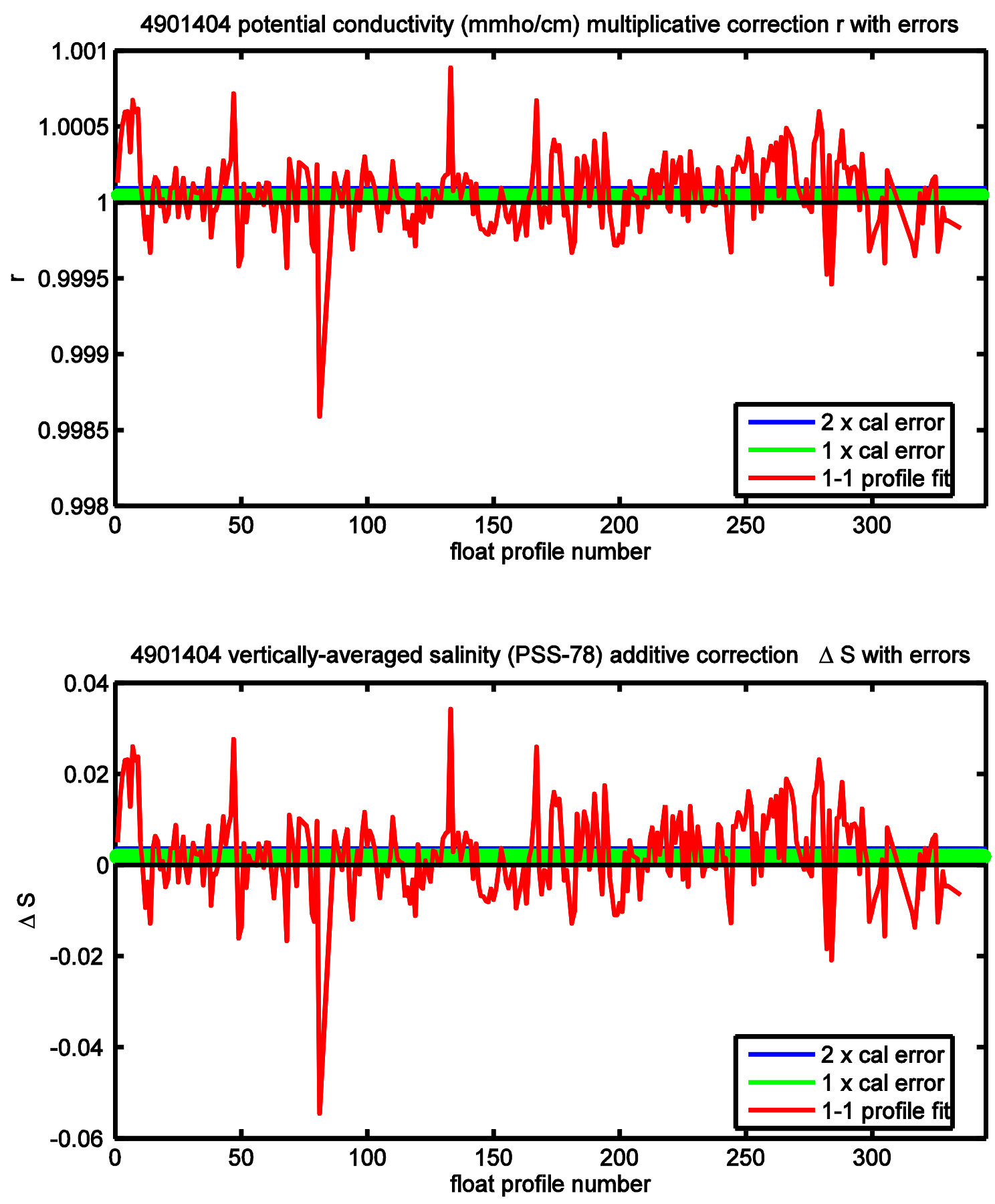

Figure F5d. APEX s/n 5264 / WMO \#4901404. 


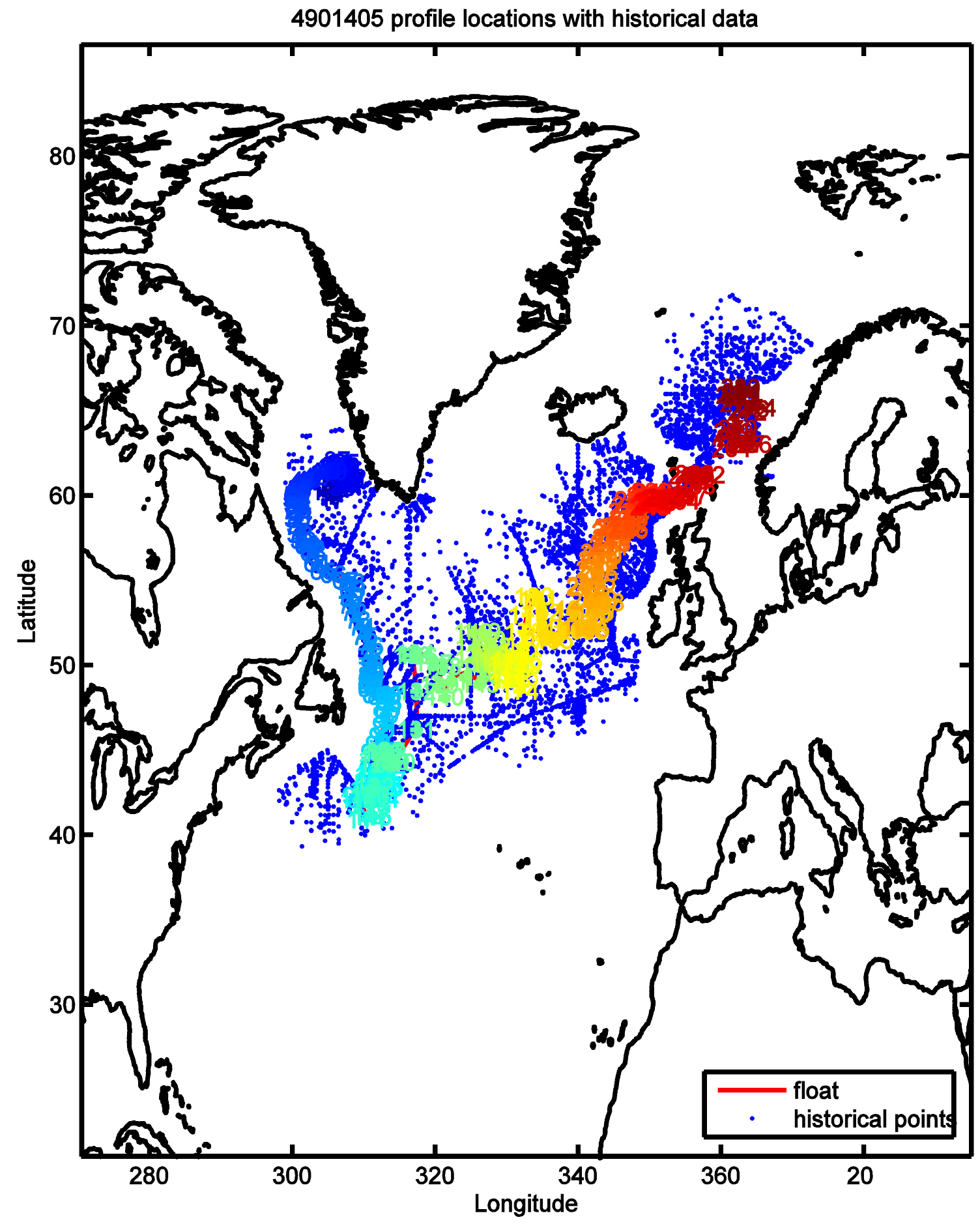

Figure F6a. APEX s/n 5265 / WMO \#4901405. 
4901405 uncalibrated float data (-) and mapped salinity (0) with objective errors

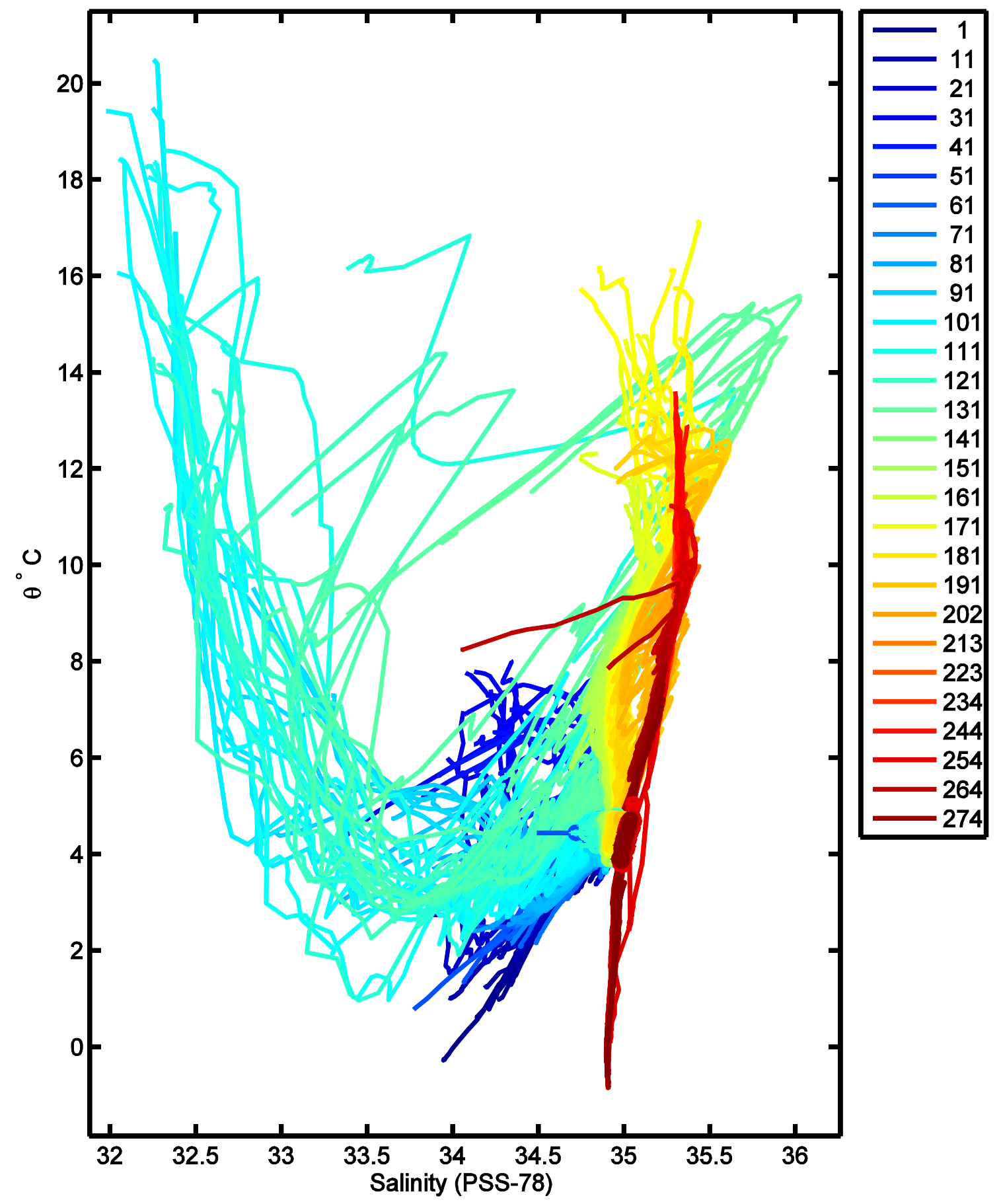

Figure F6b. APEX s/n 5265 / WMO \#4901405. 

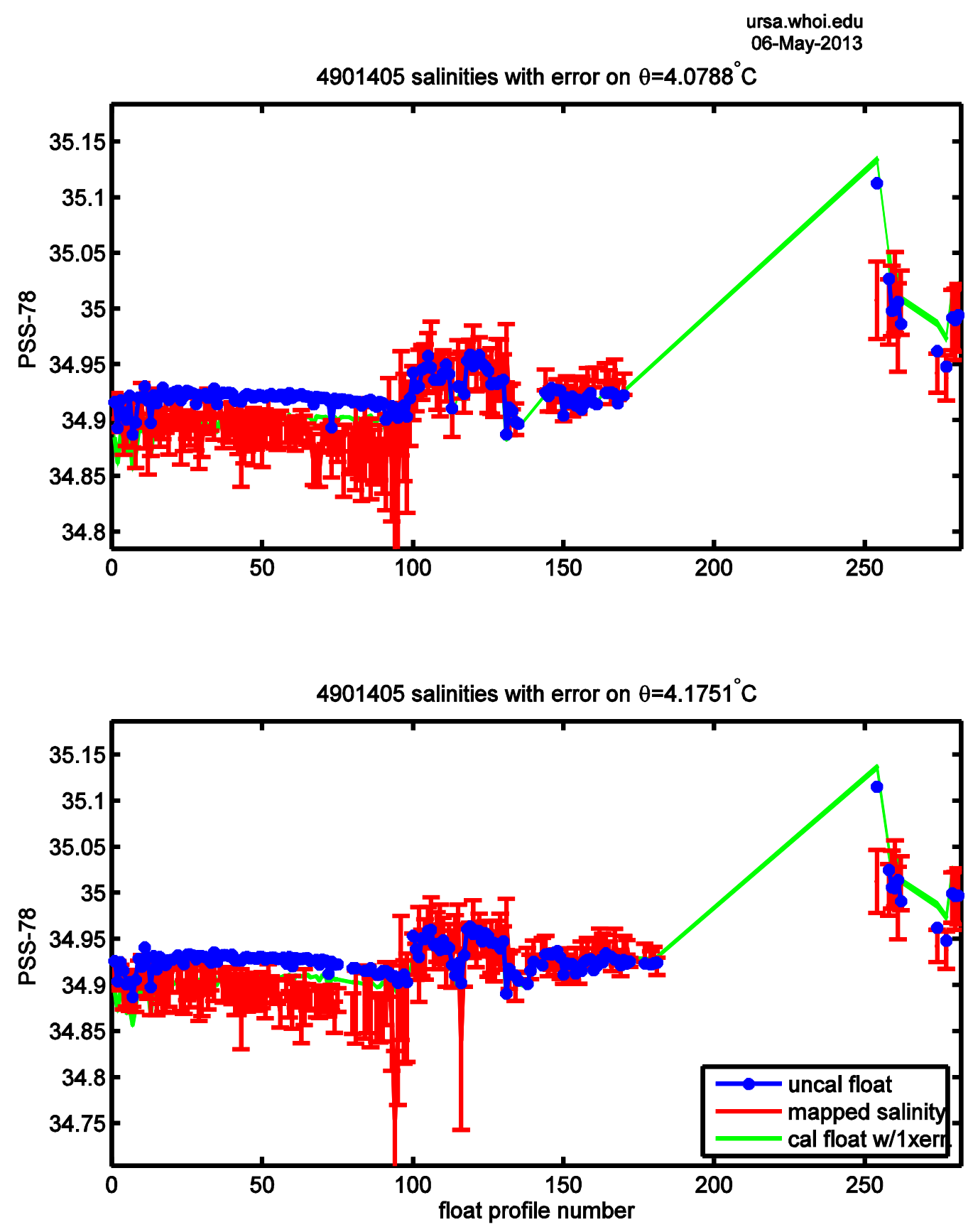

Figure F6c. APEX s/n 5265 / WMO \#4901405. 

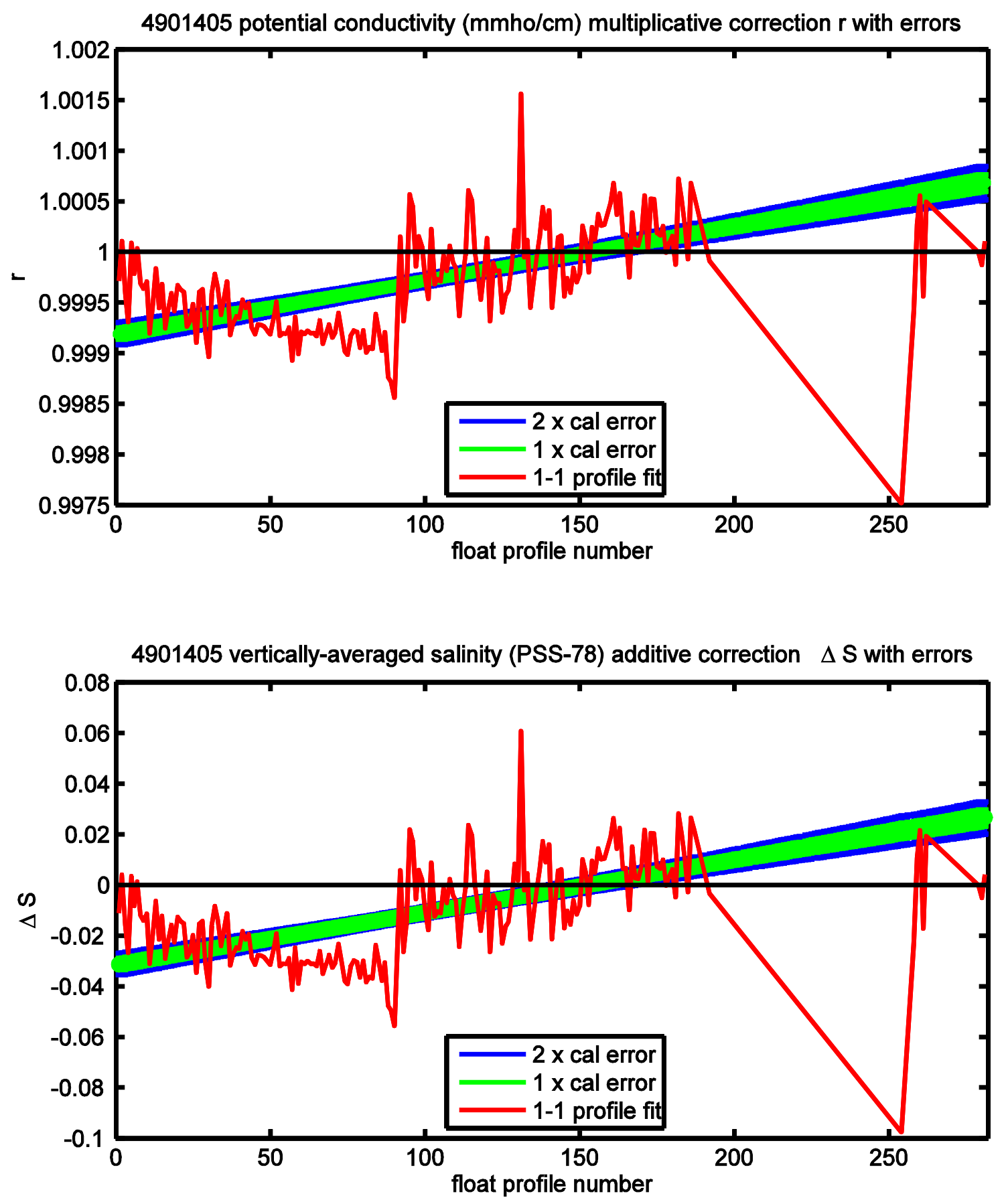

Figure F6d. APEX s/n 5265 / WMO \#4901405. 


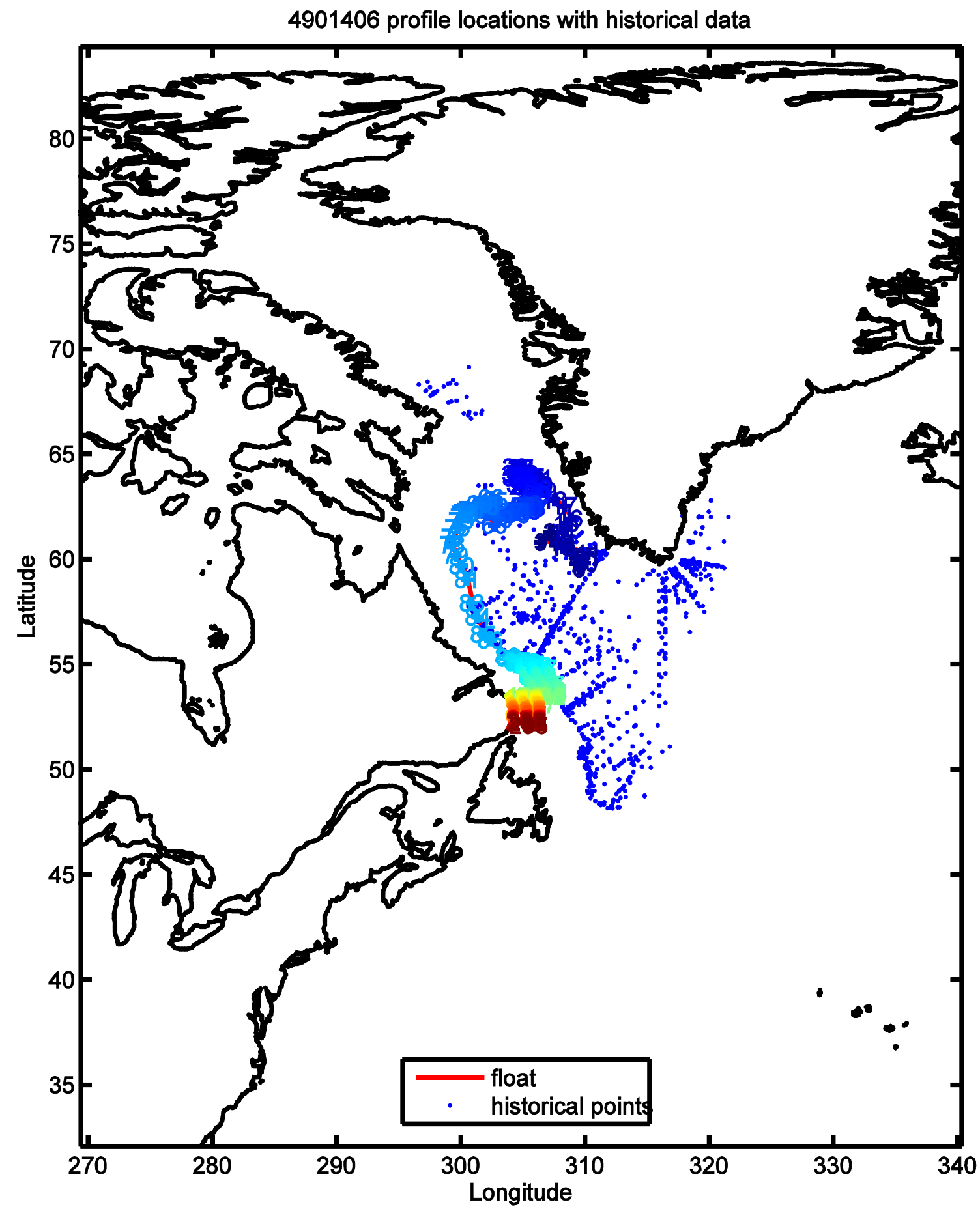

Figure F7a. APEX s/n 5266 / WMO \#4901406. 


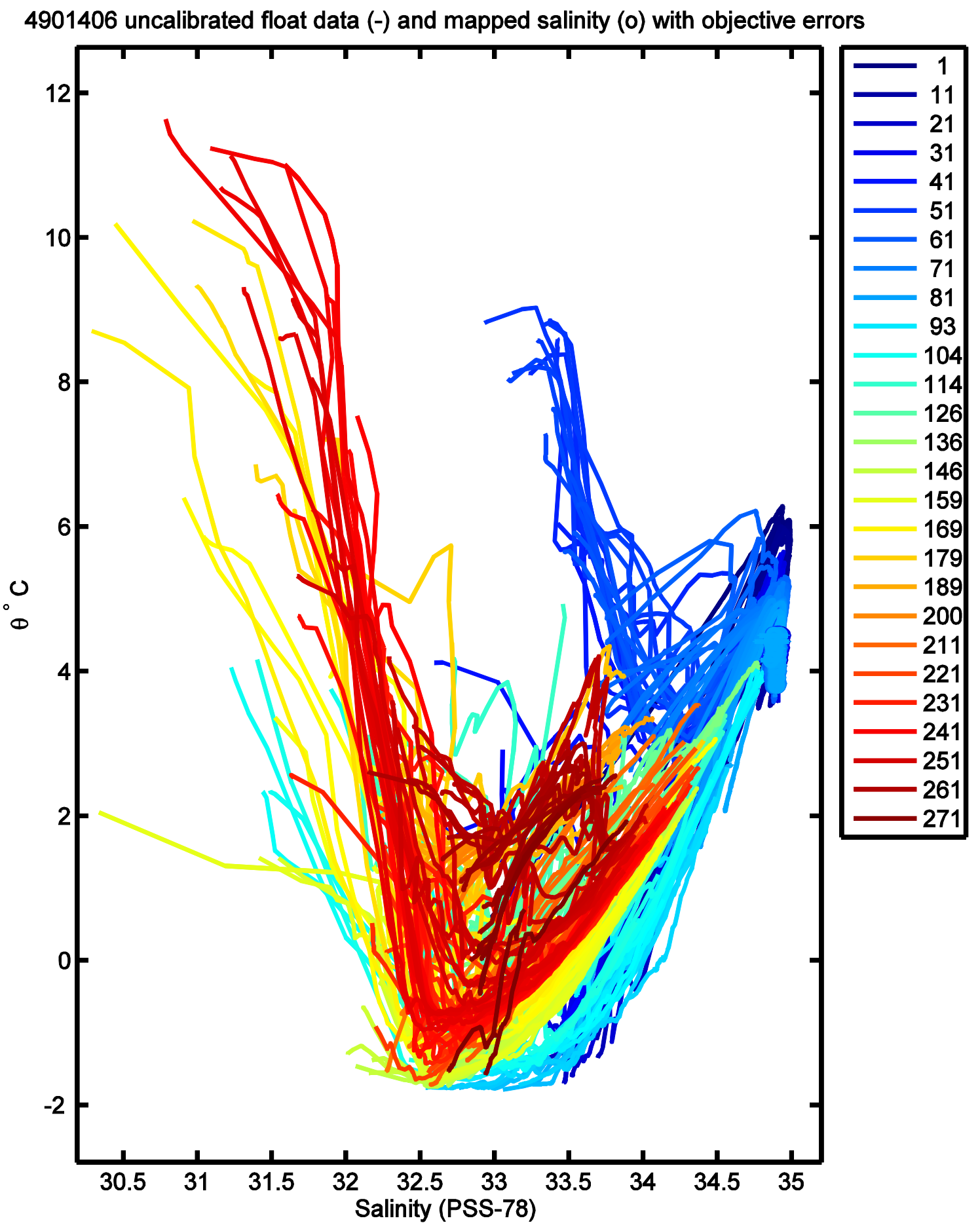

Figure F7b. APEX s/n 5266 / WMO \#4901406. 

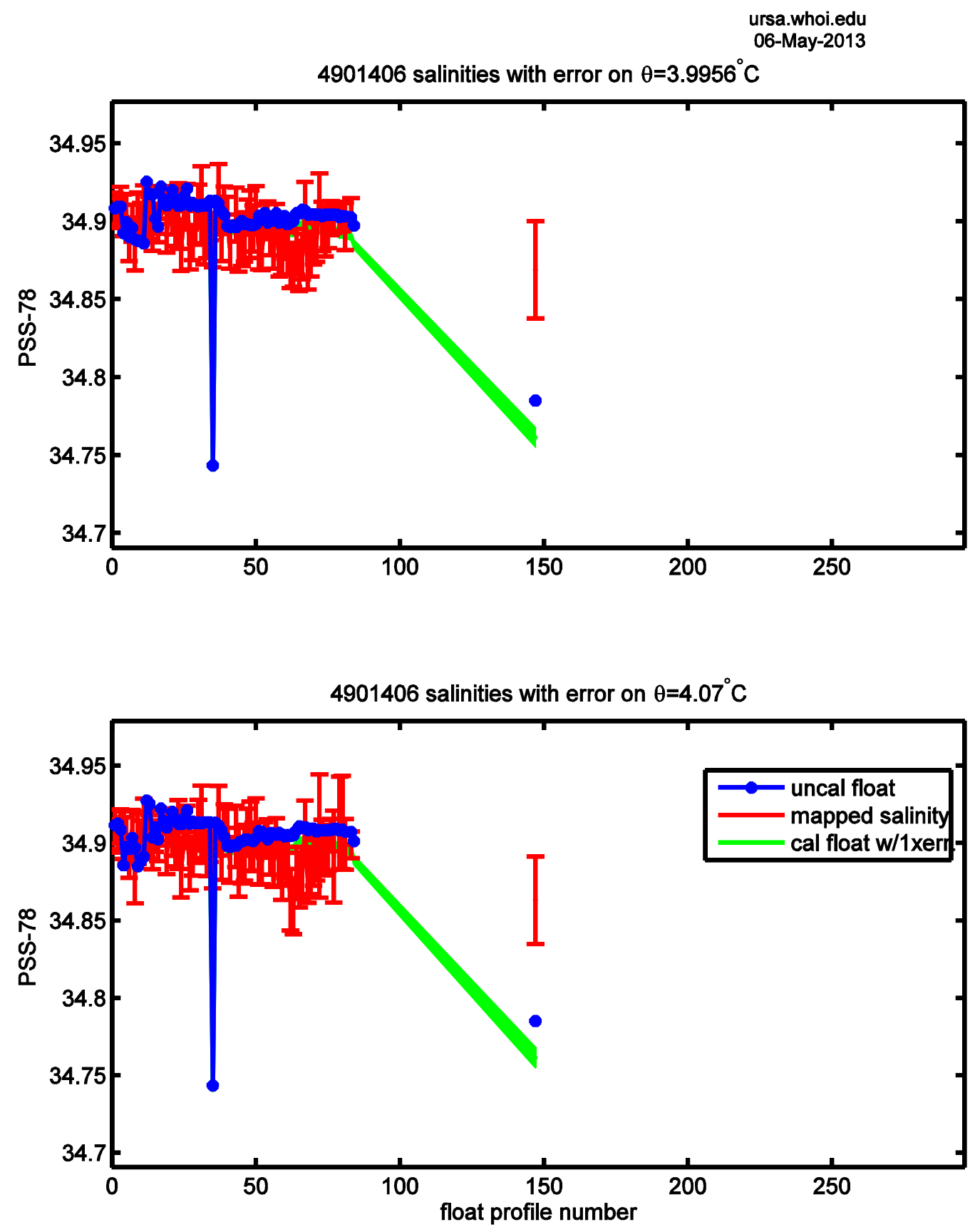

Figure F7c. APEX s/n 5266 / WMO \#4901406. 

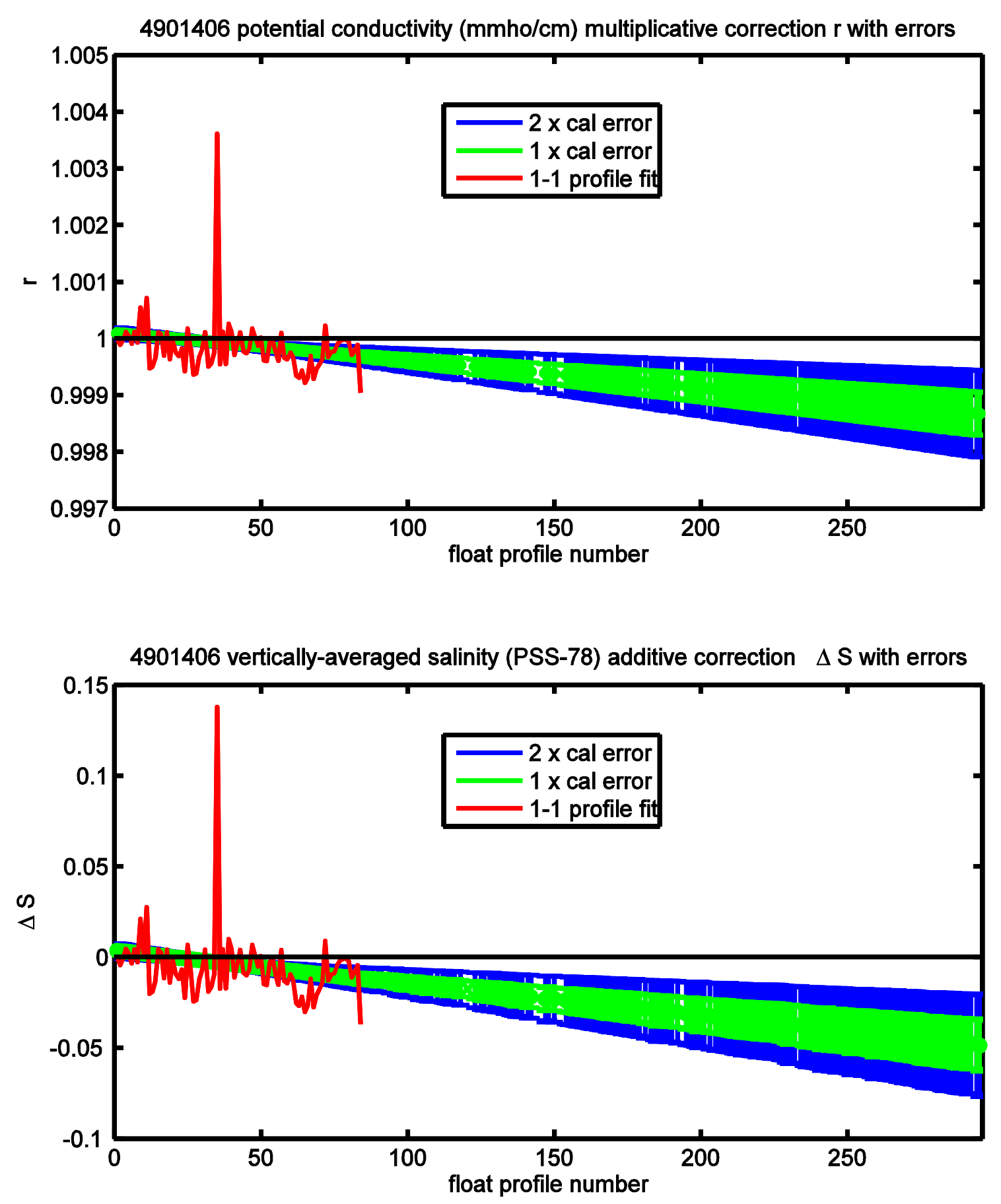

Figure F7d. APEX s/n 5266 / WMO \#4901406. 


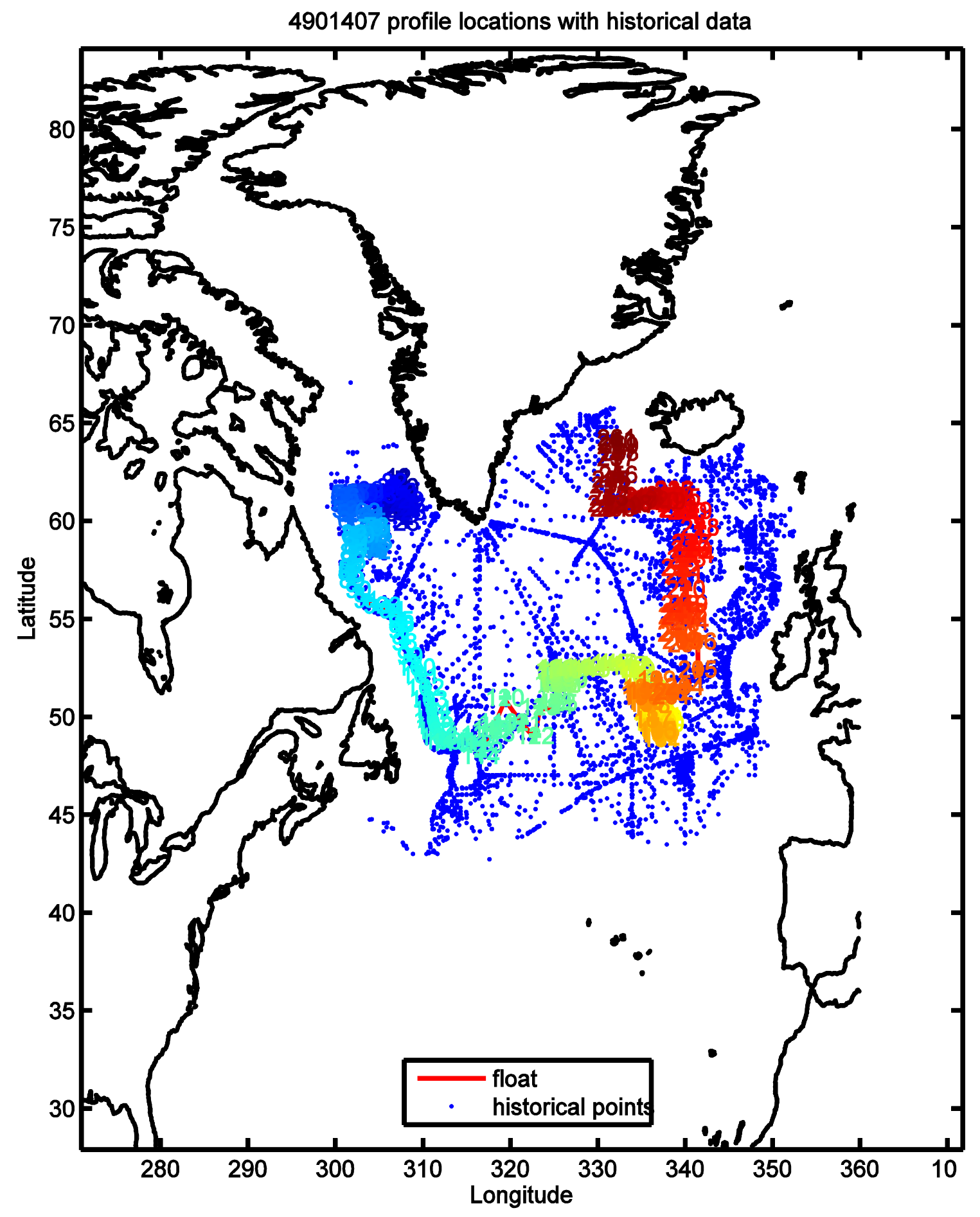

Figure F8a. APEX s/n 5267 / WMO \#4901407. 


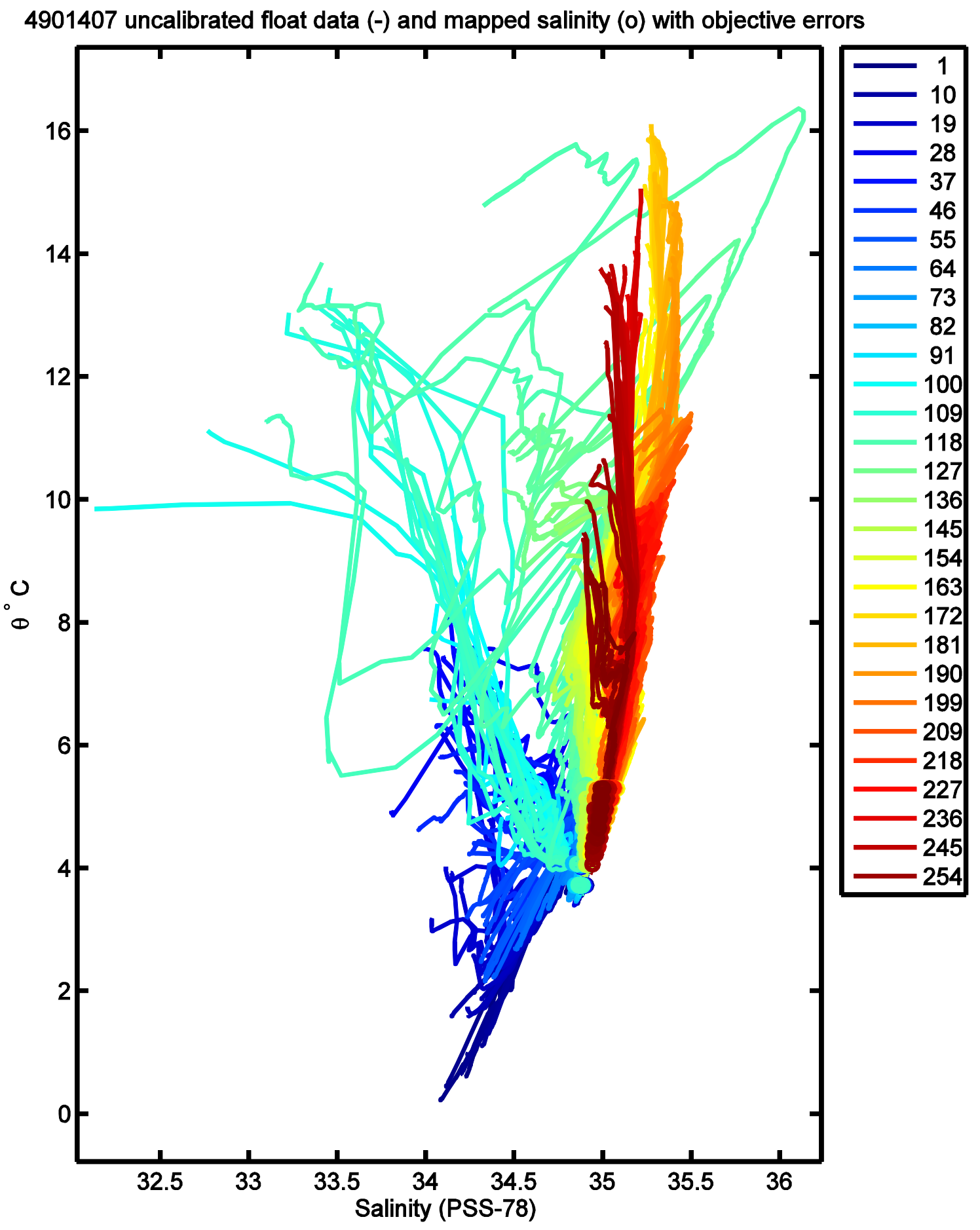

Figure F8b. APEX s/n 5267 / WMO \#4901407. 

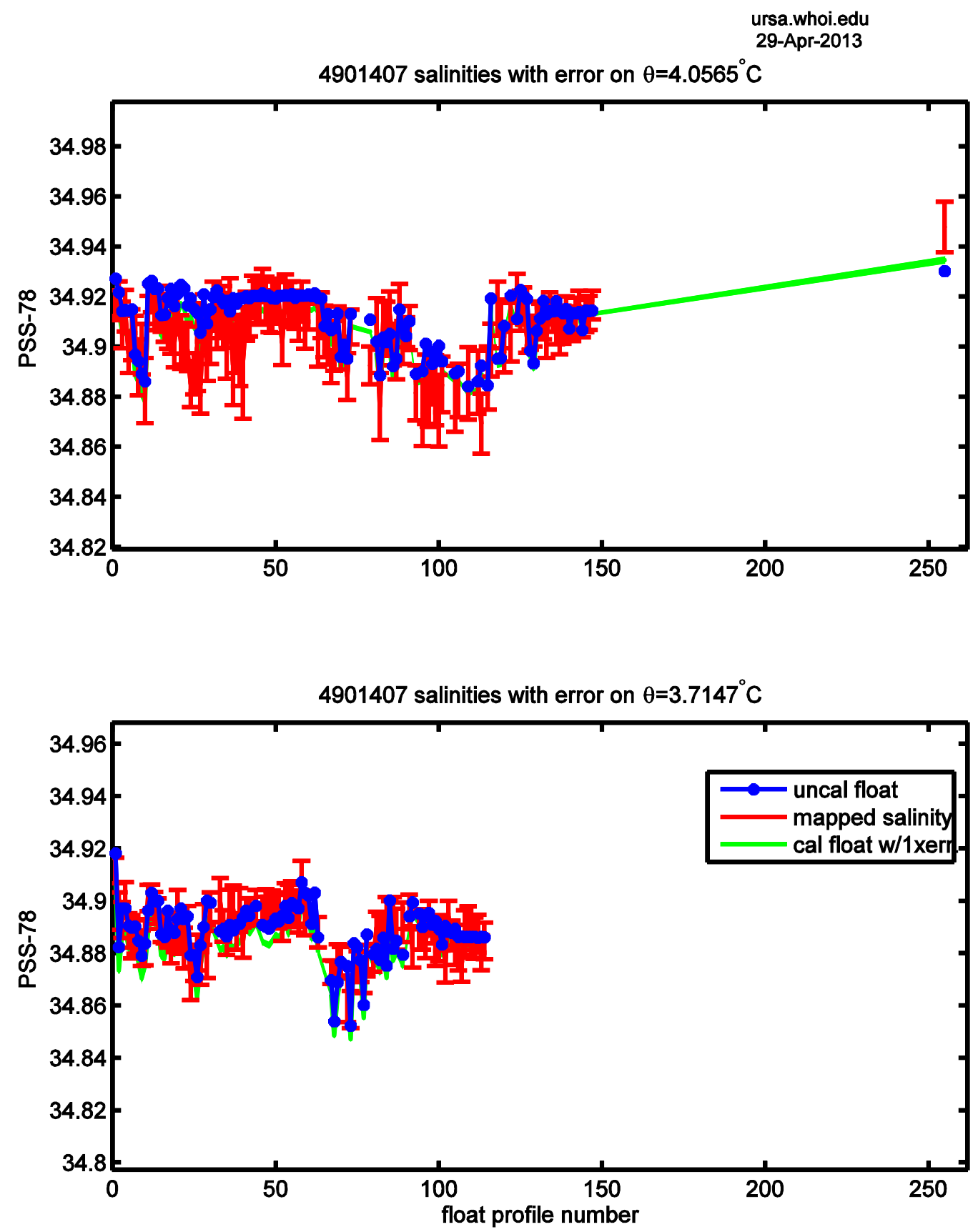

Figure F8c. APEX s/n 5267 / WMO \#4901407. 

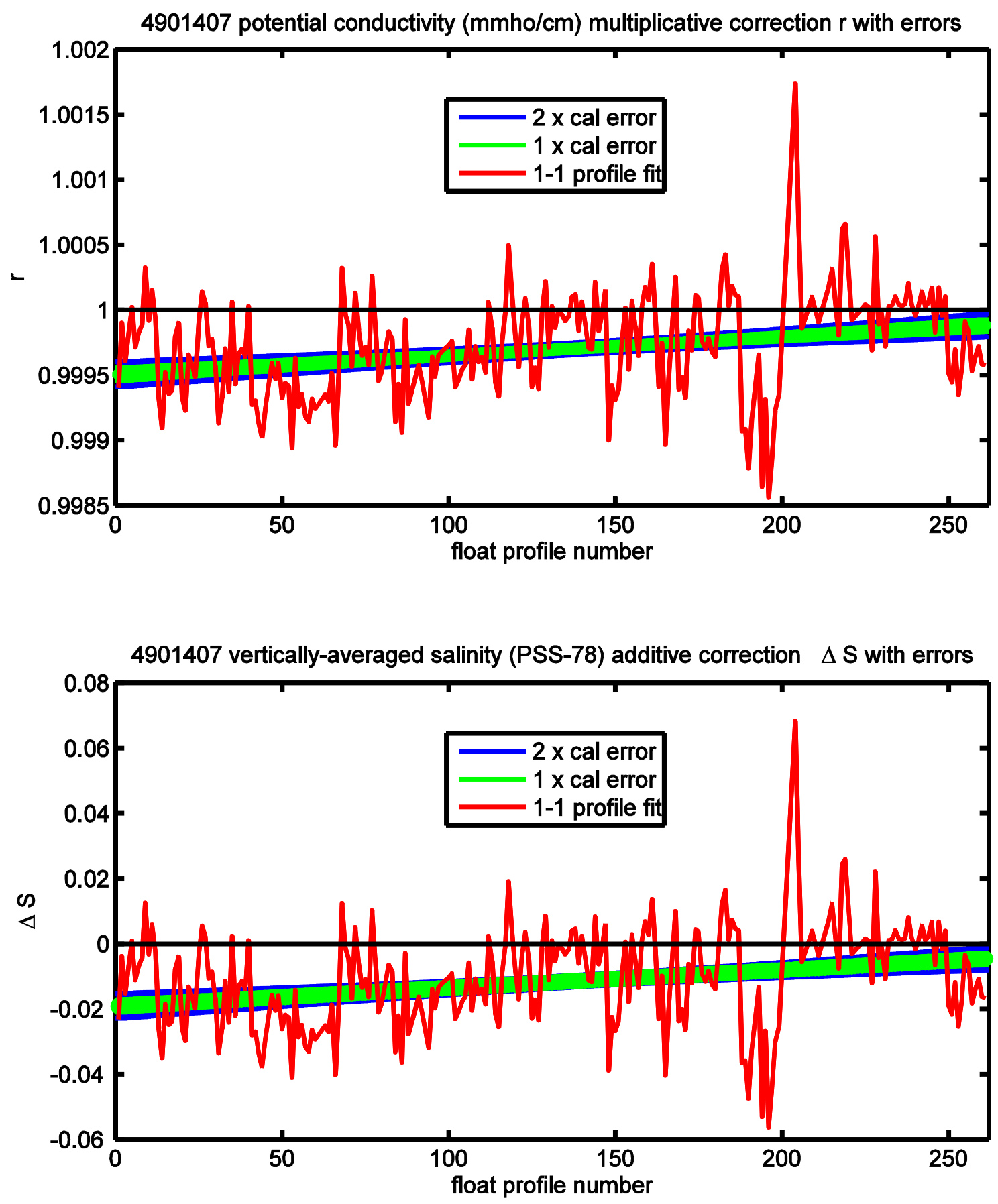

Figure F8d. APEX s/n 5267 / WMO \#4901407. 
This page left intentionally blank. 


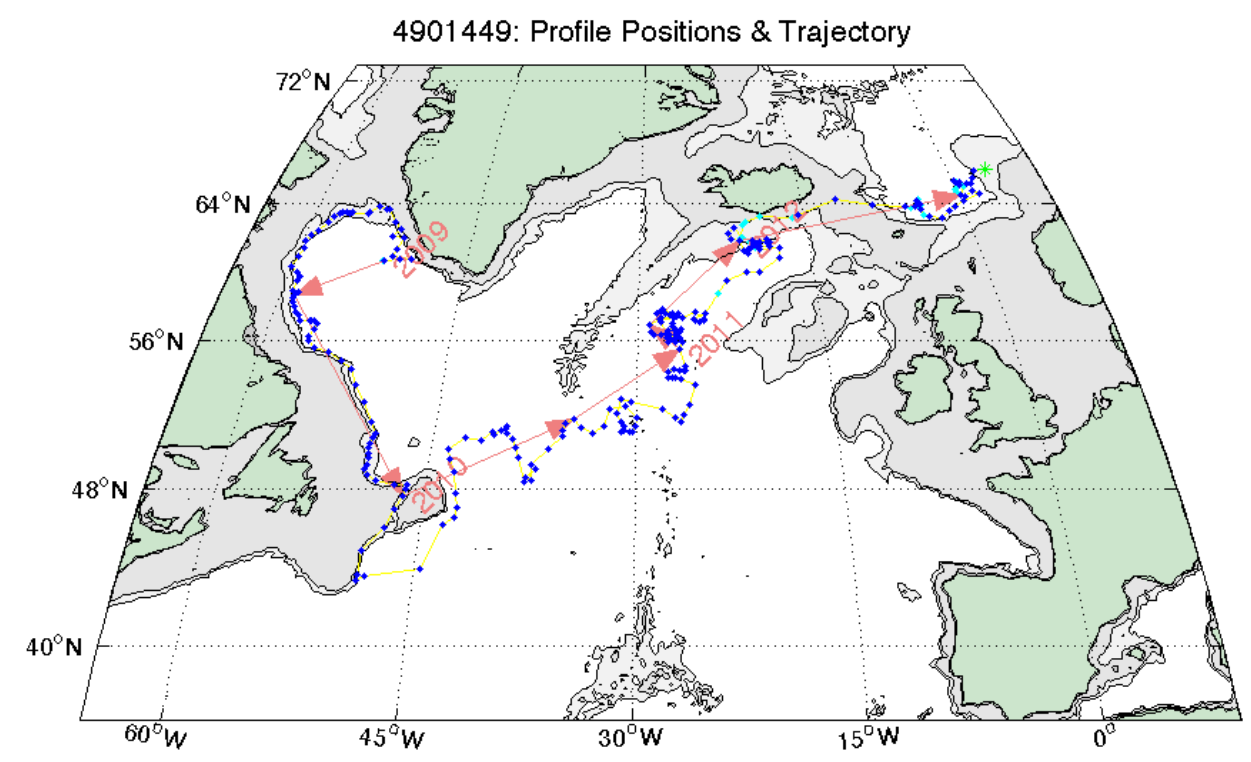

WHOI Argo:01-May-2013

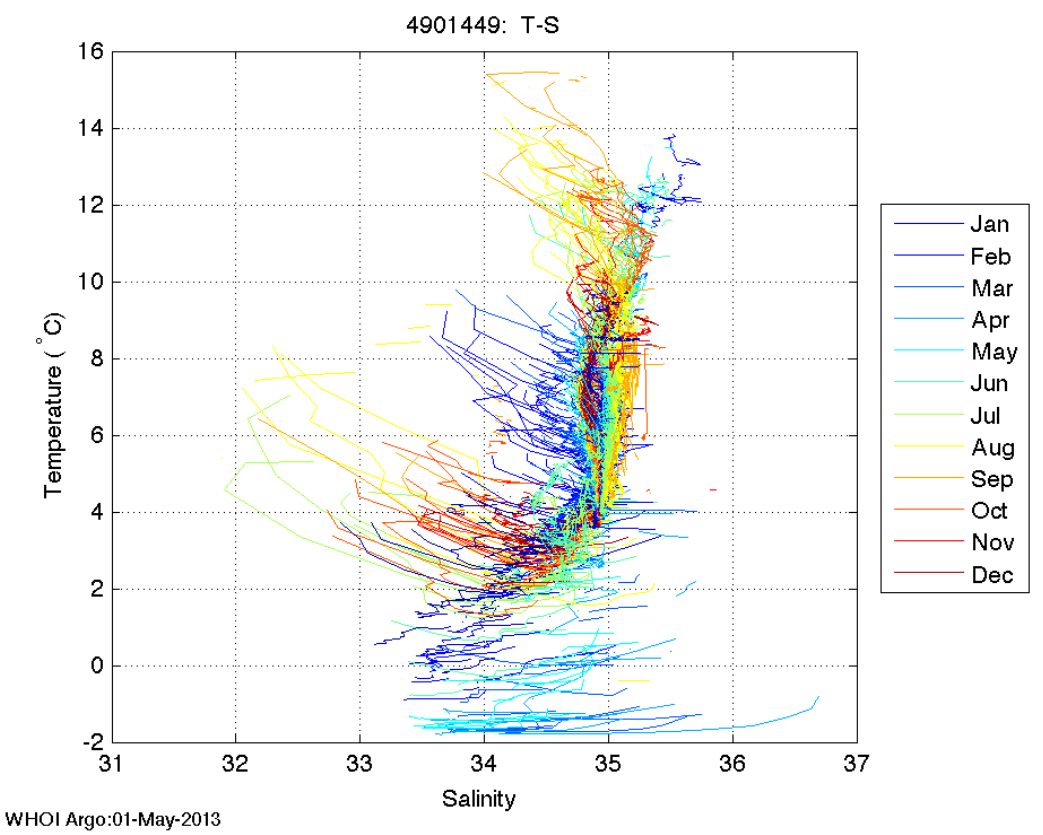

Figure 9. (top) APEX trajectory. (bottom) T-S diagram, showing bad salinity data. This float had no salvageable salinity, so suite of four plots shown for other floats not available. 


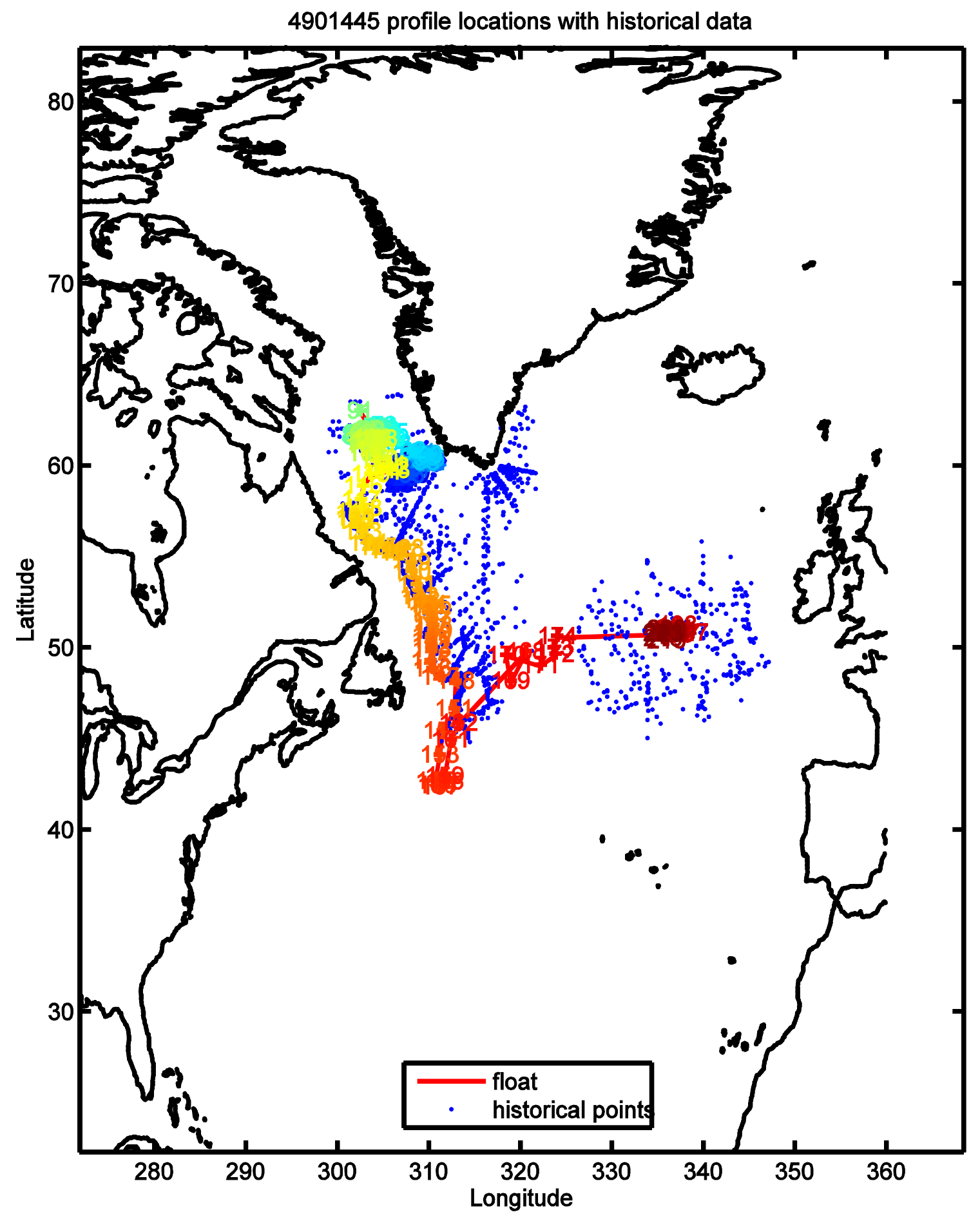

Figure F10a. APEX s/n 5270 / WMO \#4901445. 


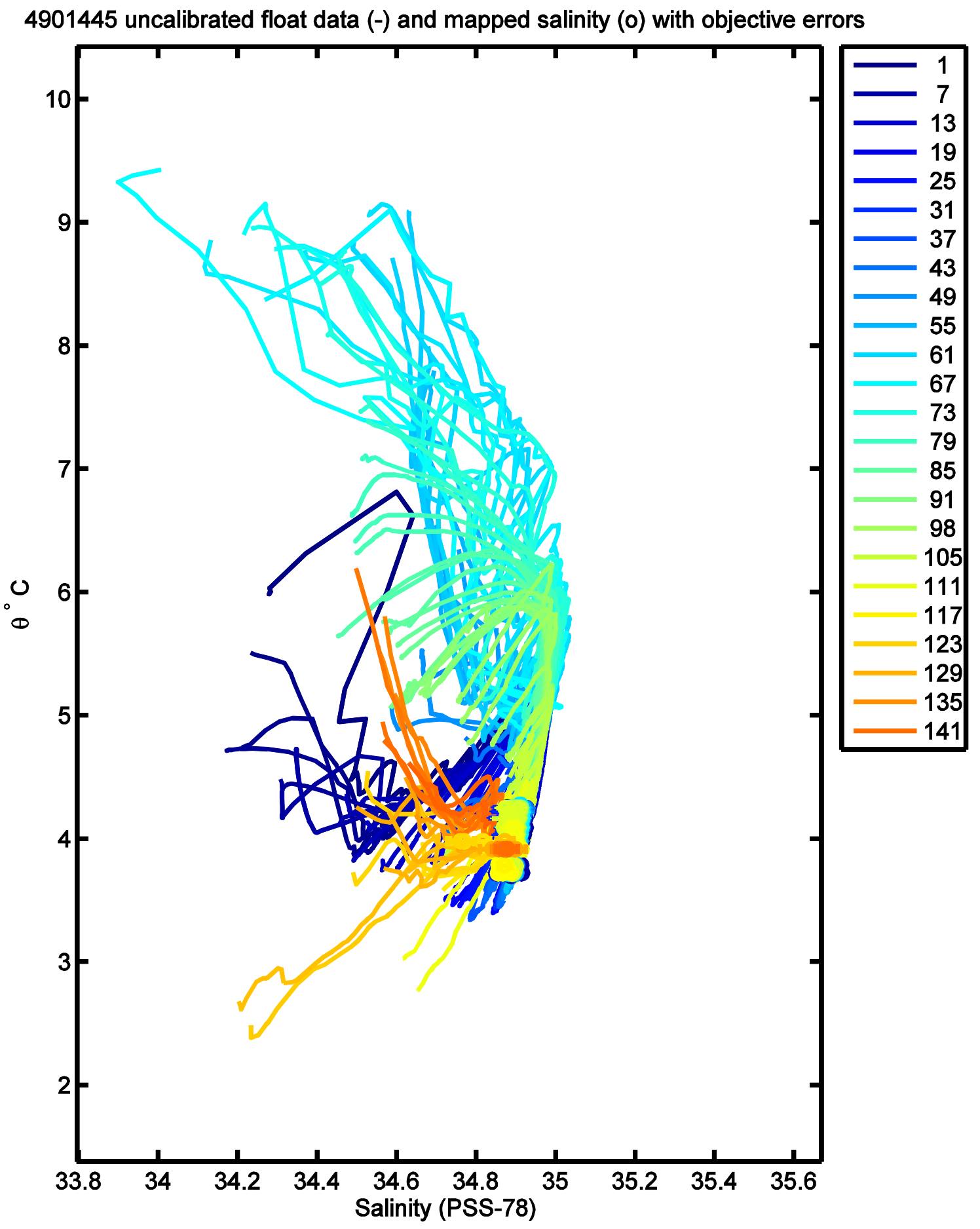

Figure F9b. APEX s/n 5270 / WMO \#4901445. 

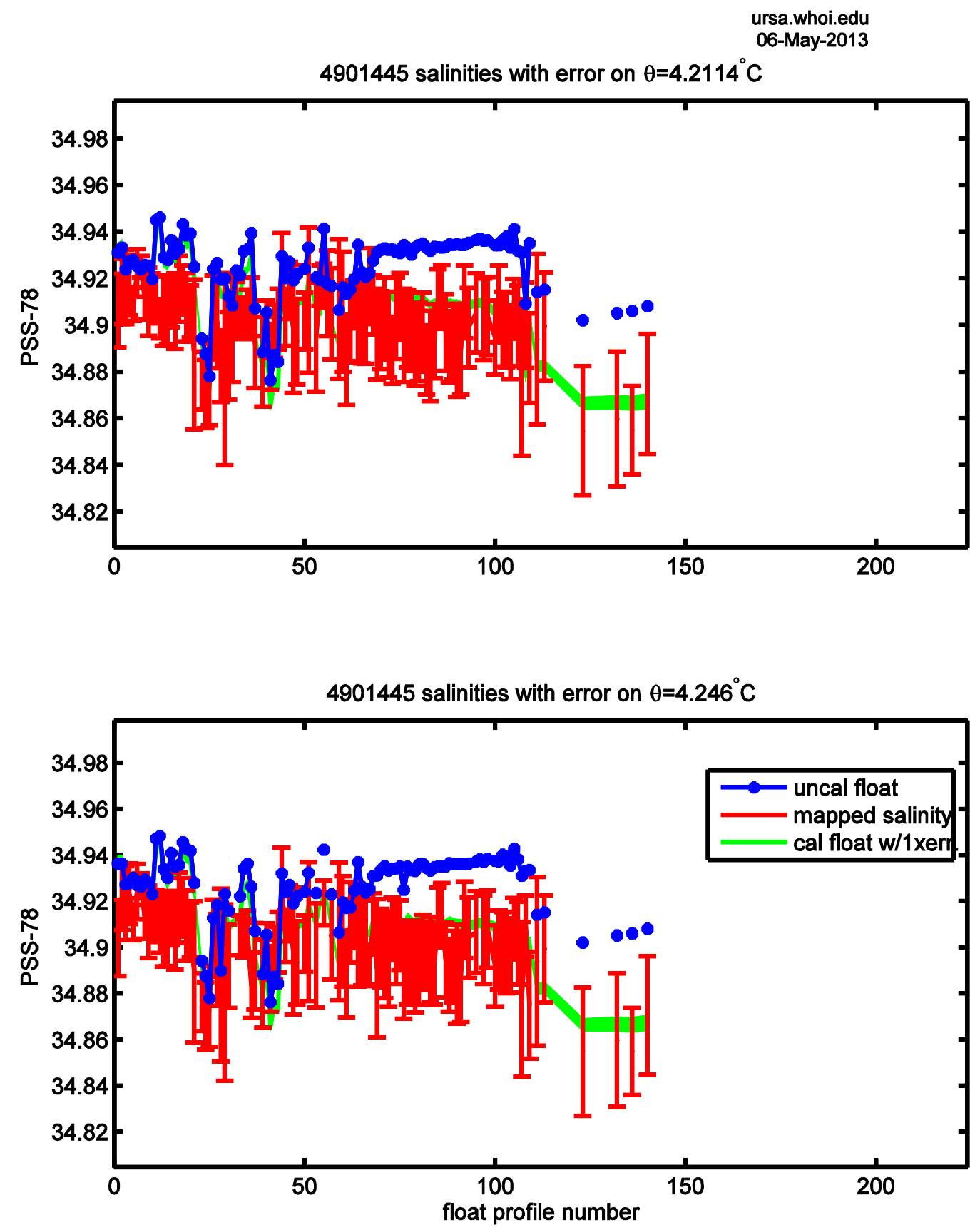

Figure F9c. APEX s/n 5270 / WMO \#4901445. 

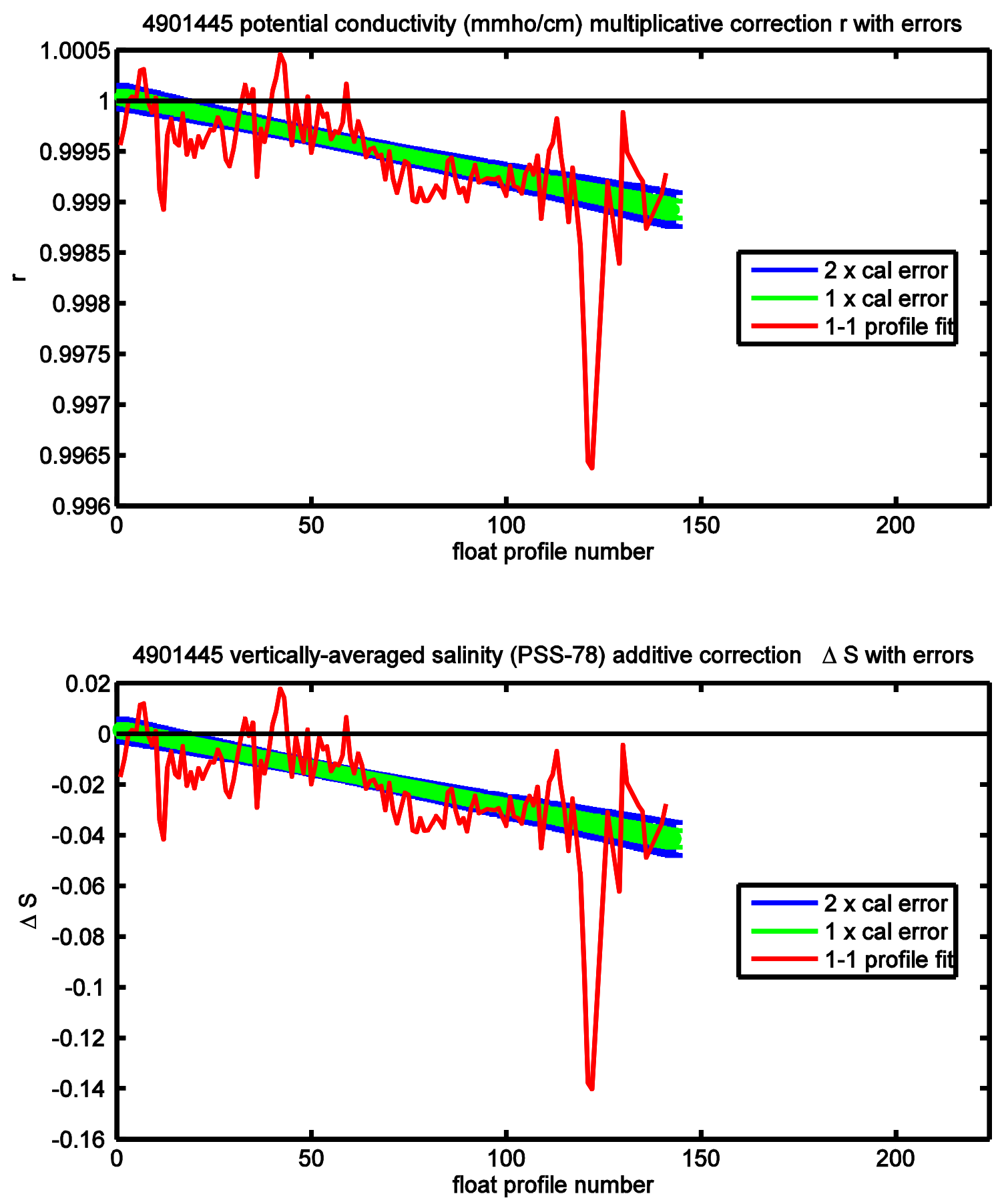

Figure F9d. APEX s/n 5270 / WMO \#4901445. 


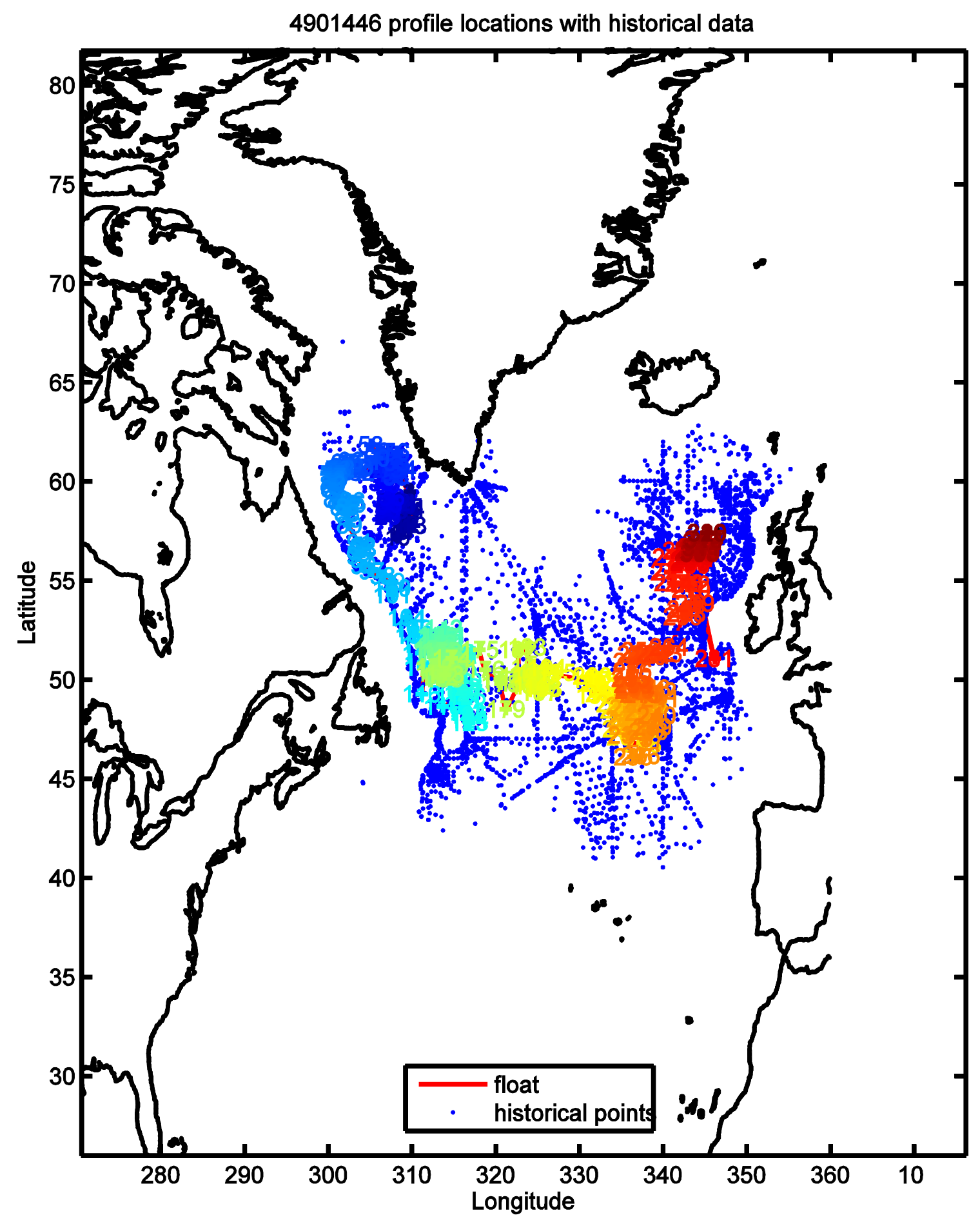

Figure F10a. APEX s/n 5271 / WMO \#4901446. 


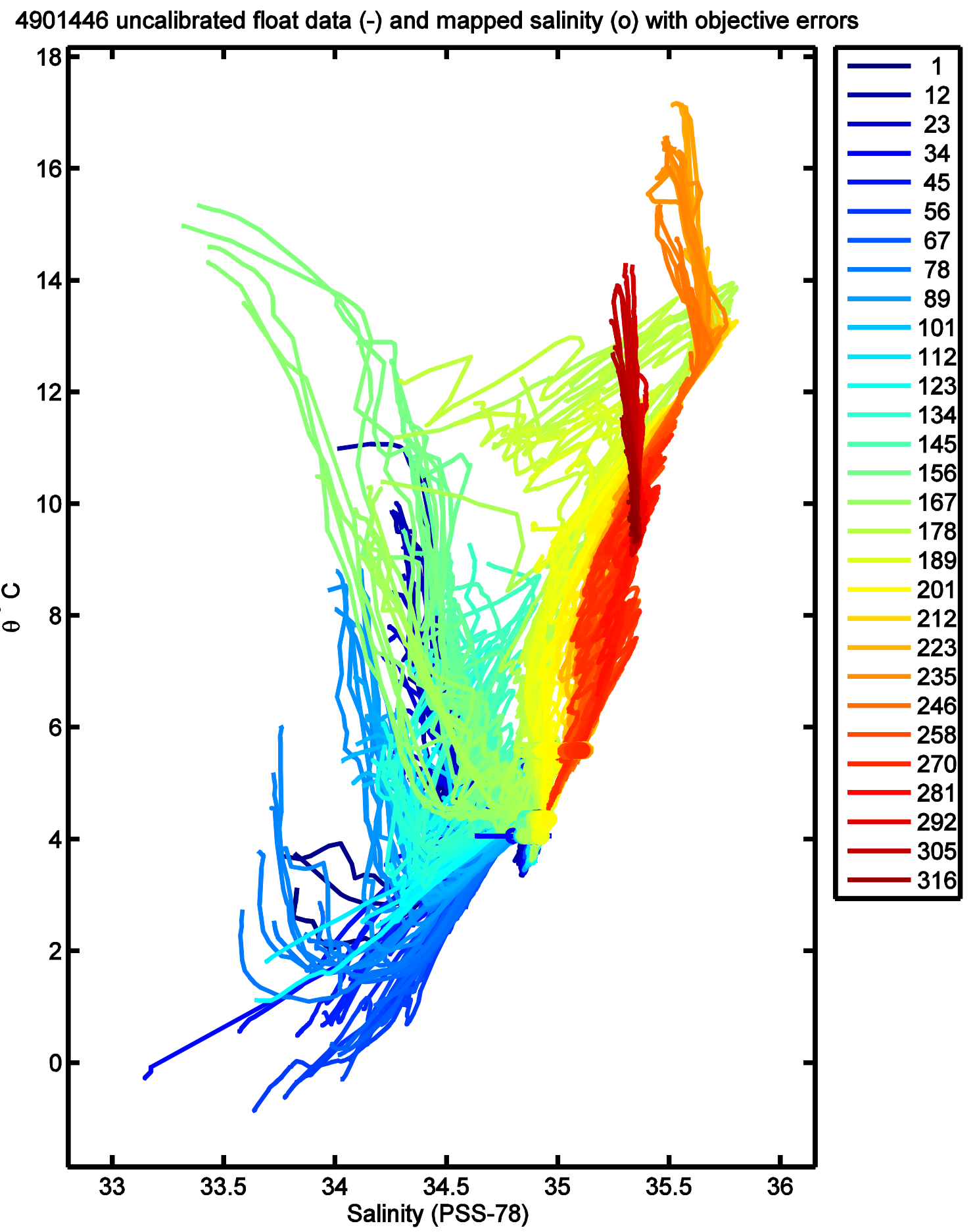

Figure F10b. APEX s/n 5271 / WMO \#4901446. 

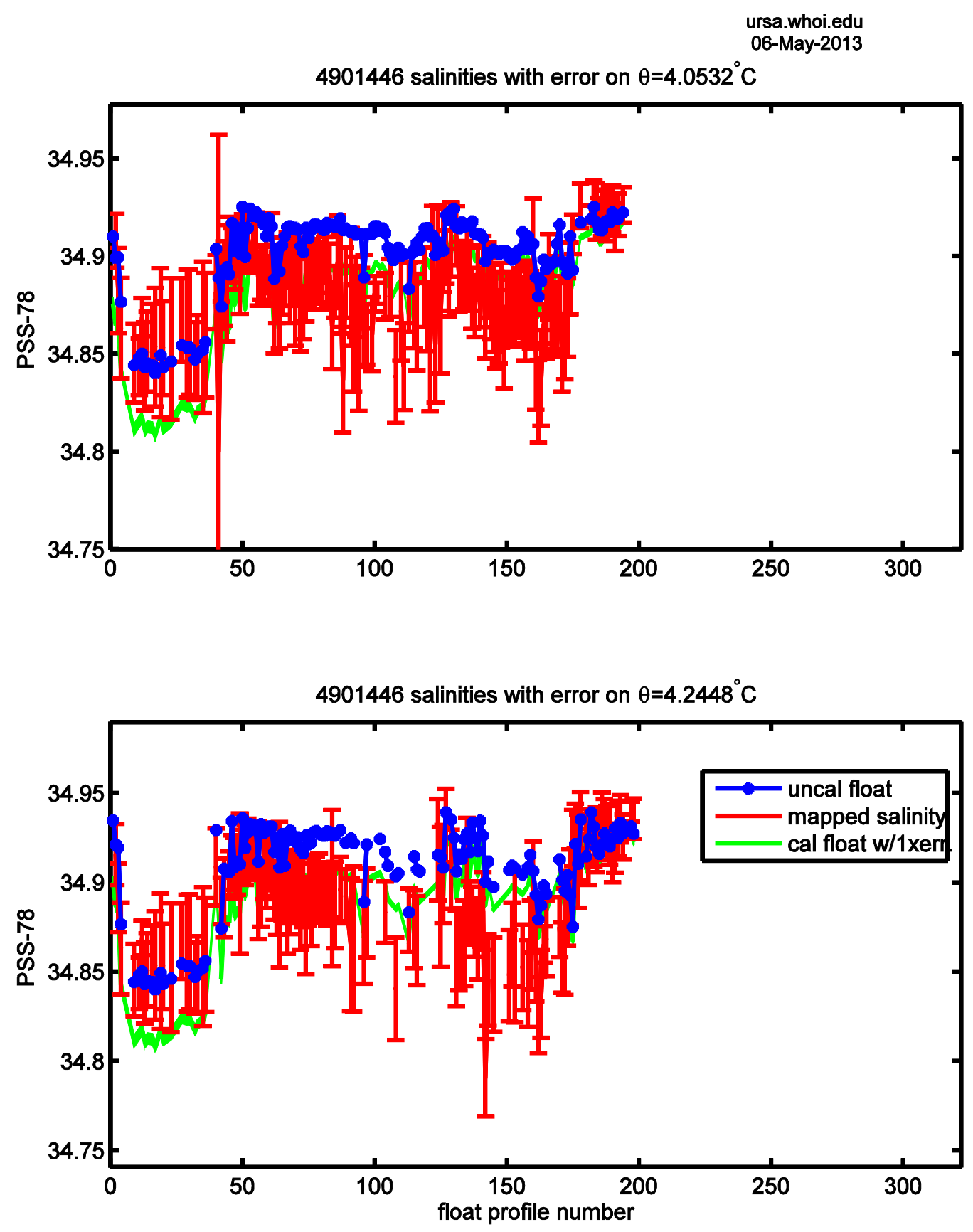

Figure F11c. APEX s/n 5271 / WMO \#4901446. 

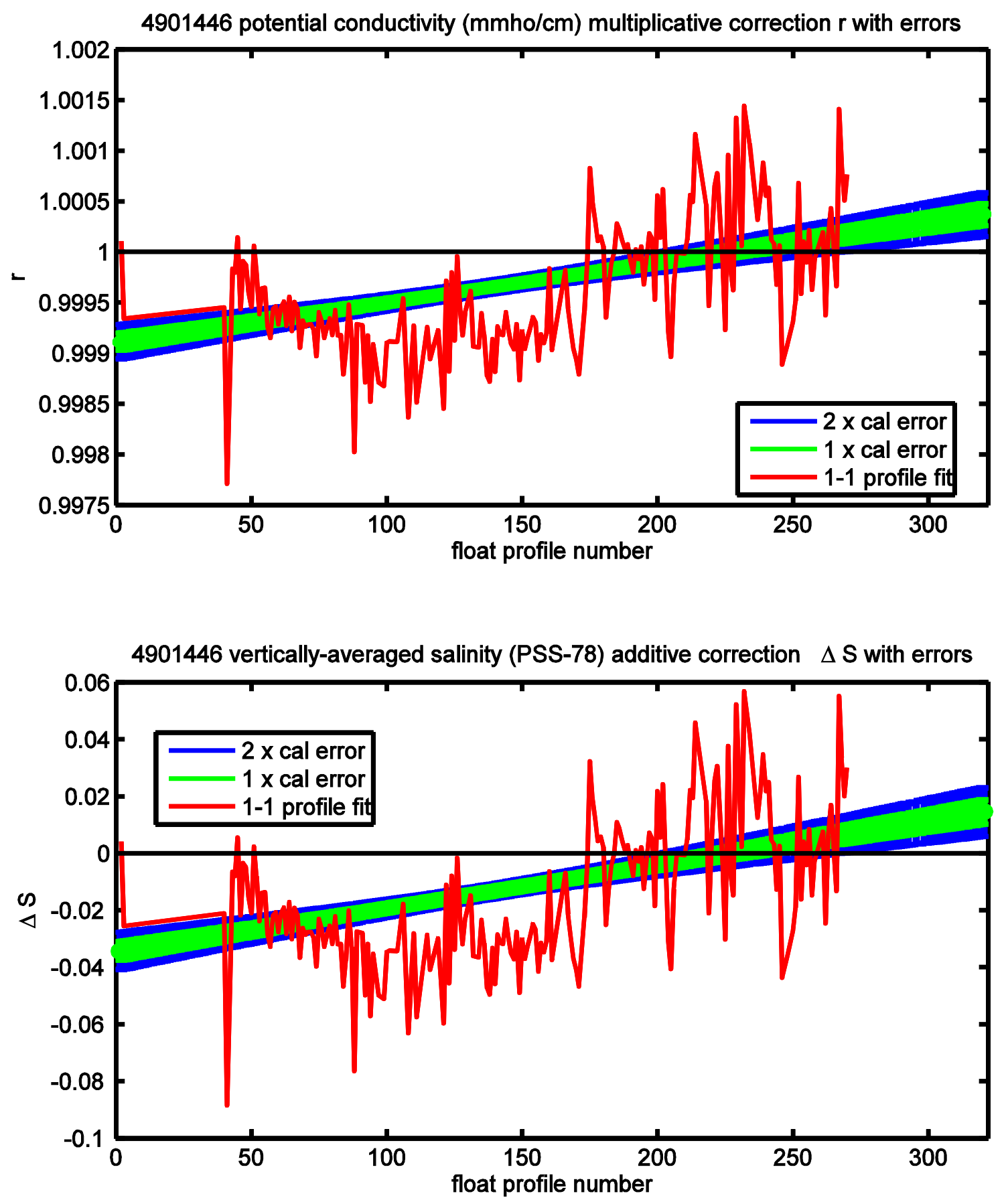

Figure F11d. APEX s/n 5271 / WMO \#4901446. 


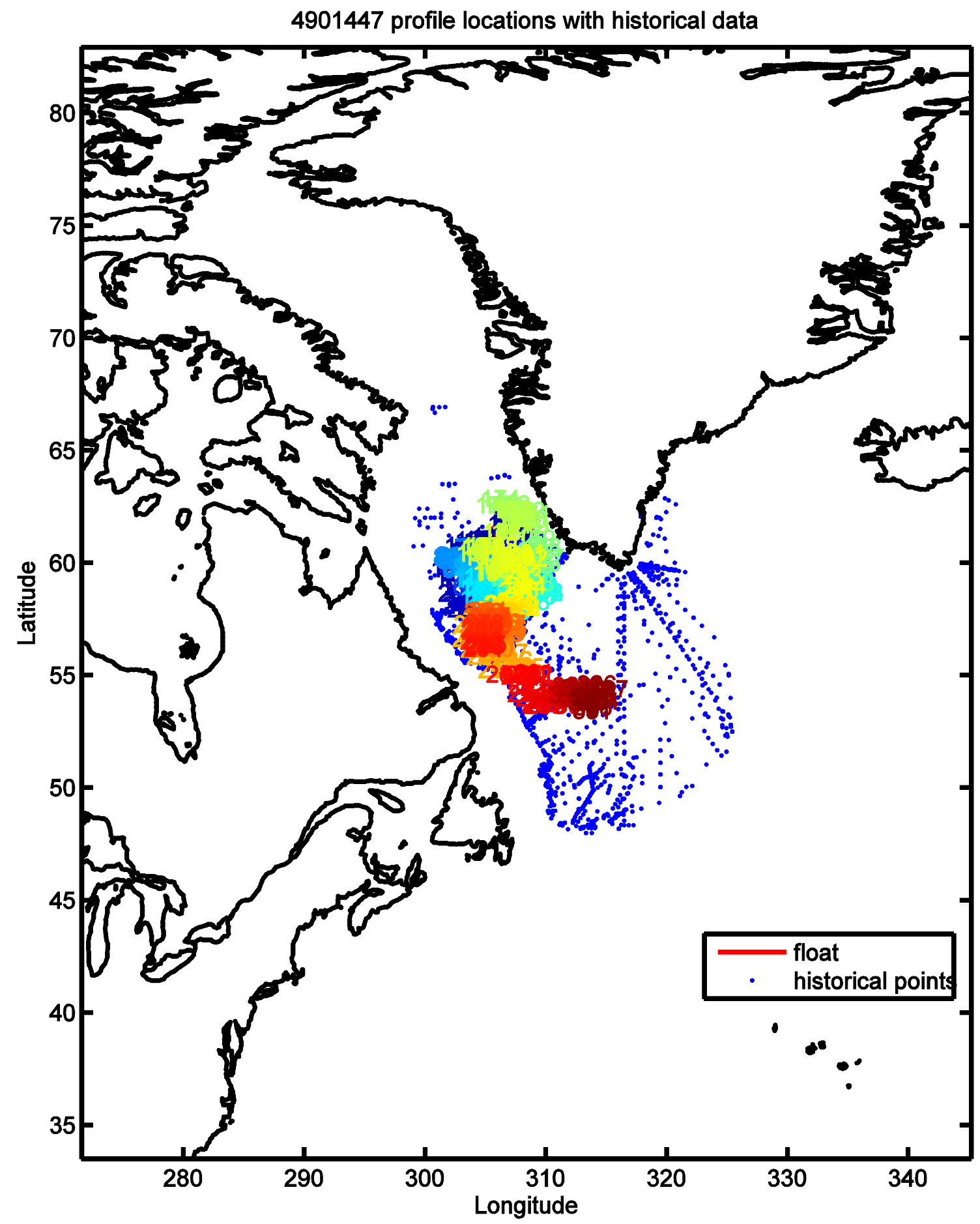

Figure F12a. APEX s/n 5272 / WMO \#4901447. 


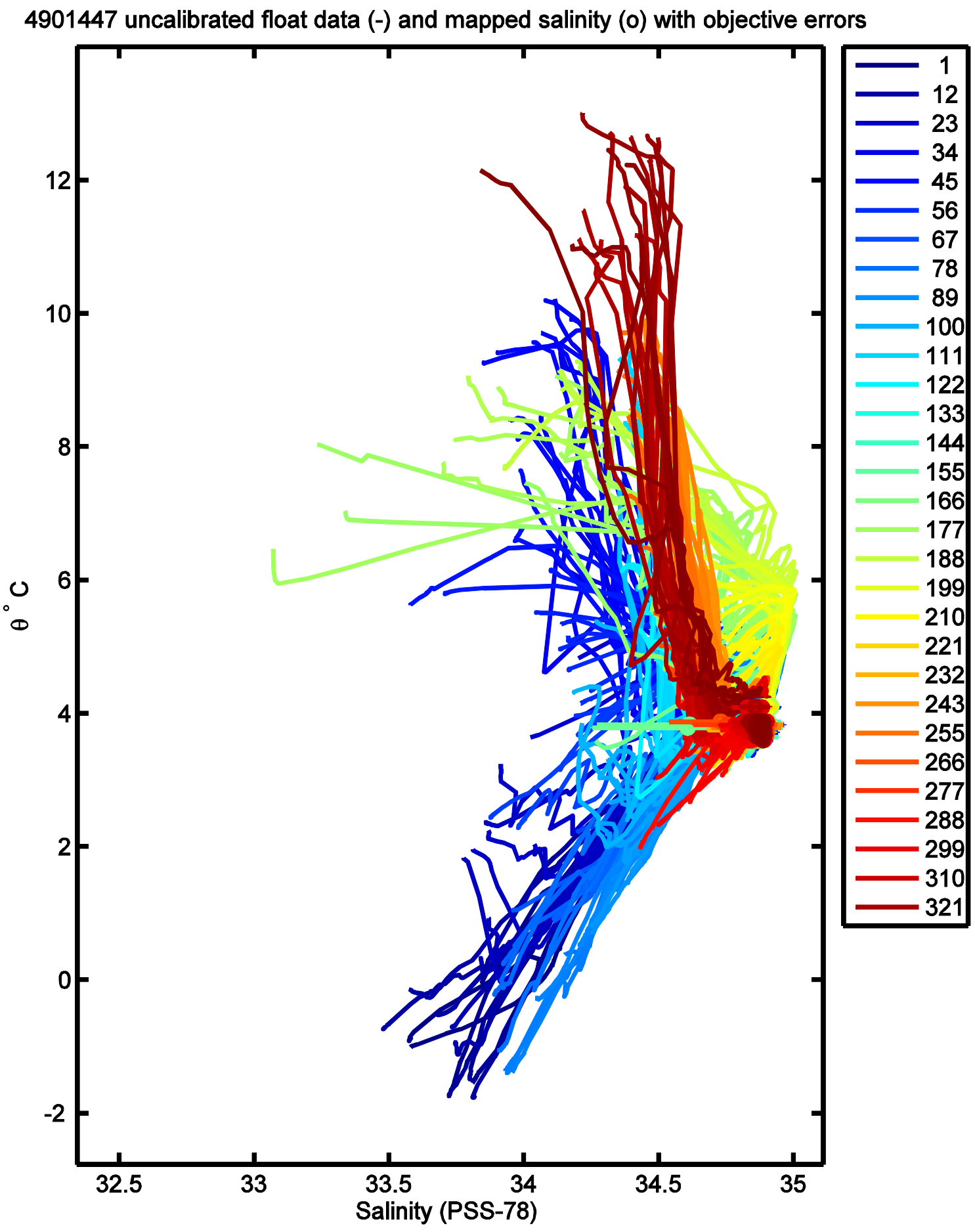

Figure F12b. APEX s/n 5272 / WMO \#4901447. 

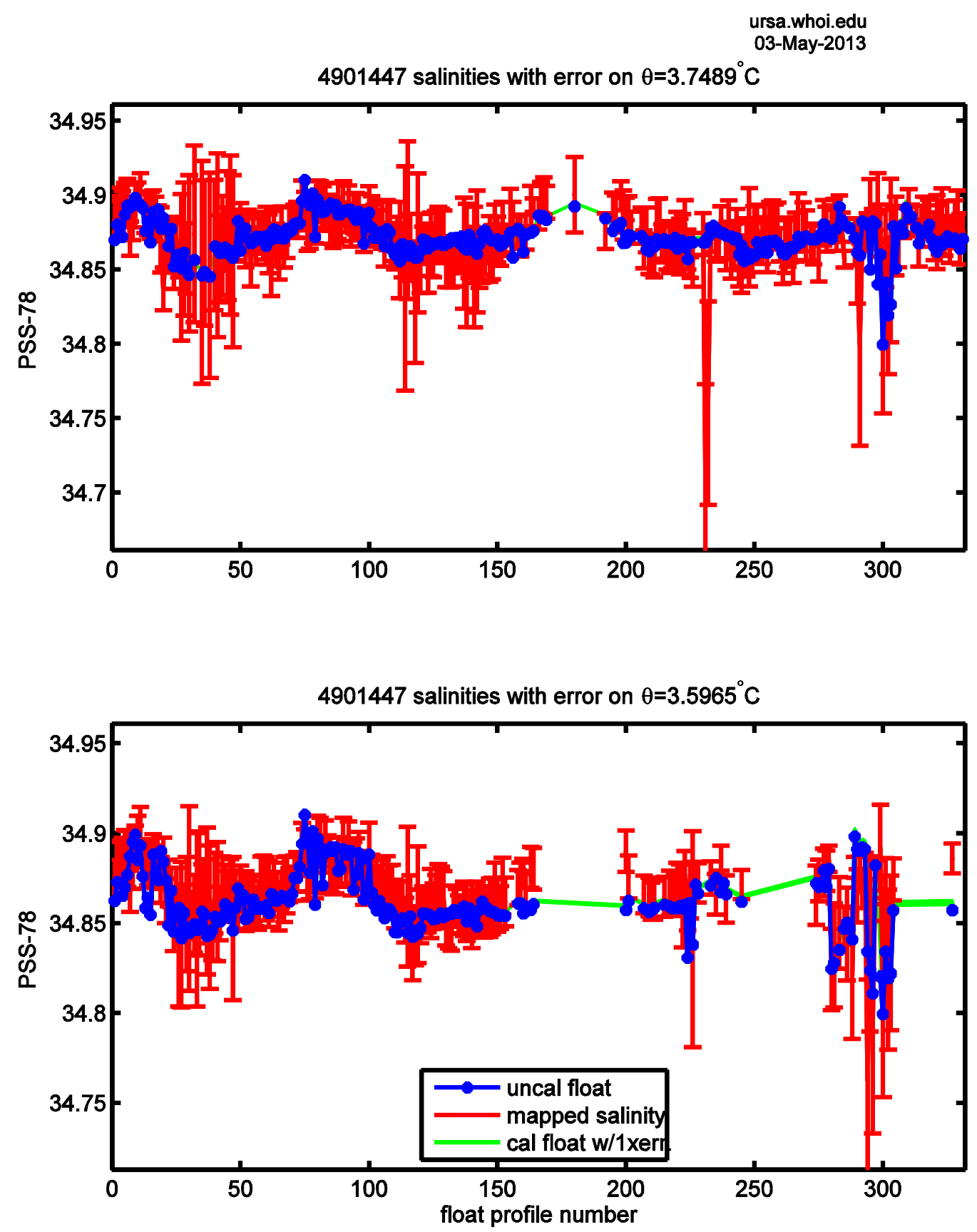

Figure F12c. APEX s/n 5272 / WMO \#4901447. 

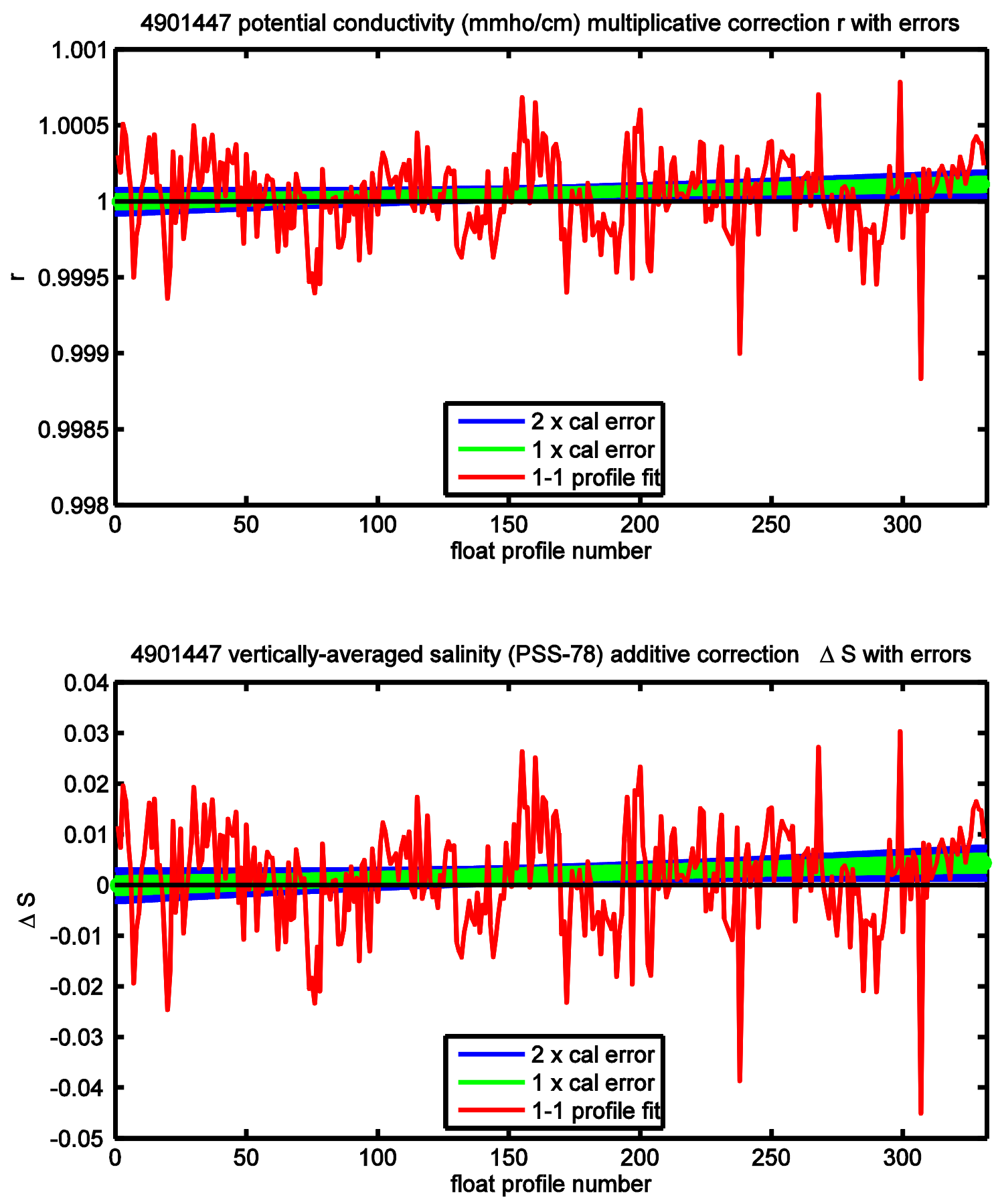

Figure F12d. APEX s/n 5272 / WMO \#4901447. 



\begin{tabular}{|c|c|c|}
\hline $\begin{array}{l}\text { REPORT DOCUMENTATION } \\
\text { PAGE }\end{array}$ & 1. REPORT NO. WHOI-2013-05 & 3. Recipient's Accession No. \\
\hline \multirow{2}{*}{\multicolumn{2}{|c|}{$\begin{array}{l}\text { 4. Title and Subtitle } \\
\text { Impact of Irminger Rings on deep convection in the Labrador Sea: Mooring } \\
\text { Instrument, CTD, and APEX Data Report September } 2007 \text { - September } 2009\end{array}$}} & $\begin{array}{l}\text { 5. Report Date } \\
\text { May } 2013\end{array}$ \\
\hline & & 6. \\
\hline \multicolumn{2}{|c|}{ 7. Author(s) H. H. Furey, T. K. McKee, F. M. de Jong, P. E. Robbins, and A. S. Bower } & 8. Performing Organization Rept. No. \\
\hline \multirow{2}{*}{\multicolumn{2}{|c|}{$\begin{array}{l}\text { 9. Performing Organization Name and Address } \\
\text { Woods Hole Oceanographic Institution } \\
\text { Woods Hole, Massachusetts } 02543\end{array}$}} & 10. Project/Task/Work Unit No. \\
\hline & & $\begin{array}{l}\text { 11. Contract(C) or Grant(G) No. } \\
\text { (C)OCE-0623192 } \\
\text { (G) }\end{array}$ \\
\hline \multicolumn{2}{|c|}{ 12. Sponsoring Organization Name and Address } & 13. Type of Report \& Period Covered \\
\hline \multirow{2}{*}{\multicolumn{2}{|c|}{ National Science Foundation }} & Technical Report \\
\hline & & 14. \\
\hline
\end{tabular}

15. Supplementary Notes

This report should be cited as: Woods Hole Oceanographic Institution Technical Report, WHOI-2013-05.

16. Abstract (Limit: 200 words)

This is the final data report of all hydrographic station, mooring, and subsurface float data collected by the Woods Hole

Oceanographic Institution in 2007-2009 during the Impact of Irminger Rings on Deep Convection in the Labrador Sea experiment (IRINGS). The objectives of IRINGS were to (1) to determine the full water column hydrographic and velocity structure of newlyformed Irminger Rings that have entered the interior Labrador Sea; (2) to observe how Irminger Ring core properties are modified by atmospheric forcing over their lifetime; and (3) to improve the interpretation of sea surface height (SSH) anomalies in terms of newly formed coherent heat containing Irminger Rings. The mooring deployment and recovery cruises were both on the R/V

Knorr: KN192-01 in September 2007 and KN196-01 in September 2009, respectively. The single mooring held eight Aanderaa current meters (RCM-11), two Submerged Autonomous Launch Platforms (SALPs), and nine Seabird microcats (SBE37), deployed from 26 September 2007 through 27 September 2009, yeilding full water column (100-3000 meters) records of temperature, salinity, pressure, and velocity data for the two year period. The two SALP cages contained eleven APEX floats, and released some of these floats according to local oceanographic conditions, so as to seed the floats in passing Irminger Rings, and the remainder of floats as timed releases. Thirteen conductivity-temperature-depth (CTD) stations were taken on the mooring recovery cruise, creating a boundary current cross-section from the mooring site to Nuuk, Greenland.

\section{Document Analysis a. Descriptors}

Submerged Autonomous Launch Platform

Labrador Sea

mooring

b. Identifiers/Open-Ended Terms

c. COSATI Field/Group

18. Availability Statement

Approved for public release; distribution unlimited.

\begin{tabular}{|l|l|}
\hline $\begin{array}{c}\text { 19. Security Class (This Report) } \\
\text { UNCLASSIFIED }\end{array}$ & $\begin{array}{c}\text { 21. No. of Pages } \\
102\end{array}$ \\
\hline 20. Security Class (This Page) & 22. Price \\
\hline
\end{tabular}

